\author{
UNIVERSIDADE DE SÃO PAULO \\ Faculdade de Filosofia, Ciências e Letras de Ribeirão Preto \\ Departamento de Psicologia \\ Programa de Pós-Graduação em Psicobiologia
}

Mariana Ducatti Horiquini de Almeida

Estudos sobre a produção de discurso em idosos com Doença de Alzheimer em fase inicial

Ribeirão Preto

2018 
MARIANA DUCATTI HORIQUINI DE ALMEIDA

\section{Estudos sobre a produção de discurso em idosos com Doença de Alzheimer em fase inicial}

Tese apresentada à Faculdade de Filosofia, Ciências e Letras de Ribeirão Preto, como parte das exigências para obtenção do título de Doutor em Ciências. Área de Concentração: Psicobiologia.

Orientadora: $\operatorname{Prof}^{\mathrm{a}} \mathrm{Dr}^{\mathrm{a}}$ Andréia Schmidt

Ribeirão Preto

2018 
Autorizo a reprodução e divulgação total ou parcial deste trabalho, por qualquer meio convencional ou eletrônico, para fins de estudo e pesquisa, desde que citada a fonte.

\author{
Catalogação na publicação \\ Serviço de Biblioteca e Documentação \\ Faculdade de Filosofia, Ciências e Letras de Ribeirão Preto
}

Ducatti, Mariana.

Estudos sobre a produção de discurso em idosos com Doença de Alzheimer em fase inicial. Ribeirão Preto, 2018.

$154 \mathrm{f}$.

Tese (Doutorado). Faculdade de Filosofia, Ciências e Letras de Ribeirão Preto/USP. Programa de Pós Graduação em Psicobiologia. Área de Concentração: Psicobiologia.

Orientadora: Schmidt, Andréia.

1. Idoso. 2. Doença de Alzheimer. 3. Comprometimento Cognitivo Leve. 4. Spaced Retrieval. 5. Fading Out. 6. Linguagem. 
Nome: Mariana Ducatti Horiquini de Almeida

Título: Estudos sobre a produção de discurso em idosos com Doença de Alzheimer em fase inicial

Tese apresentada à Faculdade de Filosofia, Ciências e Letras de Ribeirão Preto da USP para obtenção do título de Doutor em Ciências.

Aprovado em: / 2018

\section{Banca Examinadora}

Prof ${ }^{\mathrm{a}}$. Dr ${ }^{\mathrm{a}}$. Andréia Schmidt (orientadora)

Instituição: Universidade de São Paulo

Julgamento:

Assinatura:

\section{Prof. Dr. Marcos Hortes Nisihara Chagas}

Instituição: Universidade Federal de São Carlos

Julgamento:

Assinatura:

\section{Prof. Dr. Cesar Alexis Galera}

Instituição: Universidade de São Paulo

Julgamento:

Assinatura:

\section{Prof $^{\text {a }}$. Dr ${ }^{\text {a }}$. Camila Domeniconi}

Instituição: Universidade Federal de São Carlos

Julgamento:

Assinatura:

\section{Prof $^{\mathrm{a}}$. Dr ${ }^{\mathrm{a}}$. Maria Paula Foss}

Instituição: Hospital das Clínicas da Faculdade de Medicina de Ribeirão Preto Julgamento: Assinatura: 
Dedieatória

As minhas queridas avós:

Elza, Julia, Myaria e Judith.

\#ara sempre em meu coração. 


\section{Agradecimentos}

A Deus, pela saúde.

Ao Everton, meu esposo, pelo carinho e cuidado constante.

Aos meus pais, Alberto e Rosana, pelo incentivo; e a querida irmã Juliana, pelo companheirismo.

À professora $\operatorname{Dr}^{\mathrm{a}}$ Andréia Schmidt, pelas orientações que vão além de orientações relacionadas a tese.

À Alana Brunini e Sara Cirilo, pela amizade que não terminou em nossas defesas de mestrado. Que a vida de vocês seja "fora de série". Ao Vinícius Warisaia, por sempre me animar.

Aos meus queridos alunos, por me fazerem estudar mais e mais e tentar ser, a cada dia, uma professora melhor.

Aos participantes desta pesquisa, por compartilharem suas histórias e me ensinarem o valor de uma lembrança. Que Deus os abençoe!

Às professoras $\operatorname{Dr}^{\mathrm{a}}$ Natalia Aggio e $\mathrm{Dr}^{\mathrm{a}}$ Marisa Tomoe Hebijara Fukuda e Professor Dr. Cesar Alexis Galera, pelas contribuições durante a qualificação.

À Coordenação e Secretária do Programa de Pós-Graduação em Psicobiologia. 
Osnúmerosmedizemquejápassoumuitotempo. Masa memóriaignora:écomosetivesseacontecidoontem.Assim é: oque amemória amafica eterno (Alves, 1998). 


\section{RESUMO}

Ducatti, M. (2018). Estudos sobre a produção de discurso em idosos com Doença de Alzheimer em fase inicial (Tese de Doutorado). Programa de Pós-Graduação em Psicobiologia, Universidade de São Paulo, Ribeirão Preto-SP.

A Demência de Alzheimer (DA) é um transtorno neurocognitivo, progressivo, que afeta principalmente a memória e a linguagem. Não há tratamentos curativos para a DA, contudo há medicações e técnicas de reabilitação cognitiva que atrasam o desenvolvimento da demência. $\mathrm{O}$ objetivo geral desta tese foi investigar o efeito de diferentes procedimentos de intervenção sobre repertórios verbais de idosos com DA. Para isto foram propostos três estudos. O Estudo 1 teve como objetivo averiguar o efeito da apresentação de objetos tridimensionais (dicas visuais) na tarefa de recontar histórias. Quarenta e oito idosos, sendo 24 sem indicativos de perdas cognitivas e 24 com DA, ouviram duas estórias e as recontaram em seguida. Em uma das condições a estória foi narrada, apenas; na outra foram apresentados objetos tridimensionais relacionados à história enquanto a mesma era narrada. Todos os participantes emitiram maior quantidade de informações gerais sobre as histórias do que informações específicas e os objetos tridimensionais não serviram como dicas para melhorar a narrativa dos idosos. O objetivo do Estudo 2 foi verificar a eficácia do procedimento fading out (FO) de perguntas na produção de narrativas com apoio visual de idosos com DA. Doze idosos, sendo seis sem demência (Grupo Comparação - GC) e seis com DA (Grupo Experimental - GE) realizaram narrativas de histórias com base em sequências de imagens. O procedimento foi dividido em três fases. Na Fase 1 (Pré-Teste) e Fase 3 (Pós-Teste) foram apresentadas pranchas com imagens aos participantes e pedido para que os mesmos contassem uma história com base naquelas imagens. A Fase 2 (intervenção) foi subdividida em três etapas. Todas as etapas iniciavam-se com o participante narrando uma história com base em uma sequência de três de imagens. Após a narrativa eram feitas perguntas aos participantes sobre cada imagem e, por fim, era solicitada uma nova narrativa. Realizouse um FO das dicas (perguntas) a cada etapa. De forma geral, os idosos com GC narram histórias com mais coerência em todas as fases e os idosos do GE se beneficiaram da intervenção pois melhoraram a coerência de suas narrativas. O objetivo do Estudo 3 foi comparar a eficácia dos procedimentos Spaced Retrieval (SR) e FO sobre o desempenho de nomeação de figuras em idosos com DA. Oito idosos com DA foram ensinados a nomear sete figuras por meio do SR e outras sete figuras por meio do FO. A ordem de dos procedimentos foi balanceada entre os participantes. Ao final de cada procedimento, assim como depois das duas intervenções, as imagens foram apresentadas e solicitou-se que os idosos as nomeassem. Ambos os procedimentos foram eficazes para ensinar a nomeação das figuras aos idosos, de forma que todos, ao final, nomearam corretamente no mínimo metade das figuras ensinadas. Os resultados encontrados aqui contribuem com os estudos sobre envelhecimento, especificamente com a área de reabilitação da linguagem, ao oferecer informações sobre o funcionamento da linguagem de idosos com DA e indicar procedimentos eficazes para melhorar os repertórios verbais desta população.

Palavras-chave: Comprometimento Cognitivo Leve; Doença de Alzheimer; Fading Out; Linguagem; Spaced Retrieval. 


\begin{abstract}
Ducatti, M. (2018). Studies of production of speech in the elderly with Dementia of Alzheimer's in initial phase (Tese de Doutorado). Programa de Pós-Graduação em Psicobiologia, Universidade de São Paulo, Ribeirão Preto-SP.
\end{abstract}

Alzheimer's Dementia (AD) is a progressive neurocognitive disorder that affects memory and language, mainly. There are no curative treatments for $\mathrm{AD}$, however there are medications and cognitive rehabilitation techniques that delays the development of dementia. The general objective of this study was to investigate the effect of different intervention procedures on behavior of speaking from elderly with $\mathrm{AD}$. For this were proposed three studies. For the Study 1 we aimed to investigate the effect of threedimensional objects (visual cues) on the task of retelling stories. Forty-eight elderly, 24 with no indicative of cognitive losses and 24 with $\mathrm{AD}$, heard two stories and then recounted them. In one of the conditions the story was narrated, only; and in the other was presented three-dimensional objects related to the story while it was narrated. All participants gave more general information about the stories than specific information and that the three-dimensional goals did not serve as clues to improve the narration of the elderly. The purpose of Study 2 was to verify the effectiveness of the fading out procedure (FO) of questions in the production of narratives. Twelve elderly subjects, six without dementia (Control Group - CG) and six with AD (Experimental Group - GE) carried out narrative stories based on images. The procedure was divided into three phases. InPhase 1 (Pre-Test) and Phase 3 (Post-Test), boards were presented with pictures to the participants and asked for them to tell a story based on those images. Phase 2 (intervention) was subdivided into three stages. All steps began with the participant narrating a story based on a sequence of three of images. After the narrative, the participants were asked questions about each image and, finally, a new narrative was requested. There was a FO of the tips (questions) at each step. In general, the elderly with $\mathrm{CG}$ report more coherent histories at all stages and the elderly of the GE benefited from the intervention because they improved the coherence of their narratives. The aim of Study 3 was to compare the efficacy of the Spaced Retrieval (SR) and FO procedures for the naming performance of figures in the elderly with AD. Eight elderly with AD were taught to name seven images by SR and seven images by FO. At the end of each training, as well as at the end of the procedures, the images were presented and were asked to name them to the elderly. Both procedures were effective in teaching the naming of the figures to the elderly, so that, in the end, they all correctly named at least half of the figures taught. The results found in the studies contribute to the area of aging, specifically the rehabilitation of the language, since they contribute for the information about the functioning of the language of the elderly with $\mathrm{AD}$ and indicate effective procedures to improve the discourses of this population.

Keywords: Mild Cognitive Impairment; Alzheimer's Disease; Fading Out Language; Spaced Retrieval. 


\section{LISTA DE TABELAS}

\section{Estudo 2}

Tabela 1. Características gerais dos participantes do Estudo 2: idade, escolaridade, desempenho nos testes Mini Exame do Estado Mental (MEEM), Exame Cognitivo de Addenbrooke (ACE-R) e Escala de Depressão Geriátrica (GDS). .71

Tabela 2. Estímulos utilizados no Estudo 2: tirinhas de história em quadrinhos da Turma da Mônica (Maurício de Souza) composta por três quadrinhos .72

Tabela 3. Análise da Coerência das Narrativas dos Idosos do Grupo Comparação (GC) e Grupo Experimental (GE) .79

\section{Estudo 3}

Tabela 1. Características gerais dos idosos participantes do Estudo 3: idade, escolaridade, desempenho nos testes Mini Exame do Estado Mental (MEEM) e Escala de Depressão Geriátrica (GDS). 


\section{LISTA DE FIGURAS}

\section{Estudo 1}

Figura 1. Frequência média de emissões de macroestruturas (M), microestruturas (m) e outras informações $(\mathrm{O})$ emitidas por grupo durante a reprodução oral das narrativas. 51 Figura 2. Frequência média de emissão das categorias macroestrutura (M), microestrutura (m) e outras informações (O) para os grupos Controle (GC) e Experimental (GE) 52

Figura 3. Frequência de emissões de macroestruturas (M), microestruturas (m) e outras informações (O) nas condições com objeto (C) e sem objeto (S), para os grupos experimental (GE) e controle (GC).

\section{Estudo 2}

Figura 1. Número médio de palavras emitidas pelos participantes do Grupo Comparação (GC) e Grupo Experimental (GE) nas narrativas de histórias de cada uma das fases do procedimento.

\section{Estudo 3}

Figura 1: Média de acertos de todos os participantes nas duas condições de ensino (FO e SR) nos testes de nomeação de figuras realizados nas Fase 2 e 3.

Figura 2: Número de acertos dos participantes individuais nos testes de nomeação da Fase 2 na condição de ensino por Fading Out (FO) e por Spaced Retrievel (SR). Os participantes do G1 iniciaram pela condição de ensino FO e os do G2 por SR. 104

Figura 3: Número de acertos dos participantes individuais nos testes de nomeação da Fase 3 na condição de ensino por Fading Out (FO) e por Spaced Retrievel (SR). 106 


\section{SUMÁRIO}

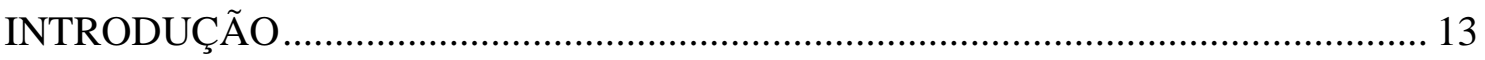

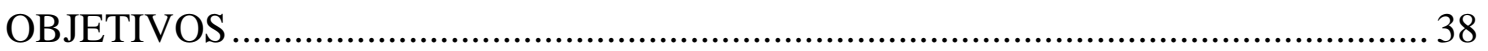

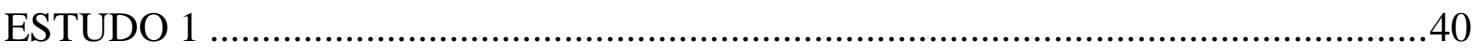

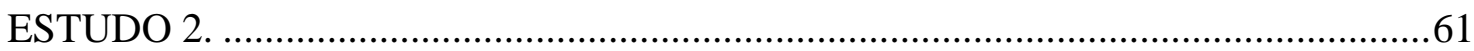

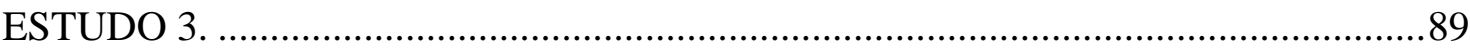

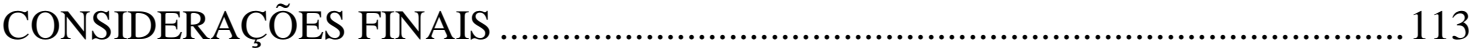

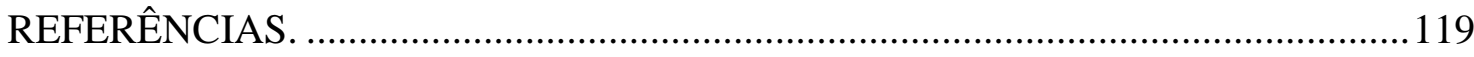

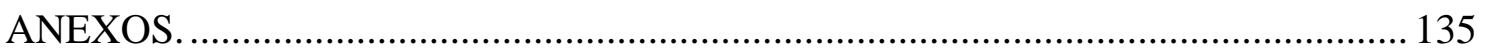

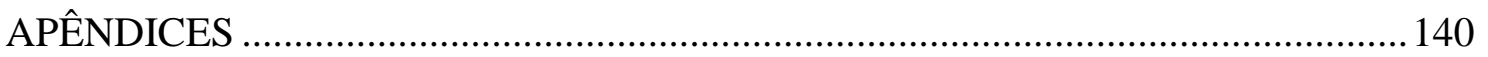


Jntroduęão 


\section{Envelhecimento Populacional}

O processo de envelhecimento faz parte de um continuum que se inicia com a concepção e encerra-se com a morte. Este continuum é marcado por diversas fases do desenvolvimento que, algumas vezes, são determinadas por marcadores biofisiológicos como, por exemplo, as mudanças orgânicas vivenciadas no período denominado "puberdade". No entanto, não há um marcador específico para o envelhecimento, uma vez que ele pode ser compreendido sob diferentes aspectos, como um fenômeno biológico, psicológico, social e/ou cronológico (Papaléo-Netto, 2006). Levando-se em conta apenas o aspecto cronológico, em países desenvolvidos considera-se idosa a pessoa com mais de 65 anos; porém, nos países em desenvolvimento, como o Brasil, a idade mínima de corte é de 60 anos de idade (WHO, 2005; Brasil, Lei n 10.741, 2003). Contudo, independentemente do aspecto considerado sobre o envelhecimento, observase em todo o mundo um aumento significativo no número de idosos (IBGE, 2016; WHO, 2015), o que faz, ou deveria fazer, com que pesquisadores de saúde e das ciências sociais se preocupassem mais com esta parcela da população e com as consequências econômicas, sociais e biológicas do envelhecimento populacional.

Estimativas indicam que no ano 2000 havia 15 países com mais de 10 milhões de idosos e que este número de países dobrará até 2050, sendo que, neste período, o Brasil será o sexto país do mundo com o maior número de idosos (UNFPA, 2000; WHO, 2005). O crescimento da população idosa é justificado pelo aumento na expectativa de vida, pela queda na taxa de natalidade e pela evolução da medicina. Entretanto, esse aumento na expectativa de vida também traz consequências negativas: os idosos costumam declarar uma piora na saúde com o avanço da idade, fator justificado pelo processo de envelhecimento estar acompanhado de incapacidade funcional, doenças crônicas e perdas cognitivas (IBGE, 2009; Kane, Ouslander, \& Abrass, 2004). Parahyba e Simões (2006), 
ao analisarem dos dados da Pesquisa Nacional por Amostra em Domicílio (PNAD) realizado pelo Instituto Brasileiro de Geografia e Estatística nos anos de 1998 e 2003, concluiu que a expectativa de vida da mulher é sempre maior do que a do homem, no entanto as mulheres idosas tendem a perceber de forma mais negativa sua saúde do que a população idosa masculina. As mulheres idosas, independentemente da condição social, declararam ter saúde "ruim e muito ruim" nos dois períodos analisados. Esse resultado sugere que, apesar da população estar vivendo mais, não tem envelhecido com qualidade de vida.

A perda cognitiva causada pelo "envelhecimento normal" é uma das principais condições que afetam a qualidade de vida do idoso. O processo de envelhecimento pode acarretar um quadro de comprometimento cognitivo leve (CCL), que é caracterizado principalmente por danos na memória, perceptível por quem apresenta tais sintomas e para os seus familiares, a despeito da função cognitiva nesses idosos manter-se preservada, sem indicativos de demência e prejuízo das atividades diárias (Caxieta, 2012; Petersen, et al., 1997). Clemente e Ribeiro-Filho (2008) definem o CCL de forma mais ampla e o subdividem em três grupos: (1) quando o único sintoma é o déficit de memória; (2) quando, além deste déficit, a linguagem ou a capacidade visuo-espacial também são afetadas; e (3) quando há perda apenas de outras funções cognitivas, que não a memória.

O CCL faz parte de um continuum que se inicia com o envelhecimento normal, podendo evoluir até um quadro de demência (Petersen, et al., 1997). Apesar de alguns autores questionarem se o CCL pode ser considerado um estágio inicial de demência (Petersen et al., 1997), Studart-Neto e Nitrini (2016) e Klekociuk, Saunders e Summers (2016) afirmam que, por mais que alguns idosos que apresentem CCL não demonstrem evolução do quadro clínico para diagnósticos de demência, a maioria deles tem possibilidade de desenvolver demência dentro de três a quatro anos. Os autores defendem 
que o termo CCL é usado de forma errônea, uma vez que não é uma possibilidade diagnóstica, mas sim uma fase que antecede a demência.

É importante ressaltar que há diferentes tipos de demência, mas que todas se caracterizam por serem condições crônicas, progressivas, com alterações cerebrais, que acarretam declínio nas funções cognitivas, mas não necessariamente na memória (CID10, 1993). Estima-se que, em 2050, cerca de 115 milhões de pessoas em todo o mundo apresentarão algum tipo de demência (Alzheimer's Disease International, 2009), sendo a Doença de Alzheimer (DA) a mais prevalente na população idosa (Papaléo Netto, 2006; Souza, Rocha, Teixeira, \& Caramelli, 2017).

\section{Doença de Alzheimer}

O Manual Diagnóstico e Estatístico de Transtornos Mentais (DSM V - APA, 2014) define as alterações cognitivas adquiridas durante a vida como Transtornos Neurocognitivos (TNC). Estes por sua vez, são subdivididos em TNC maior e TNC leve, a depender de alguns critérios diagnósticos. Para indicação de TNC maior, o indivíduo deve apresentar: (a) declínio do funcionamento cognitivo em um ou mais domínios cognitivos; (b) necessidade de ajuda para realizar as atividades de vida diária; (c) presença dos sintomas em contextos diferentes do delirium; e (d) déficits cognitivos que não são explicados por outras patologias (DSM V - APA, 2014).

O TNC leve, por sua vez, é caracterizado quando: (a) há declínio cognitivo em um ou mais domínio cognitivo; (b) há dificuldade em realizar as atividades de vida diária, porém não há dependência; (c) os déficits cognitivos são notados em outros contextos que não apenas na ocasião de delirium; e (d) os déficits cognitivos não são explicados por outras doenças. Observa-se, assim, que a principal diferença entre o TNC maior e o leve é que o primeiro provoca maior grau de dependência para a realização das atividades de 
vida diária, como tomar banho ou pagar contas, em comparação ao segundo. Contudo, independentemente do tipo de TNC, considera-se que o transtorno foi ocasionado pela Doença de Alzheimer (DA) quando: (a) há critérios diagnósticos para TNC maior ou leve; (b) há surgimento insidioso; (c) há critérios para DA provável ou possível; e (d) o quadro clínico não é explicado por outras doenças (DMS V - APA, 2014).

É diagnosticado TNC maior devido a provável DA quando um dos seguintes critérios estão presentes: (1) evidência de mutação genética e (2) evidência de declínio na memória e outro domínio cognitivo, declínio progressivo e ausência de outras demências. Caso nenhum desses critérios seja identificado, entende-se como TNC maior devido a possível DA. O TNC leve devido a provável DA é diagnosticado se há evidências genéticas de DA ou história familiar. O TNC leve devido à possível DA é sugerido quando, na ausência de evidências genéticas, o indivíduo apresenta: (1) declínio na memória e aprendizagem, (2) declínio progressivo e gradual das funções cognitivas, e (3) ausência de outras doenças. Em suma, a DA é classificada como um TNC, não tem cura, e acarreta prejuízos significativos nas funções cognitivas, em especial na memória e na linguagem, e interfere no funcionamento social do indivíduo (DSM V - APA, 2014; Pessoa, Faria, Morais, \& Chagas, 2016).

A DA causa deterioração cognitiva lenta, e pode ser classificada de início precoce ou tardio, a depender da idade em que o indivíduo apresente os primeiros sintomas (CID10, 1993). Os indivíduos diagnosticados com DA costumam ter, na maioria dos casos, entre 75 e 84 anos, contudo, idosos com 65 anos ou menos também podem desenvolver a doença. Considera-se a DA antes dos 65 anos como de início precoce (DSM-V, 2014). A DA é dividida em três fases: leve, moderada e grave.

A fase leve é caracterizada pelos déficits da memória e deficiência em captar e processar informações, assim como dificuldade na tomada de decisões. Szatloczki, 
Hoffmann, Vincze, Kalman e Pakaski (2015) ainda afirmam que alterações na fala de pacientes com DA podem ser notadas desde o início da doença, pois estes pacientes apresentam, mesmo na fase inicial da doença, dificuldade de realizar tarefas de nomeação e reconhecimento de objetos. Szatloczki, et al., (2015) ressaltam que tais dificuldades tendem a agravar-se com o avanço da doença.

Na fase moderada, há a intensificação das falhas de memória, assim como prejuízo em outras funções cognitivas, em especial na linguagem. Nesta fase, os idosos tendem a criar histórias para suprir eventos que não conseguem recordar, e apresentam déficits de coordenação motora e dificuldade de reconhecer pessoas familiares. É possívelobservar, também, alterações de personalidade, uma vez que os pacientes podem apresentar comportamentos que não faziam parte de seu repertório comportamental. Com o avanço da doença, o discurso torna-se "vazio", desorganizado, composto por frases sem sentido e com muitos questionamentos (Ask, Moore, Vesely, \& Grossman, 2007; Jackson, 2011). A última fase - fase grave - é caracterizada pelo prejuízo significativo de todas as funções cognitivas. Na fase final o paciente não mais se comunica, apresentando ecolalias e mutismo, demonstra dificuldade no auto-reconhecimento e apresenta comprometimento no sistema orgânico geral (Azevedo, Landim, Fávero, \& Chiappetta, 2009; Dijkstra, Bourgeois, Allen, \& Burgio, 2004; Jackson, 2011). Pacientes com DA podem viver de 10 a 20 anos com a doença (DSM V - APA, 2014); a fase inicial costuma durar de dois a três anos, a fase intermediária de dois a 10 anos e a fase final pode durar de oito a 10 anos (Machado, 2017).

Grinberg, Suemoto, Leite, Ferretti e Farfel (2012) afirmam que a DA apresenta as características típicas de uma demência, uma vez que é caracterizada por perda de neurônios, que acarreta na diminuição de sinapses e atrofiamento cerebral, e acúmulo de proteínas, sendo a proteína beta-amiloide e a proteína Tau, as principais encontradas. A 
DA precoce é marcada pela "herança autossômica dominante", devido à mutação em um dos seguintes genes: proteína percussora do amiloide (APP), presenilina 1 (PSEN 1) ou presenilina 2 (PSEN 2) (DSM V - APA, 2014). A DA também é caracterizada por alterações na estrutura cerebral do paciente. Di Paola, Spattela e Calgagirone (2010) afirmam as alterações no hipocampo, córtex e corpo caloso são as mais comuns na DA.

Considera-se que a DA tem causas multifatoriais que, de forma geral, ponderam a influência mútua de fatores genético e/ou fisiológicos com fatores ambientais (DSM V - APA, 2014; Souza, et al., 2017). Sob a óptica genética, a DA é explicada pela herança autossômica dominante e por mutações genéticas que costumam acontecer antes dos 60 anos de idade de uma pessoa (Souza, et al., 2017). Por outro lado, há fatores de risco ambientais que parecem favorecer o desenvolvimento da DA, tais como a exposição continua ao alumínio (Ferreira, Piai, Takayanagui, \& Segura-Nuñoz, 2008), diagnóstico prévio de diabetes mellitus tipo 2 (de Felice \& Ferreira, 2014; Guimarães \& Lazzaratti, 2017; Yang \& Song, 2013), hábito de fumar cigarro e/ou consumir drogas (Cataldo, Prochaska, \& Glantz, 2010; Plassman, Williams, Burke, Holsinger, \& Benjamin, 2010; Prince, Albanese, Guerchet, \& Prina, 2014) e o baixo nível de escolaridade (Beydoun, Beydoun, Gamaldo, Teel, \& Zonderman, 2014; Brucki \& Nitrini, 2008; Sando et al., 2008; Vieira \& Caixeta, 2012).

Observa-se, assim, que os fatores de risco para DA podem ser divididos em fatores de riscos não modificáveis e fatores de riscos modificáveis (Baumgart, et al., 2015). A condição genética é classificada como um fator não modificável, uma vez que o indivíduo tem em sua composição genética genes responsáveis pela doença e isto não é alterável. Porém, os demais fatores de risco para DA podem ser evitados com hábitos de vida mais saudáveis. O consumo de cigarro e o diagnóstico de diabetes, por exemplo, estão 
relacionados a quadros de demência porque podem provocar alterações neurovasculares (Baumgart, et al., 2015; Chen, Lin, \& Chen, 2009), e são condições evitáveis.

O diagnóstico da DA é realizado por meio de avaliação clínica e análise de resultados laboratoriais e exames de imagens (Caixeta, 2012; DSM-V, 2014). A avaliação clínica exige a observação do quadro clínico e entrevista do paciente e seu acompanhante. Nesta, deve-se avaliar as funções cognitivas por meio de perguntas simples que podem ser feitas ao paciente ou ao cuidador, como por exemplo: "O paciente tem dificuldades para se lembra de conversas?" (Caixeta, 2012, p. 99; Caramelli \& Barbosa, 2002). Além disto, o diagnóstico pode ser complementado com exames de tomografia e ressonância magnética. Gallucci-Neto, Tamelini e Forlenza (2005) ressaltam que o diagnóstico definitivo só é feito por meio da análise histopatológica do tecido cerebral, exame realizado após o óbito do paciente.

As avaliações neuropsicológicas também são muito importantes para o diagnóstico da DA. Ramos e Hamdan (2016) afirmam que o objetivo da avaliação neuropsicológica é delinear as alterações cognitivas advindas de lesões cerebrais. Hamdam (2008) descreve que a avalição neuropsicológica é realizada por meio de testes psicométricos, cujo objetivo é quantificar o rendimento cognitivo. Alguns dos testes mais utilizados para o rastreio do comprometimento cognitivo e avaliação da demência são: Mini-Exame do Estado Mental, Teste do Relógio, Teste de Trilhas, Stroop, e subteste da WISC III e WAIS III (Hamdam, 2008; Soares, Soares, \& Caixeta, 2012).

Os tratamentos propostos têm como objetivo estabilizar e atrasar o avanço da DA, uma vez que não há fármacos e/ou tratamentos não-farmacológicos que proporcionem a cura da DA. Intervenções farmacológicas implicam no uso de medicamentos que revertem processos fisiopatológicos, agindo de forma profilática e restaurando parcialmente as capacidades cognitivas (Engelhardt, et al., 2005; Forlenza, 2005; 
Massoud \& Gauthier, 2010). O tratamento farmacológico para a DA é dividido em tratamento para os transtornos cognitivos e tratamento para os sintomas comportamentais e psicológicos da demência (Vale et al, 2011). De forma geral, os fármacos utilizados para controlar o prejuízo cognitivo causado pela DA são inibidores de acetilcolinesterase, pois como na DA as vias colinérgicas são afetadas e há redução na sua atividade, a medicação visa inibir a degradação desta via. Pode-se também associar este tratamento ao uso da memantina, que favorece a neuroplasticidade e neurotransmissão colinérgica, que é um neurotransmissor excitatório associado às funções cognitivas (Forlenza, 2005; Massoud \& Gauthier, 2010; Vale et al, 2011). Os sintomas comportamentais e psicológicos da demência são tratados por meio de antipsicóticos, benzodiazepínicos, anticonvulsivantes e antidepressivos (Vale, et al, 2011).

O tratamento não farmacológico da DA é feito por meio de intervenções cognitivas, cujo objetivo é estimular, habilitar e/ou reabilitar as funções cognitivas e comportamentais que foram prejudicadas pelo avanço da demência (Costa, Bertola, \& Malloy-Diniz, 2017). Taveira, Taveira e Caxieta (2012) enfatizam que a proposta não farmacológica deve seguir um "plano de tratamento de estágios-específicos", ou seja, a cada fase da doença, deve-se propor um tipo específico de intervenção, uma vez que, à medida que a doença avança, o comprometimento das áreas lesadas intensifica-se e novos déficits surgem. Neste sentido, a Psicologia Cognitiva e a Análise do Comportamento têm

contribuído de forma significativa para o desenvolvimento de intervenções não farmacológicas para os diferentes déficits causados pela DA.

\section{Intervenções em linguagem baseadas na Psicologia Cognitiva}

Ao longo das últimas décadas muitas intervenções muitas intervenções não farmacológicas têm sido desenvolvidas com o objetivo de ensinar ao paciente com DA 
estratégias compensatórias e formas de lidar com as perdas cognitivas (Wilson, 2006). Entre os processos de avaliação e intervenção sobre as funções cognitivas, vários pesquisadores têm se dedicado especificamente ao estudo da produção de discurso por idosos com CCL e com DA (Brandão, \& Parente, 2011; Parente, Capuano, \& Nespoylous, 1999) e reabilitação da memória desta população (Silva \& Yassuda, 2009; Verhaeghen, Marcoen, \& Gossens, 1992).

Os principais problemas relacionados à linguagem que acometem as pessoas com DA são dificuldade de nomear objetos, de emitir falas espontâneas e de manter o discurso coerente. As alterações na linguagem provocadas pela DA tendem a se agravar à medida que a doença evolui e o idoso pode chegar a emitir apenas sons que são funcionais para o seu dia-a-dia, até que desenvolva um quadro de mutismo. Os idosos com DA apresentam dificuldade para compreender informações auditivas, apresentam déficits semânticos (relacionadas ao significado de palavras) e dificuldade para compreender e emitir frases complexas. Idosos com DA na fase inicial também são capazes de manter preservada a capacidade de leitura e escrita, contudo, essa habilidade se deteriora com o avanço da doença (Mansur, Carthery, Caramelli, \& Nitrini, 2005; Ortiz \& Bertolucci, 2005).

Considerando as dificuldades de idosos com DA na produção de discurso, é preciso compreender tal comprometimento em função da maneira como este se organiza em indivíduos saudáveis. Brandão (2005) considera que a produção de discurso se consolida em duas fases. A primeira é caracterizada pelo planejamento do discurso, que envolve a definição do objetivo do falante, a identificação do contexto do diálogo e das informações que o falante tem a respeito do interlocutor, juntamente com a ativação dos modelos mentais (que seriam construções mentais sobre espaço, tempo e ações, por exemplo). A segunda envolve o processamento semântico do discurso. Brandão (2005), baseada na teoria de Van Dijk e Kintsch (1983, apud Brandão 2005), propõe que há, 
durante o discurso, a ativação da memória semântica (responsável pelo significado de palavras) e da memória episódica (responsável pela recordação de eventos), característica que dá início à produção proposicional que, por sua vez, é responsável por dar significado ao discurso. Além disso, a memória de trabalho, que é responsável pela capacidade de resolução de tarefas cognitivas, parece também atuar para a produção de discurso.

O discurso precisa ter coerência, ou seja, um fluxo compreensível, tanto em termos globais (coerência global, que diz respeito ao tema do discurso), quanto em termos específicos (coerência local, que representa a relação entre as frases do texto/discurso) (Brandão, 2005; Kintsch, \& van Dijk, 1978). Assim, a avaliação de um discurso deve envolver a análise da coerência da produção, além de outros fatores, como a produção de aspectos gerais (macroestrutura) ou específicos, que podem ser relevantes (microestrutura relevante) ou irrelevantes (microestrutura irrelevantes). Sobre a análise do discurso de idosos com DA, Parente, Capuano e Nespoulous (1999) e Brandão, Parente e PeñaCasanova (2008), por exemplo, concluíram que uma característica do discurso de pacientes com DA é pobreza de detalhes nas histórias e a necessidade de mais turnos revezamento na conversa - para a manutenção do discurso.

O conjunto de estudos realizados para avaliação do discurso de idosos (Dijkstra, et al., 2004; Brandão, Castelló, Dijk, Parente, \& Peña-Casanova, 2009) indica que auxílios mnemônicos externos, como fotos ou frases sobre o tema a ser conversado, podem ajudar na produção do discurso (Bourgeois, 1993; Brandão, et al, 2008; Brandão \& Parente, 2011). Essas pesquisas produziram conhecimentos importantes sobre o discurso dos idosos, contudo, ainda é importante propor estratégias sistematizadas de intervenção que possam promover uma melhora da comunicação.

A reabilitação da linguagem pode envolver o ensino ou a reabilitação de vários aspectos, como a nomeação de pessoas e/ou a produção de informações biográficas, assim 
como o ajuste da orientação temporal. Monteiro, Crove e Fuentes (2012) propõem que sejam utilizadas diferentes técnicas para reabilitar a memória e a linguagem do idoso, tais como: evocação de lista de palavras a partir da associação destas palavras com outros itens ou por meio de categorização; estratégias compensatórias de memória, como o peg system, que propõe diferentes formas de registrar a informação; e a aprendizagem pela memória implícita, que utiliza procedimentos com redução de pista e suportes externos para a memorização, tais como agendas e alarmes.

Diferentes autores também têm demonstrado em revisões sistemáticas a eficácia dos trabalhos de reabilitação cognitiva na melhoria da memória e linguagem. No entanto, apesar dos dados indicarem que os treinos de memória, treino cognitivo, procedimentos de instrução verbal, tarefas de recuperação espaçada e até mesmo exercícios físicos, são eficientes para reestabelecer as funções cognitivas, todos os autores enfatizam que os resultados devem ser analisados com cautela, uma vez que não há padronização de protocolos, sistematização dos exercícios e podem ser encontradas várias limitações metodológicas nos estudos (Teixeira, et al., 2012; Rodakoeski, Saghafi, Butters, \& Skidmore, 2015; Hopper, et al., 2013), especialmente porque eles costumam testar a combinação de diferentes técnicas e não as técnicas separadamente, ou um protocolo específico de técnicas em diferentes condições e com diferentes perfis de idosos. Assim, nota-se que diferentes pesquisadores têm proposto estratégias para estimular a memória, contudo não se tem ainda padronização das técnicas, o que dificuldade a compreensão das estratégias mais e menos eficazes.

Além das muitas intervenções de reabilitação cognitiva utilizadas, a Reabilitação Neuropsicológica propõe outras técnicas para reabilitar as funções cognitivas e diferentes comportamentos dos idosos, tais como: técnicas comportamentais, terapia de reminiscência e técnicas de orientação à realidade. Para elaborar um programa de 
reabilitação neuropsicológica é preciso primeiramente estabelecer o objetivo a ser alcançado e este deve ser específico, mensurável, alcançável, relevante e passível de ser alcançados num tempo pré-determinado (Monteiro, et al., 2012).

\section{Intervenções em linguagem baseadas na Análise do Comportamento}

Estudos realizados sob a vertente teórica da análise do comportamento também têm demonstrado preocupação em investigar e intervir sobre os processos comportamentais de idosos com CCL ou DA. Os pesquisadores têm proposto intervenções em diferentes aspectos da aprendizagem, considerando técnicas e estratégias para reabilitar diferentes tipos de desempenhos de idosos com DA, estimulando a recuperação de déficits comportamentais e/ou controlando excessos comportamentais (e.g., Goyos, Rossit, Elias, Escobal, \& Chereguini, 2009; McCurry \& Drossel, 2011; Taveira, Taveira, \& Caxieta, 2012) e verificando a manutenção e recuperação de relações simbólicas envolvidas na reabilitação da memória e da linguagem (Aggio \& Domeniconi, 2012; Camara, Ducatti, \& Schmidt, 2017; Ducatti \& Schmidt, 2016; Haydu, \& Morais, 2009; Souza, 2011; Steingrimsdottir \& Arntzen, 2011). Neste sentido, McCurry e Drossel (2011) sugerem que a análise funcional seja utilizada como técnica para avaliar todos estes comportamentos e estabelecer planos de intervenção. A respeito da intervenção na linguagem, diferentemente das pesquisas anteriormente detalhadas, as pesquisas conduzidas sob a vertente teórica da análise do comportamento tentam identificar variáveis ambientais críticas que podem interferir positiva ou negativamente na produção do discurso de idosos, sob a percepctiva da análise da emissão de operantes verbais específicos (Dixon, Baker, \& Sadowski, 2011). A análise do controle de estímulos envolvido na produção de diferentes comportamentos verbais produzidos por idosos com TCN tem sido, portanto, um aspecto norteador de todas essas pesquisas. 
Por exemplo, Dixon, et al. (2011) propuseram um procedimento para aumento de emissão de comportamento ecóico e de comportamento intraverbal durante uma tarefa de recordação, com o objetivo de verificar se o treino ecócio (repetição de uma palavra-alvo) e de intraverbal (responder perguntas sobre esta palavra-alvo), teriam efeitos positivos sobre a recordação dessas palavras em testes de manutenção posteriores. Para tanto, três idosas com DA passaram por um procedimento cuja tarefa consistia em olhar para 40 figuras diferentes. Se as figuras estivessem sobre um fundo azul, as participantes deveriam olhar a figura, repetir o nome da figura que seria ditado pelo pesquisador (emissão de ecoico) e responder a uma pergunta referente à figura, também feita pelo pesquisador (comportamento intraverbal). Se as imagens estivessem sobre um fundo vermelho, a participante deveria apenas olhar para a imagem e tentar memoriza-la.

Após a finalização da tarefa e uma semana após a sua conclusão, o pesquisador solicitava que a participante falasse o nome de todas as figuras que ela lembrava. Em ambos os momentos, as idosas conseguiram lembrar com maior facilidade das figuras projetadas sobre o fundo azul, sobre as quais elas tiveram que responder perguntas e cujo nome elas repetiram. Esses resultados indicam que a forma como se estabelece o contato com os estímulos interfere em quanto o idoso irá lembrar posteriormente desse estímulo, o que pode ter implicações na produção de um discurso descritivo e, até mesmo, narrativo. No caso da pesquisa de Dixon et al. (2011), a emissão dos comportamentos ecóico e intraverbal aparentemente serviram para o fortalecimento das relações nome-figura ensinadas/testadas.

O uso de estímulos visuais para a melhora do discurso de idosos com DA também tem sido estudado por analistas do comportamento. Bourgeois $(1990 ; 1993)$ testou o uso de um "caderno de memórias", compostos por frases simples e fotos, sobre o desempenho verbal de idosos durante conversas. Bourgeois (1993) expôs seis idosos com DA a uma 
condição experimental em que cada dupla de idosos deveria conversar, um com o outro, utilizando ou não o caderno de memória, que foi construído pela pesquisadora. Em cada dupla havia um idoso saudável e um idoso com DA. O caderno tinha informações simples sobre temas pertinentes à vida de cada idoso com DA (e.g., rotina, família, etc.). Os resultados indicaram que os idosos tiveram um melhor desempenho na tarefa e mantiveram um discurso mais coerente e sem repetições, quando utilizavam os "cadernos de memória". Os estímulos visuais que compunham o caderno parecem ter funcionado como estímulos discriminativos eficientes para evocar narrativas mais longas, completas e coerentes sobre os temas a que se relacionavam.

Além da dificuldade de comunicação apresentada pelos idosos com DA ocasionada por falhas de nomeação ou presença de discurso vazio, também é comum que alguns deles apresentem falas excessivas ou inapropriadas. Pesquisadores analistas do comportamento também desenvolveram estudos a fim de intervir nestes comportamentos inadequados, utilizando como base o reforço diferencial. Pinkston e Linsk (1984), por exemplo, testaram um procedimento para diminuir falas inadequadas de dois casais de idosos (sendo que o homem apresentava os comportamentos inadequados de comunicação). Para tanto, as esposas foram ensinadas a reforçar diferencialmente as falas "adequadas" dos esposos. Os treinamentos foram feitos por meio de instruções, observações e role-playing. Os resultados mostraram que falas inadequadas diminuíram de frequência após o procedimento.

Buchnan e Fisher (2002), com o objetivo de verificar o papel da "avaliação funcional" nas intervenções com idosos com demência e avaliar a eficácia de procedimentos de reforço não contingente sobre "vocalizações perturbadoras", estruturaram um procedimento em que dois idosos com demência que apresentavam tais vocalizações, ou seja, falas inadequadas e/ou altas, participaram de cinco sessões de 30 a 
50 minutos que tinham como propósito diminuir a frequência deste comportamento considerado inadequado. Durante as sessões de linha de base, observou-se a emissão do comportamento (o contexto em que ele ocorria, sua topografia e as consequências de sua emissão). Após a determinação dos possíveis reforçadores que mantinham tais vocalizações, tanto os pesquisadores quanto a equipe de enfermagem deixaram de apresenta-los contingentemente aos comportamentos inadequados, e passaram a não interagir com os dois idosos durante esses episódios.

Durante a fase de intervenção, foram apresentados os estímulos reforçadores, como a atenção, que supostamente mantinham as falas inadequadas (ou gritos), em um esquema não contingente de tempo fixo. O tempo foi calculado a partir da quantidade média de tempo entre o início das sessões de análise funcional e a primeira emissão do comportamento alvo (vocalizações inadequadas). Para um dos participantes, a sessão iniciou-se com o reforçador sendo apresentado de forma contínua, contudo isto foi alterado para um tempo fixo após o comportamento passar a ser emitido em níveis abaixo da linha de base. Foi possível notar, a partir da análise funcional, que as falas inadequadas estavam sendo reforçadas pela atenção das pessoas do ambiente. A partir do momento em que a atenção passou a ser dispensada independentemente da emissão do comportamento inapropriado, este diminuiu significativamente de frequência sendo, então, possível controlá-lo (Buchnam \& Fisher, 2002).

Ainda no sentido de verificar o papel da análise funcional para a modificação de comportamentos inadequados, McCurry e Drossel (2011) propuseram que o cuidador do idoso com demência seja ensinado a identificar os estímulos antecedentes ao comportamento alvo e as consequências apresentadas após a emissão do comportamento. As pesquisadoras defendem que o ensino da análise funcional para os cuidadores de idosos ocorra de forma didática, por meio de perguntas pontuais que auxiliem na 
identificação dos termos da contingência. A fim de identificar os estímulos antecedentes, McCurry e Drossel (2011) sugerem que o cuidador fique sob controle do seguinte questionamento "Onde e perto de quem o comportamento ocorreu?"; para identificar o comportamento, é preciso responder "O que exatamente a pessoa fez?"; e por fim, para identificar as consequências, é preciso responder "O que aconteceu imediatamente após a emissão do comportamento?" e "Como você respondeu?". As autoras afirmam que intervenções para idosos com demência precisam ser individualizadas, uma vez que cada idoso apresenta uma demanda. Utilizar da análise funcional permite que seja realizada uma análise individualizada do sujeito a fim de proporcionar o tratamento específico para aquela pessoa, tanto para comportamentos gerais apresentados por eles, como para comportamentos verbais que precisem aumentar ou diminuir de frequência.

Analistas do comportamento também têm se dedicado a desenvolver procedimentos que auxiliem no comportamento de lembrar de idosos com DA (Aggio, Ducatti \& de Rose, 2018; Camara, Ducatti, \& Schmidt, 2017; Ducatti \& Schmidt, 2016; Sidman, 2012; Souza, 2011; Steingrimsdottir \& Arntzen, 2011), especialmente aqueles relacionados à emissão de comportamentos verbais (de falante e de ouvinte). Muitas das situações envolvendo esses comportamentos envolvem tarefas de emparelhamento de acordo com o modelo (MTS), uma estratégia bastante empregada em pesquisas sobre desempenhos relacionais. Por exemplo, alguém pode perguntar para um idoso "qual desses é a caneta?", diante de uma mesa contendo um par de óculos, um celular e uma caneta. A pessoa precisa relacionar a palavra ditada um dos objetos à sua frente, o que é comumente chamado de "tarefa de reconhecimento". O estabelecimento de uma relação entre uma palavra e um objeto específico é também a base para o comportamento de tatear (ou nomeação): para que um idoso fale o nome de um objeto (e.g., caneta) é necessário que uma relação estável entro o objeto e essa palavra tenha sido estabelecida na história 
do indivíduo, isto é, que o idoso identifique aquele objeto específico dentre outros como caneta, e que emita a palavra "caneta" diante desse objeto e não de outros.

Pesquisas sobre a perda, o estabelecimento e a manutenção de relações condicionais entre estímulos por idosos com DA, sobretudo entre estímulos verbais e visuais, têm sido feitas por diversos autores (e.g., Ducatti \& Schmidt, 2016; Souza, 2011) e a grande maioria deles têm verificado a dificuldade de idosos com DA, tanto na aprendizagem de novas relações, como na recuperação de relações perdidas em função da demência (Camara, et al., 2017; Ducatti \& Schmidt, 2016; Sidman, 2012; Steingrimsdottir \& Arntzen, 2011). Essas pesquisas têm indicado a necessidade de se desenvolver procedimentos de intervenção para o ensino de relações condicionais para idosos com DA, assim como para que essas relações sustentem a formação de classes de equivalência, que são a base para aquilo que se tem chamado de "significado" (de Rose \& Bortoloti, 2007). O primeiro passo para isso seria o desenvolvimento de intervenções que favorecessem a aprendizagem dessas relações.

Ducatti e Schmidt (2016), por exemplo, com o objetivo de verificar a eficácia de um procedimento de ensino de relações condicionais por exclusão e com dica atrasada, apresentaram a quatro idosas com DA uma tarefa emparelhamento ao modelo envolvendo fotos e nomes, apresentados por meio de um computador. Os estímulos utilizados foram distribuídos em três conjuntos (fotos - conjunto A - e palavras escritas referentes a nomes - conjunto B - e profissões - conjunto C), cada um composto por três estímulos. O estímulo modelo era sempre apresentado na parte superior da tela do computador e os estímulos de comparação na parte inferior da tela. Os estímulos de comparação eram apresentados de forma gradual: nas primeiras tentativas os estímulos de comparação incorretos permaneciam na tela por tempo determinado, enquanto que o comparação correto permanecia até que a resposta de escolha fosse emitida, o que forçava a seleção 
da resposta correta, de forma que o tempo de permanência do S- aumentava ao longo da sessão. Ao final do treino, foi testado o desempenho das idosas em relação às relações ensinadas e em tarefas de nomeação e equivalência (apresentar relações entre estímulos que não foram diretamente ensinadas durante o procedimento, mas que poderiam ser derivadas deste; por exemplo, após aprender que uma determinada foto está relacionada ao nome "Ana" [relação $\mathrm{AB}$ ], e que essa é a foto de uma enfermeira [relação $\mathrm{AC}$ ], é possível verifica se a idosa relaciona, sem ensino direto, o nome "Ana" à profissão de enfermeira [relação $\mathrm{BC}$ ] e vice-versa [relação $\mathrm{CB}]$ ). As idosas aprenderam as relações condicionais, selecionando corretamente as fotos diante dos nomes e profissões ditadas, contudo apresentaram desempenho inconsistente na tarefa de equivalência e de nomeação.

Além das muitas pesquisas que ensinaram relações condicionais para idosos com DA, envolvendo desempenhos verbais (de falante e de ouvinte) por meio de tarefas de MTS, uma série de outros estudos têm investigado outros procedimentos que podem estabelecer relações auditivo-visuais envolvidas em desempenhos de falante e de ouvinte. Um dos procedimentos mais investigados nas últimas duas décadas é o procedimento Spaced Retrieval (SR), utilizado para o ensino de diversas relações entre palavras/instruções e objetos, figuras, e tomadas de decisões diante de problemas práticos (Carpenter, Cepeda, Roher, Kang, \& Pashler, 2012; Cherry, Walvoord, Hawley, 2010; Creighton, Ploeg, \& O’Conner, 2013; Thivierge, Simard, Jean, \& Grandmaison, 2008).

O SR, ou recuperação espaçada, é um procedimento que consiste em repetir informações que devem ser aprendidas, em intervalos pré-determinados de tempo (Landauer \& Bjork, 1978). De forma geral, procedimentos de SR que têm por objetivo o ensino de relações entre palavras e figuras, por exemplo, iniciam-se com a apresentação de uma palavra que será aprendida, junto com a figura correspondente (e.g., "Essa é figura 
do sapato. Repita: sapato”.). A palavra é repetida pelo participante, e, após períodos de tempo pré-determinados, o participante deve repetir a palavra diante do pedido do pesquisador, nomeando a figura ("Qual o nome do objeto dessa figura?).

A maioria dos estudos implementa intervenções em que o intervalo entre as tentativas é aumentado gradativamente na medida em que o participante apresenta o desempenho esperando (e.g., 2s, 4s, 8s... 30 minutos). Caso haja erros, o pesquisador pode fazer a correção da palavra e o intervalo da tentativa seguinte retrocede ao último intervalo, anterior àquele em que ocorreu o erro (e.g., Jang et al, 2015). Outros estudos testaram os efeitos de intervalos regulares entre as tentativas (e.g., 10s, 10s, 10s...), em comparação com intervalos ajustados (crescentes) (e.g, Balota et al., 2006; Hawley, Cherry, Boudreaux, \& Jackson, 2008; Hochhalter, Bakke, Holub, \& Overmier, 2004). Os resultados desses estudos comparativos não são uniformes: enquanto alguns não encontram diferenças entre os tipos de intervalo (Balota et al., 2006; Hochhalter, 2004), outros verificaram o melhor desempenho dos idosos em procedimentos com intervalos crescentes (e.g., Hawley et al., 2008).

Um exemplo de estudo sobre os efeitos do SR é o trabalho de Jang et al. (2015), no qual a eficácia do SR foi avaliada como procedimento de ensino sem erro para a reabilitação da linguagem e memória de uma amostra de pacientes com demência. Vinte e nove pacientes com demência (Vascular ou Alzheimer) participaram do estudo. A intervenção baseada no procedimento SR iniciou-se com a realização de uma pergunta para os participantes e a apresentação da resposta. Nas demais tentativas, a pergunta era realizada pelo pesquisador, que esperava que os participantes emitissem a resposta. Se a resposta não era emitida ou o participante fornecia uma resposta errada, o pesquisador falava a resposta certa. As tentativas ocorreram em intervalos crescentes de 45, 90, 180, 360 e 720 segundos. Entre as tentativas, os participantes eram convidados a realizar 
tarefas que não tinham relação com a memória. Os resultados indicaram que o SR foi um procedimento eficaz para estimular a aprendizagem de idosos com demência, uma vez que todos aprenderam as palavras ensinadas e demonstraram melhora no desempenho em testes como Mini-Exame do Estado Mental, que avalia as funções cognitivas, e Teste de Nomeação de Boston.

As pesquisas têm mostrado que este procedimento é eficaz na aprendizagem de relações envolvendo palavras (e.g., reconhecimento de faces, nomeação de figuras, etc) e recomendado para ser utilizado na reabilitação de desempenhos verbais em idosos com DA (Creighton, Ploeg, \& O-Conner, 2013; Erkes, Raffard, \& Meulemans, 2009; Jang, Lee, \& Yoo, 2015). Há dúvidas, porém, quanto aos resultados de generalização gerados a partir do procedimento de SR. Hawley e Cherry (2004), por exemplo, com o objetivo de testar o procedimento SR para ensinar a relação face-nome e verificar a possibilidade de generalização após o treino, construíram um procedimento em que seis idosos com DA foram treinados, em seis sessões, a nomear fotos. Ao longo das tentativas, os idosos deviam olhar uma determinada foto e falar o nome da pessoa daquela foto, em intervalos crescentes de tempo. Após está tarefa, os idosos passaram por uma tarefa de generalização, que consistia em olhar para as pessoas reais (referentes às fotos) e dizer seus nomes. Os resultados indicaram que o procedimento SR foi eficaz para a aprendizagem dos nomes diante das fotos, no entanto, apenas metade dos participantes conseguiu generalizar esse desempenho para as pessoas reais.

Os procedimentos de ensino estruturados a partir do SR parecem ser eficazes para a aprendizagem de novas informações, principalmente quando comparados a procedimentos que favorecem a ocorrência de erros, como o procedimento de tentativa e erro. Contudo, assim como Jang, et al., (2015) ressaltam, novos estudos sobre a eficácia deste procedimento para a população idosa com demência, são necessários. 
Outro procedimento de ensino explorado em estudos de intervenção com idosos com DA é o fading out (FO - esvanecimento de dicas, também referido na literatura como vanishing cues).

O FO consiste em fornecer ao participante no início da tarefa determinada dica, e ao longo da tarefa, retirar de forma progressiva a dica, até que nenhuma dica seja fornecida (Glisky, Schacter, \& Tulving, 1986). Estudos de FO com a população idosa com DA tem sido utilizado em tarefas que ensinam ou recuperam informações relacionadas a memória, orientação espacial e atividades de vida diária (Clare et al., 2000; Clare, Wilson, Carter, Roth, \& Hodges, 2002; Haslam, Moss, \& Hodder, 2010; Mimura \& Komatsu, 2010; Provencher, Bier, Audet, \& Gagnon, 2008; Thivierge, Simard, Jean, \& Grandmaison, 2008).

Thivierge, et al. (2008) verificaram a eficácia dos procedimentos o SR e FO para ensinar determinadas habilidade para idosos com DA. O idoso A foi treinando para utilizar o "correio de voz" e o participante B para utilizar a "secretaria eletrônica". A intervenção ocorreu duas vezes por semana, durante 10 semanas, e com duração de 45 minutos por sessão. Para isto, os idosos deveriam executar a tarefa em períodos pré determinados (30s, 1m, 2m, 4m e 8m) (SR) e poderiam utilizar "ajuda", que era fornecida de modo descrente, ou seja, no primeiro tipo de ajuda, havia maior participação do pesquisador e no quarto (e último) tipo de ajuda, menor assistência (procedimento de FO). Se o participante, por exemplo, estivesse executando a tarefa no intervalo de $4 \mathrm{~m}$ com o terceiro tipo de assistência e mesmo assim cometesse um erro, a próxima tentativa aconteceria após $2 \mathrm{~m}$ e seria utilizado o segundo tipo de assistência. Os resultados indicaram que os procedimentos foram eficazes para a aprendizagem, além de promover manutenção do comportamento. Apesar do estudo não trabalhar apenas com o FO, notase que o procedimento foi importante para a aprendizagem. 
Os estudos sobre intervenções para os diferentes déficits causados pela DA, tanto da perspectiva da psicologia cognitiva, quanto da abordagem comportamental, têm apresentado bons resultados. Conforme afirmam Costa, Bertola e Malloy-Diniz (2017), os resultados de estimulação têm demonstrado resultados interessantes, contudo as pesquisas ainda são "frágeis". Tal fragilidade pode ser atribuída, segundo os autores, (a) à falta de padronização da metodologia de pesquisa, de forma que cada estudo propõe um determinado procedimento, o que dificuldade a comparação de resultados obtidos de diferentes estudos; (b) muitos estudos não controlam de forma adequada as variáveis que podem influenciar os resultados; e (c) a maioria dos estudos trabalha com um número reduzido de participantes, o que dificuldade a generalização dos resultados. Os estudos sobre linguagem, por exemplo, caracterizam-se muito mais como estudos que descrevem e caracterizam o desempenho de idosos com DA do que estudos que têm como objetivo estruturar uma intervenção. As pesquisas sobre intervenção sobre a memória, por sua vez, apresentam técnicas mais estruturadas, mas mesmo assim não apresentam protocolos de intervenção estabelecidos.

Observa-se que as intervenções investigadas por psicólogos cognitivos normalmente são estruturadas com objetivos amplos, como o de realizar "intervenção cognitiva" e, portanto, há pouca especificação do desempenho esperado e dificuldades em se estabelecer quais procedimentos, dentre aqueles testados nos pacotes de intervenção, trazem resultados melhores e em quais campos específicos. Tais pesquisas costumam propor procedimentos em que os idosos respondem a diferentes tarefas a fim de melhorar, de forma geral, as funções cognitivas. Em contrapartida, as pesquisas desenvolvidas por analistas do comportamento mostram-se mais delimitadas em seus objetivos, pois tendem a propor procedimentos mais focalizados em comportamentos específicos (em função de necessidades individuais dos idosos) sem, contudo, garantir ou 
avaliar os efeitos dos procedimentos sobre os demais comportamentos do repertório do idoso. A despeito dessas diferenças de natureza epistemológica e metodológica, e das limitações dos estudos aqui revisados, ambas as abordagens têm contribuído para a ampliação dos conhecimentos sobre intervenções não-farmacológicas da DA.

O presente estudo se situa dentro de uma abordagem teórico-metodológica da análise do comportamento e reconhece a necessidade de que sejam estudadas e propostas intervenções para a melhoria de repertórios verbais de pacientes com DA, o que poderia contribuir para o atraso do avanço da doença e para o não isolamento social destes pacientes. Atualmente, há muitas pesquisas sobre formas eficazes de avaliação de pacientes com DA, com o desenvolvimento de diversos instrumentos de rastreamento e de avaliação de necessidades desses indivíduos (Caxieta, et al., 2012), contudo, ainda há muito que se avançar em termos da investigação de formas eficazes de intervenção para esses indivíduos, em especial no campo da Análise do Comportamento, pois além da quantidade relativamente reduzida de estudos com idosos, verifica-se pouca continuidade dos trabalhos, uma vez que pesquisas pontuais são desenvolvidas, com pouca atenção a estudos e/ou avaliações prospectivas.

Os preceitos de aprendizagem propostos pela Análise do Comportamento podem colaborar de forma eficaz para intervenções com foco no desenvolvimento de repertórios verbais diversos, uma vez que tais preceitos são derivados de décadas de estudo sobre a aprendizagem de comportamento simbólico por diferentes populações (de Rose, 1993). Assim, este trabalho se justifica pela necessidade de compreender melhor a aprendizagem, manutenção, perda e recuperação de repertórios verbais por idosos com DA, por meio de procedimento de investiguem de que forma estímulos verbais e não verbais adquirem função discriminativa para controlar comportamentos de falante e de ouvinte, especialmente em situações narrativas ou de nomeação de diferentes tipos de 
referentes. Compreendendo as variáveis que atuam no controle da emissão de respostas verbais é possível estruturar procedimentos de aprendizagem que melhorem o repertório verbal de idosos de forma ampliada. Ressalta-se, ainda, a necessidade de desenvolver pesquisas nesta área, uma vez que, além do aumento crescente do número de idosos com DA no mundo e os custos com a doença serem altíssimos (Alzheimer's Disease International, 2009), as demências não têm cura, o que exige o desenvolvimento de tecnologias que auxiliem os idosos a permanecer com melhor qualidade de vida pelo maior tempo possível.

Em suma, é importante responder ao questionamento proposto por Skinner e Vaughan (1985): “que fazer a respeito de sua velhice?". Os autores afirmam que os psicólogos têm se dedicado a compreender a percepção do homem sobre o envelhecimento, porém não o ajudam a estruturar maneiras de viver a velhice com qualidade. Neste sentido é preciso desenvolver mais estratégias para "viver bem a velhice", com ou sem a presença de transtornos neurocognitivos. 
Objetivos 
Esta tese está estruturada em três estudos independentes, todos sobre o desenvolvimento de repertórios verbais em idosos com DA. O objetivo geral deste trabalho foi investigar o efeito de diferentes tipos de estratégias de intervenção sobre a produção de diferentes desempenhos de falante em idosos com diagnóstico de DA leve (em fase inicial). As estratégias investigadas foram o apoio visual, o fading out progressivo de perguntas, o SR e ofading out de dicas; os repertórios verbais investigados foram os de reproduzir uma narrativa ouvida, contar uma história a partir de sequências de estímulos visuais e nomear figuras. Os objetivos específicos de cada estudo foram:

a) Estudo 1: verificar se a estratégia de apoio visual, por meio do uso de objetos tridimensionais, pode auxiliar na formulação ou reformulação de uma narrativa por idosos com DA.

b) Estudo 2: investigar se um procedimento de fading out progressivo de perguntas alteraria a produção de narrativas com apoio visual por idosos com DA.

c) Estudo 3: comparar o desempenho de idosos com DA em uma tarefa de nomeação de figuras, após aprendizagem feita por meio do ensino por Spaced Retrieval (SR) e por Fading Out (FO). 
Estudo 1 
Dicas visuais e recontagem de histórias por idosos saudáveis e com demência

\title{
Resumo
}

A Demência de Alzheimer (DA) causa prejuízos na memória e na linguagem, sendo necessárias estratégias para minimizar tais déficits. O objetivo desse estudo foi verificar o efeito de dicas visuais na tarefa de recontar histórias por idosos com DA. Participaram 48 idosos, 24 saudáveis e 24 com DA, que deveriam recontar uma história após apenas ouvirem a sua leitura, e após ouvirem sua leitura acompanhada da apresentação de objetos tridimensionais relacionadas ao enredo. Analisou-se a frequência de macroestruturas (M) e microestruturas $(\mathrm{m})$ presentes nas narrativas. Todos emitiram mais " $\mathrm{M}$ " do que " $\mathrm{m}$ "; as dicas visuais não melhoraram o desempenho dos participantes na tarefa. Discutem-se fatores que podem ter minimizado o efeito das dicas no desempenho dos idosos.

Palavras-Chave: dicas visuais, linguagem, demência de Alzheimer, idosos, análise do comportamento

\begin{abstract}
Alzheimer's Dementia (AD) causes impairments in memory and language, with strategies being necessary to minimize these deficits. The aim of this study was to verify the effect of visual cues on the task of retelling stories by older adults with AD. Participants were 48 older adults ( 24 with AD), who should to retell a story after only hearing it read, and after hearing it read accompanied by the presentation of three-dimensional objects related to the plot. The frequency of macrostructures (M) and microstructures (m) present in the narratives was analyzed. All emitted more "M" than " $m$ "; the visual cues did not improve the performance of the participants in the task. Factors that may have minimized the effect of the cues on the performance of the elderly are discussed.
\end{abstract}

Keywords: visual cues, language, Alzheimer's dementia, aged, behavior analysis 
A Demência de Alzheimer (DA) é um Transtorno Neurocognitivo, sem cura, que acarreta prejuízos em funções orgânicas e cognitivas, principalmente na memória e na linguagem (APA, 2014 - DSM-V). O avanço da DA intensifica progressivamente os sintomas, provocando a consequente piora do estado físico do paciente e o isolamento social do mesmo, uma vez que a comunicação é significativamente prejudicada (Burlá, Pessini, Siqueira, \& Nunes, 2014). Diversos estudos têm mostrado a eficácia de intervenções neuropsicológicas para a estabilização temporária dos sintomas da demência (e.g., Andrade, et al., 2016; Rojas, et al., 2013), mas Gutierrez, Silva, Guimarães e Campino (2014) afirmam que se houvesse mais investimentos em tratamentos não farmacológicos que garantissem a independência e a preservação da capacidade funcional do idoso, os custos com a saúde do idosos com DA seria menor.

Os tratamentos não farmacológicos buscam, de forma geral, estratégias para retardar a piora dos déficits causados pela DA na memória e na linguagem, ou para recuperar repertórios que se deterioraram (Ducatti \& Schmidt, 2016; Soderlund, Cronqvist, Noberg, Ternestedt, \& Hansebo, 2016; Teixeira, et al., 2012). Alguns estudos têm investigado de forma sistemática o repertório verbal dos idosos com DA a fim de caracterizar os prejuízos causados pela demência e propor formas de intervenção para garantir a melhoria da interação verbal nessa população (e.g., Brandão \& Parente, 2011; Cera, Ortiz, Bertolucci, \& Minett, 2011; Parente, Capuano \& Nespoylous, 1999; Soderlund, et al., 2016).

Essas pesquisas têm indicado uma relação significativa entre a fase da demência e a produção de discurso (Ash, Moore, Vesely, \& Grossman, 2007; Azevedo, Landim, Fávero, \& Chiappetta, 2009; Szatloczki, Hoffmann, Vincze, Kalman, \& Pakaski, 2015). Na fase inicial da DA, a comunicação é caracterizada principalmente pela dificuldade em lembrar nomes de pessoas e objetos, porém nas fases intermediária e grave nota-se a 
presença de um discurso sem coerência, podendo avançar para quadros de mutismo (Azevedo, et al, 2009). Além disso, o discurso de idosos com DA é marcado pela necessidade maior de turnos - revezamento na conversa - para a manutenção do diálogo, pois esses idosos precisam de estímulos externos (dicas verbais, como perguntas e complementos de frases provenientes do ouvinte) para manter o diálogo (Brandão, Parente, \& Penã-Casanova, 2008; 2010).

Estudos sobre a caracterização do discurso de idosos com DA são realizados a partir da análise do desempenho dos participantes em diferentes tarefas discursivas e, em geral, comparam o desempenho de idosos com DA com o de idosos saudáveis. Parente et al. (1999), por exemplo, avaliaram o desempenho de 17 adultos e 14 idosos com comprometimento cognitivo leve em uma tarefa de recontar uma história após ouvi-la sendo contada pelo pesquisador. Ambos os grupos reproduziram mais informações gerais do que detalhes da história, mas os idosos com comprometimento cognitivo apresentaram maior dificuldade em recontar a história, além de acrescentar na recontagem informações que não estavam no enredo original. Uma das formas de se intervir nesse tipo de dificuldade é fornecer algum tipo de auxílio externo à tarefa que possa melhorar o desempenho do idoso.

No estudo de Brandão et al. (2008), 16 idosos saudáveis e 18 idosos com DA foram expostos a três tarefas discursivas. Em todas, os idosos deveriam falar sobre um tema pré-determinado e era fornecida (ou não) alguma pista que poderia auxiliar o relato. Na primeira tarefa os idosos deveriam falar sobre seu casamento e não foi fornecida nenhuma pista específica que pudesse evocar o discurso, apenas dicas gerais (e,g., o pesquisador solicitava continuidade da narrativa ou retomava a tarefa). Na segunda e na terceira tarefas foram fornecidas, respectivamente, pistas informativas (o pesquisador solicitava que o idoso narrasse um evento marcante, e dava dicas específicas sobre tal 
evento para auxiliar a continuidade da narrativa) e pistas visuais (um conjunto de doze ilustrações - cartões - que mostravam a sequência da história "Chapeuzinho Vermelho"). O estudo mostrou que idosos saudáveis, quando comparados aos idosos com DA, necessitaram de uma quantidade menor de turnos para concluir a tarefa e que quanto maior o comprometimento da DA, maior a necessidade de turnos e de diferentes tipos de pistas (informativas ou não) para continuidade do discurso. Outros estudos também analisaram aspectos de coerência e conteúdo do discurso de pessoas com DA e todos indicaram deterioração do discurso de idosos com DA nos aspectos avaliados (e.g., Lima, Brandão, Parente, \& Peña-Casanova, 2014; Lira, Minett, Bertolucci, \& Ortiz, 2014).

É importante considerar, porém, que o tipo de tarefa discursiva proposta é uma variável crítica na análise dos resultados. No estudo de Brandão et al. (2008), por exemplo, apesar das três tarefas exigirem como resposta do idoso um relato verbal, o estímulo antecedente e o contexto de realização da tarefa eram diferentes. As duas primeiras tarefas diferenciaram-se pela presença ou não de dicas verbais específicas, no entanto, eram semelhantes por serem tarefas que, para serem executadas, dependiam de informações autobiográficas. Responder a este tipo de tarefa exigia que o idoso ficasse sob controle de um evento que ele viveu, portanto, ele deveria ser capaz de evocar informações com base em instruções gerais (Tarefa 1) ou de dicas específicas (Tarefa 2). A terceira tarefa, porém, exigia um repertório diferente, no qual o idoso deveria ficar sob controle de um estímulo visual (ilustrações referentes à história) e relatar uma história que seus familiares supunham que ele sabia (Chapeuzinho Vermelho). Nesse caso, o idoso poderia olhar para a ilustração e narrar aquilo que via nela, ou repetir uma história de ele mesmo leu, ouviu ou narrou para outras pessoas. Os tipos de antecedentes disponíveis para essa tarefa eram muito diferentes dos disponíveis nas tarefas anteriores, independentemente da instrução inicial e, como consequência, exigia outros 
desempenhos (e.g., descrever o que acontecia em cada cartão e juntar as informações do primeiro cartão com as do cartão seguinte, para que o relato verbal fosse a narração de uma história). Essa breve análise indica a necessidade de se entender o tipo de controle de estímulos presente em cada tipo de tarefa verbal.

Estudos sobre a relação entre antecedentes e desempenhos verbais em idosos saudáveis e com DA têm sido conduzidas por analistas do comportamento (Aggio \& Domeniconi, 2012; Gallagher \& Keenan, 2009; Ducatti \& Schmidt, 2016). Estudos específicos de intervenção sobre repertórios verbais com população idosa, porém, são em número menor e tendem a focalizar as relações de controle envolvidas na produção de desempenhos verbais de ouvinte ou de falante, e possíveis estratégias para melhorar tais repertórios (e.g., Bourgeois, 1990; 1993; Dixon, Becker, \& Sadowski, 2011). Uma dessas estratégias é o uso das chamadas "ajudas externas de memória” (external memory aids), ou apoio visual. Buchanan, Christenson, Houlihan e Ostrom (2011) descrevem este recurso como itens cuja função é suplementar a memória, fornecendo pistas sensoriais ao indivíduo capazes de ajudá-lo a compensar eventuais dificuldades em lembrar apenas a partir das dicas presentes normalmente em seu ambiente ou em instruções iniciais. Essas dicas podem ter diversos formatos (listas de palavras escritas, anotações no calendário, objetos tridimensionais) e sua aplicação prática é ampla.

Bourgeois $(1990,1993)$ conduziu dois estudos para verificar o efeito de um “caderno de memória”, utilizado como apoio visual, na conversação de idosos com DA sobre aspectos de sua vida (e.g., fatos importantes de sua história). O caderno apresentava de forma objetiva, por meio de imagens (fotos) ou frases curtas, informações sobre a vida ou a rotina do idoso que funcionavam como dicas (estímulos discriminativos) para iniciar ou manter uma conversa. Em ambos os estudos, quando o idoso utilizava o caderno ao conversar com alguém, seu discurso tornava-se menos ambíguo e repetitivo, com melhora 
no conteúdo da conversa. A dica visual, aparentemente, foi eficiente por estar presente durante toda a conversa, por ser manuseada pelo próprio participante e por estar atrelada a componentes sociais, como a própria interação e o fato da conversa ser baseada em informações autobiográficas dos participantes (fatos vividos por ele).

Dicas visuais podem ser eficientes também na recontagem de histórias, mas não há ainda evidências empíricas que comprovem sua eficácia nesse tipo específico de tarefa. Estudar esta condição é importante, uma vez que reproduzir pelo discurso uma informação nova é uma tarefa presente na vida de idosos em diferentes ocasiões, como quando eles atendem a um telefonema e precisam dar um recado ao familiar ou quando assistem ou leem alguma notícia na televisão ou jornal e a reproduzem em conversas com outras pessoas. O objetivo deste estudo foi verificar se a estratégia de apoio visual, por meio do uso de objetos tridimensionais, poderia auxiliar na formulação ou reformulação de uma narrativa por idosos com DA. Foi analisada a frequência de emissão de macroestruturas, microestruturas e outras informações pelos participantes e comparado o desempenho de dois grupos de idosos: um grupo saudável e outro com DA.

\section{Método}

\section{Participantes}

Participaram do estudo 48 idosos, de ambos os sexos, alfabetizados, com idade entre 65 e 85 anos, divididos em dois grupos. O Grupo Controle (GC) foi composto por 24 idosos (12 mulheres) saudáveis e com escore médio no Mini-Exame do Estado Mental (MEEM) de 24 pontos; o Grupo Experimental (GE), foi composto por 24 idosos (21 mulheres) com DA na fase inicial (diagnosticado por médicos) e escore médio de 14,2 no MEEM. Metade dos idosos do GC e três idosos do GE residiam com seus familiares; os demais residiam em Instituições de Longa Permanência para Idosos. Nenhum participante 
demonstrava indicativos de depressão, afasia ou problemas significativos de visão e audição. Os idosos ou seus familiares concordaram com a participação na pesquisa por meio de assinatura de um termo de consentimento livre e esclarecido. A pesquisa foi aprovada pelo comitê de Ética da Faculdade de Filosofia, Ciências e Letras de Ribeirão Preto - USP (CAEE 41678015.4.0000.5407).

\section{Materiais e Situação Experimental}

Foram utilizadas duas histórias - "Velho Homem" (H1) e "Jovem Mulher" (H2) (Parente et al., 1999; Parente, Saboskinsk, Ferreira, \& Nespoulous, 1999) - equivalentes quanto à estrutura narrativa e à extensão. Ambas as histórias apresentavam o mesmo tempo verbal e sequência de ações, assim como a mesma quantidade de personagens e elementos com os quais os personagens interagiam. Também foram empregados objetos tridimensionais relacionados a elementos do enredo das histórias. Para H1 foram utilizados dois bonecos referentes, respectivamente, a um homem velho e um menino, uma casa de madeira e uma vara de bambu; para $\mathrm{H} 2$ utilizou-se dois bonecos, referentes a uma mulher e a um homem, um carro de madeira e um revólver de madeira. Para o registro dos dados, utilizou-se uma Filmadora Digital SONY Handycam, CDR-SR 20, HDD 80GB.

A coleta de dados ocorreu em uma sala reservada do local onde os idosos residiam. Os participantes foram posicionados sentados em uma cadeira, em frente a uma mesa e a pesquisadora sentou-se do outro lado da mesa, em frente ao participante. A filmadora foi posicionada de modo a captar a imagem do idoso durante a tarefa. 


\section{Procedimento de Coleta de Dados}

Todos os participantes do GC e do GE passaram pelas duas condições de recontagem de histórias (história contada sem objetos e história contada com objetos), separadas entre si por uma semana de intervalo. A ordem de apresentação das condições foi balanceada entre os participantes. Para isto, os participantes de cada grupo foram divididos em quatro subgrupos, formados por seis idosos: (1) H1 contada com objeto seguido da $\mathrm{H} 2$ contada sem objeto, (2) H1 contada sem objeto seguido da H2 contada com objeto; (3) H2 contada com objeto seguido da H1 contada sem objeto; e H2 contada sem objeto seguido da H1 contada com objeto.

Condição 1. História Contada Sem Objetos. Inicialmente, foi apresentada a seguinte instrução aos participantes: "Agora eu irei ler uma história e o senhor (a senhora) deve ouvi-la com atenção. Depois da história eu vou pedir para o senhor (a senhora) contá-la para mim.". A história era então lida, para garantir que a mesma fosse reproduzida de forma igual para todos os participantes, uma única vez. Ao final da leitura, era dito ao participante: "Agora eu quero que o senhor (a senhora) me conte a história que acabou de ouvir, da melhor forma possível e com o maior número de detalhes”. Não havia tempo determinado para que o idoso cumprisse a tarefa. A cada pausa maior que 10 segundos, a pesquisadora dizia: "O senhor (A senhora) já terminou a história? Gostaria de acrescentar mais alguma coisa?'. Quando o idoso desse por encerrada a sua narração, a sessão era finalizada. A narrativa do idoso foi filmada para posterior transcrição.

Condição 2. História Contada Com Objetos. A pesquisadora iniciava o procedimento apresentando ao participante os objetos referentes à história. A pesquisadora pegava o primeiro objeto que apareceria na história e falava: “ $O$ que é isso?". Se o participante nomeasse o objeto com a mesma palavra que aparecia na 
história, a pesquisadora dizia que estava correto; caso a palavra empregada pelo participante fosse outra, ela dizia: "Pode ser um $X$ ?", dizendo a palavra correspondente à que apareceria na história a ser contada (e.g., se o objeto fosse um boneco de pano representando um idoso e o participante dissesse "Boneco", a pesquisadora dizia "Pode ser um homem velho?" - objeto utilizado na H1). Após a apresentação e nomeação de todos os objetos, a pesquisadora dizia: "Agora eu irei mostrar todos os objetos novamente, um por vez, e à medida que mostro, irei dizer o nome deles e o senhor (a senhora) deve repetir". Finalizado este processo, a pesquisadora iniciava a leitura da história da mesma forma descrita na condição anterior, porém, na medida em que os elementos representados pelos objetos apareciam na história, eram apresentados os objetos. Inicialmente, a seguinte instrução era apresentada: “Eu irei ler uma história para o senhor (a senhora) e, durante a leitura, irei mostrar alguns objetos relacionados a essa história. Preste atenção à história porque depois eu vou pedir para o senhor (a senhora) contá-la para mim.". Os objetos estavam dentro de uma caixa ao lado da pesquisadora e ela os colocava sobre a mesa, lado a lado, em frente ao participante, à medida em que eles eram citados na história e na sequência em que apareciam. Após colocar um objeto sobre a mesa, ele permanecia ali enquanto durasse a leitura, alinhado horizontalmente aos demais objetos, da esquerda para a direita do ponto de vista do participante. Ao final da exposição, os objetos permaneciam em cima da mesa. Em seguida, era apresentada a seguinte instrução: “Agora eu quero que o senhor (a senhora) conte a história que acabou de ouvir. Se desejar, pode utilizar os objetos". Da mesma forma que na Condição 1, a cada pausa na narrativa maior que 10 segundos, a pesquisadora dizia: " $O$ senhor $(a$ senhora) já terminou a história? Gostaria de acrescentar mais alguma coisa?’. Quando o idoso desse por encerrada a sua narração, a sessão era encerrada. A narrativa do 
participante era filmada e a pesquisadora não oferecia nenhum outro tipo de dica ou feedback.

\section{Análise de Dados}

Após a transcrição das narrativas dos participantes, foi registrada a frequência de ocorrência de macroestruturas (M), microestruturas (m) e outros comentários (O), relacionadas às Histórias 1 e 2. A macroestrutura é a estrutura responsável por dar coerência global ao texto, oral ou escrito, por meio do fornecimento de aspectos gerais do texto, podendo ser considerada uma espécie de resumo. As microestruturas são as diversas ideias detalhadas que, coesas, formam o texto. Assim, a macroestrutura e a microestrutura podem apresentar o mesmo assunto, porém, a macroestrutura fornece uma ideia geral do tema e a microestrutura, os detalhes. Um texto pode apresentar diversas macroestruturas e microestruturas (Kintsch, \& van Dijk, 1978; Parente et al., 1999). Além disto, no presente trabalho considerou-se como "Outros", informações referentes à moral da história, comentários pessoais e informações acrescidas às histórias que não estavam presentes no momento da narração.

Após a contagem da frequência de ocorrência de "M", "m" e "O" da Condição 1 e Condição 2, os dados foram analisados, separadamente, por meio da ANOVA de dois fatores (Grupos e Condições) seguido pelo teste post-hoc de Newman-Keuls. Para o teste estatístico aplicado a diferença foi considerada significativa quando $p \leq 0,05$. Os dados foram apresentados como média \pm erro padrão da média $(\mathrm{EPM})$ e foram analisados usando o software Statistica 12 (StatSoft Inc., Tulsa, OK, USA).

Uma segunda observadora, com experiência em análise do comportamento, assistiu a $20 \%$ dos vídeos que foram gravados e conferiu a transcrição que a pesquisadora havia feito. Posteriormente essa observadora analisou cada transcrição a fim de computar 
o que ela caracterizava como "M", "m", e "O". Foi calculada a concordância entre as categorizações da observadora e a pesquisadora (Kazdin, 1982), que foi de 86,5\%.

\section{Resultados}

Serão apresentados primeiramente os resultados das análises intragrupo e, em seguida, as análises intergrupos. A Figura 1 apresenta a frequência total de emissões de "M", "m" e "O" de cada grupo (em ambas as condições de recontagem). Foi verificada diferença significativa para o $\mathrm{GC}\left(\mathrm{F}_{(1,141)}=69,47 ; \mathrm{p}=0,001\right)$ no elemento " $\mathrm{M}$ " ( $\left.p<0,001\right)$ em comparação a "m” ( $p<0,001)$ e “O” ( $p<0,001)$, ou seja, os idosos do GC emitiram maior frequência de "M" em comparação às demais categorias, mas a frequência de "m" e "O" foi igual. Também foram encontradas diferenças significativas para o $G E\left(F_{(1,141)}\right.$ $=16,11 ; \mathrm{p}=0,001)$ na frequência da categoria "M" em comparação às demais. Assim como no GC, para o GE não houve diferença na frequência de emissão das categorias “m” $(p<0,001)$ e “O” $(p<0,001)$.

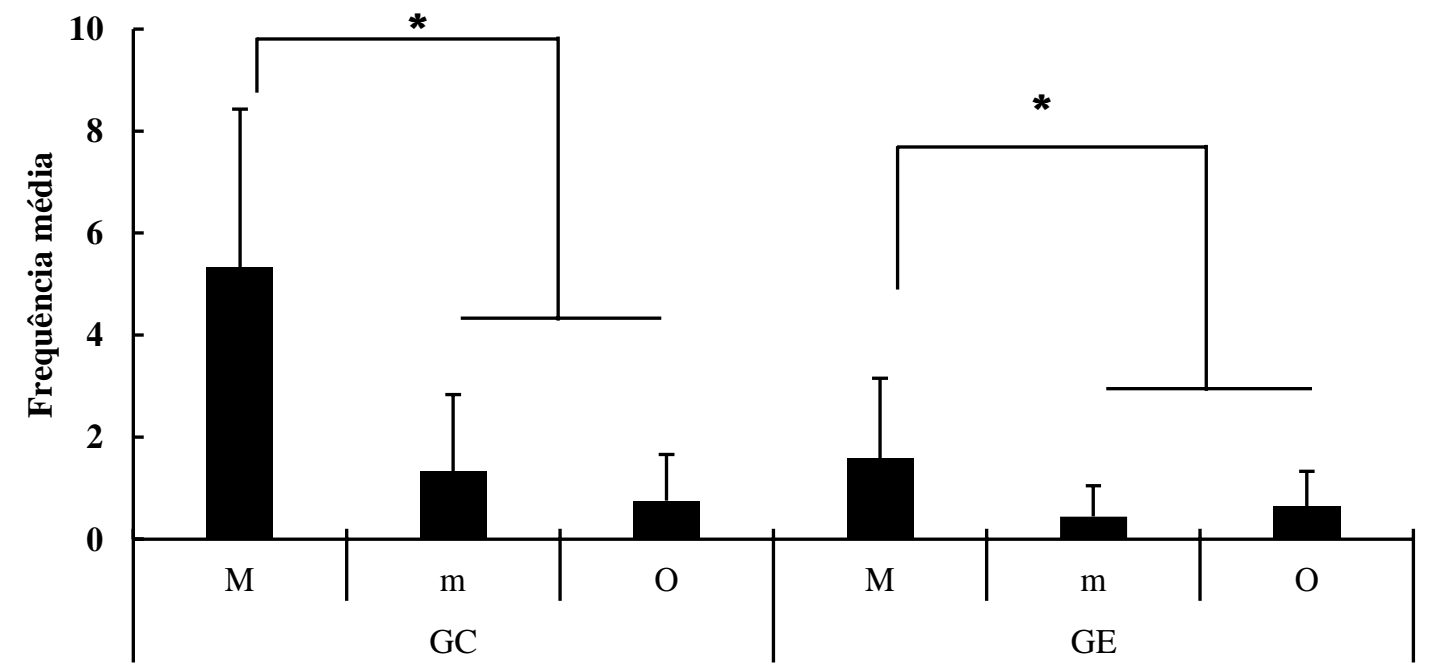

Figura 1. Frequência média de emissões de macroestruturas (M), microestruturas (m) e outras informações $(\mathrm{O})$ emitidas por grupo durante a reprodução oral das narrativas. * $\mathrm{p}>0,05$. 
Analisando a frequência média de emissão de cada categoria ("M", "m”, “O”) em ambas as condições (com objeto e sem objeto), o teste t não revelou diferenças entre "M" $[\mathrm{t}(46)=0,55 ; \mathrm{p}=0,58]$, “m” $[\mathrm{t}(46)=0,00 ; \mathrm{p}=1,00] \mathrm{e}$ “ $\mathrm{O}$ ” $[\mathrm{t}(46)=0,31 ; \mathrm{p}=0,75]$ nas diferentes condições para o GC. Os dados do GE também não se mostraram significativamente diferentes para as categorias “ $\mathrm{M}$ ” [t $(46)=0,18 ; \mathrm{p}=0,85]$, “m” [t (46) $=0,23 ; \mathrm{p}=0,81], \mathrm{e}$ “ $\mathrm{O}$ ” $[\mathrm{t}(46)=1,46 ; \mathrm{p}=0,15]$. Este resultado indica que a presença ou ausência dos objetos não foi um fator determinante para a maior ou menor emissão de qualquer uma das categorias analisadas.

A comparação dos resultados dos dois grupos (análise intergrupos) é apresentada nas Figuras 2 e 3. A Figura 2 compara a frequência média de emissões de cada categoria nos dois grupos. $\mathrm{O}$ teste $\mathrm{t}$ revelou diferença estatística entre a emissão de " $\mathrm{M}$ " $[\mathrm{t}(94)=$ $7,44 ; \mathrm{p}=0,001]$, e “m” [t $(94)=3,75 ; \mathrm{p}=0,001]$, indicando que o GC apresentou frequência significativamente maior de emissões das categorias " $\mathrm{M}$ " e "m" em comparação ao GE, mas não foram encontradas diferenças entre os grupos em relação à categoria “ $\mathrm{O}$ ” $[\mathrm{t}(94)=0,62 ; \mathrm{p}=0,53]$.

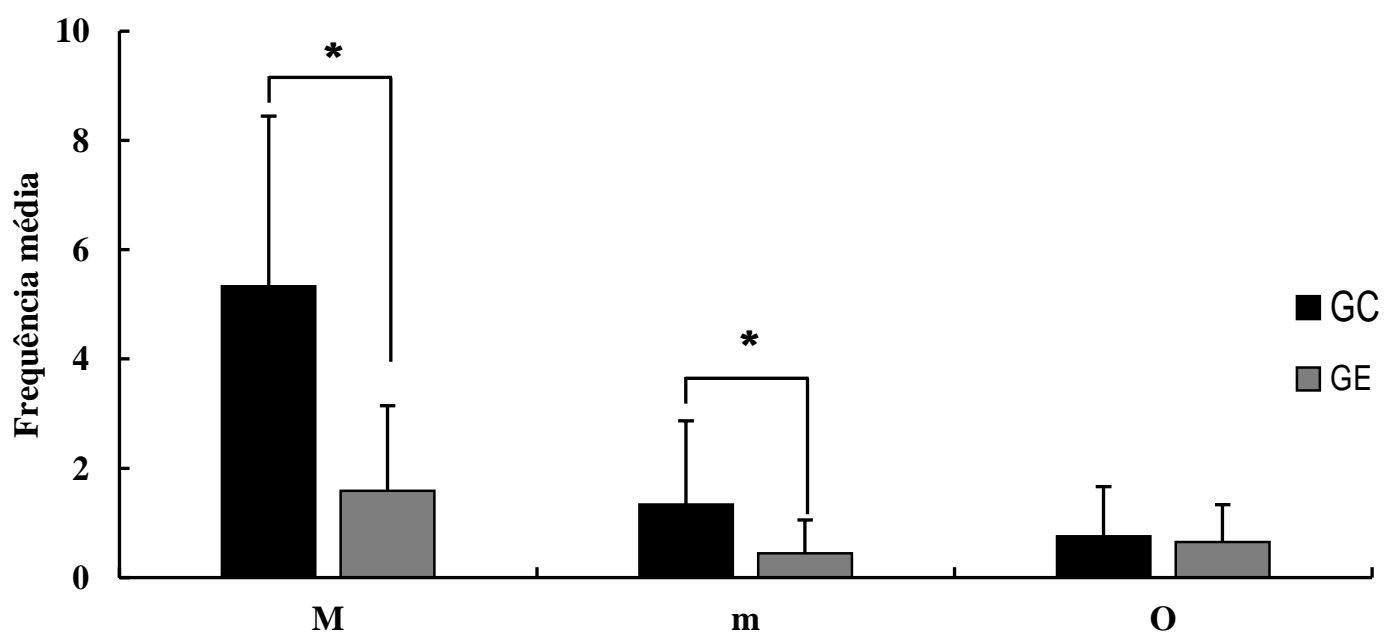

Figura 2. Frequência média de emissão das categorias macroestrutura (M), microestrutura (m) e outras informações (O) para os grupos Controle (GC) e Experimental (GE). * - p>0,05. 
A análise intergrupos, que considerou a condição (história contada com ou sem objetos) é apresentada na Figura 3. Observa-se diferença estatística para a categoria "M" $\left(\mathrm{F}_{(1,92)}=18,34 ; \mathrm{p}=0,001\right)$, e o teste post hoc mostrou que o $\mathrm{GC}$ emitiu maior frequência de "M" que o GE, independentemente da condição (com ou sem objeto) $(p<0,001)$. Também houve diferença para " $\mathrm{m}$ " de acordo com ANOVA $\left(\mathrm{F}_{(1,92)}=4,6 ; \mathrm{p}=0,001\right)$ e o teste post hoc também relevou que o GC emitiu maior frequência de "m" do que o GE em ambas condições $(\mathrm{p}<0,001)$. Não foi verificada diferença para a categoria “ $O$ ” entre os grupos $\left(\mathrm{F}_{(1,92)}=0,68 ; \mathrm{p}=0,56\right)$, independentemente da condição.

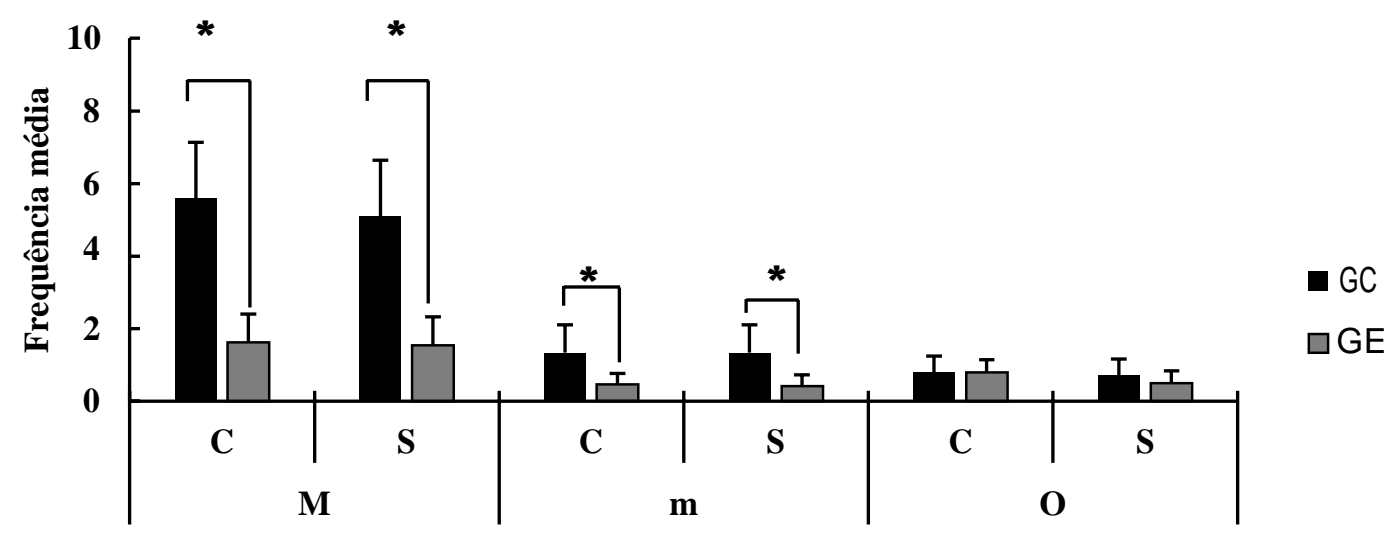

Figura 3. Frequência de emissões de macroestruturas (M), microestruturas (m) e outras informações (O) nas condições com objeto (C) e sem objeto $(\mathrm{S})$, para os grupos experimental (GE) e controle (GC). * - p>0,05

\section{Discussão}

O objetivo deste estudo foi verificar se a estratégia de apoio visual, por meio do uso de objetos tridimensionais como dicas, auxiliaria idosos com DA na tarefa de recontar uma história. De forma geral, não foram encontradas evidências de que o apoio visual (a presença dos objetos tridimensionais) teve um efeito positivo sobre o desempenho dos idosos na tarefa estudada, independentemente de sua condição cognitiva (com ou sem DA). Por outro lado, na análise intragrupo foram encontradas diferenças significativas na frequência de emissão das diferentes categorias do discurso analisadas, com maior 
emissão de macroestruturas em comparação às demais categorias. Além disso, verificouse que os idosos do GC apresentaram significativamente maior frequência de emissão de macro e microestruturas, em comparação com o GC, em ambas as condições.

O uso de dicas visuais (imagens, palavras escritas e objetos) como apoio para diversos tipos de tarefa, como recontar histórias, descrever imagens ou fazer descrições sobre si e seu cotidiano, tem sido estudado por diversos autores e em diversas populações (Bourgeois, 1990; 1993; Brandão, Parente, \& Peña-Casanova, 2010; Brandão \& Parente, 2011; Buchanam, et al., 2011; Sella, et al., 2015). A ideia central desses estudos baseiase no pressuposto de que a presença de uma dica visual serviria como um facilitador para a produção do discurso, uma vez que suplementaria a estimulação fornecida pela instrução (ou pela contingência na qual o discurso deve ser emitido), favorecendo a diminuição de erros e o encadeamento da descrição.

O uso de dicas visuais também tem sido investigado em diferentes tarefas para idosos. Barbosa e Martin (2012) realizaram uma revisão de pesquisas que empregavam esse tipo de estratégia para idosos com o intuito de melhorar o desempenho deles em tarefas de memória. Os autores verificaram que as ajudas externas são os auxílios mais utilizados, mas que quanto maior o comprometimento, maior a dificuldade do idosos em manusear o auxílio. Os resultados das pesquisas são, de forma geral, positivos, mas os autores destacam a necessidade de não apenas fornecer o auxílio, mas de treinar o idoso para que o mesmo saiba manuseá-lo (Bourgeois, et al., 2003; Brandão \& Parente, 2011; Buchanan, et al., 2011). Além disso, os procedimentos que utilizaram auxílios de memória que demonstraram maior eficácia foram aqueles que apresentaram como dicas objetos comuns para o indivíduo (como calendários ou fotos) e aqueles em que os auxílios foram inseridos em treinos longos (mais de uma semana) e associados a outras técnicas de reabilitação cognitiva. 
As dicas visuais podem auxiliar o discurso dos participantes por delimitar o assunto a ser explorado e, em alguns casos, por serem utilizados em situações sociais, o interlocutor pode agir no sentido de modelar ou reforçar a resposta daquele que usa a dica visual de forma eficiente. Buchanan et al. (2011) ressaltam que a dica visual costuma funcionar porque diminui a demanda da tarefa e compensa as dificuldades de memória, uma vez que funciona como um estímulo discriminativo visual presente durante a realização da tarefa, fazendo com que a instrução inicial ou a própria situação a ser descrita não seja o único estímulo discriminativo da situação. Isso é relevante para pessoas com DA cuja dificuldade central, muitas vezes, reside nas suas possibilidades de ficar sob controle adequado de estímulos ausentes fisicamente. A hipótese deste estudo era de que a apresentação de objetos tridimensionais ao longo da história, e a sua permanência durante a tarefa de recontagem, poderia suplementar a estimulação necessária para o desempenho adequado da recontagem. Os resultados obtidos, porém, não confirmaram essa hipótese e discutir as razões pelas quais as dicas visuais, nesse caso, não tiveram efeito positivo, é importante para a própria compreensão da dificuldade do idoso e de ações voltadas para sua remediação.

No presente estudo, a tarefa do participante era, após ouvir uma história completamente nova para ele, reproduzi-la com o maior número de detalhes possível. Entre a apresentação do estímulo discriminativo (a leitura da história) e a emissão da resposta (a recontagem da história) havia sempre um atraso, dada a natureza auditiva do estímulo antecedente. Diversos estudos mostram a dificuldades de certos indivíduos (e.g., crianças pré-escolares, pessoas com deficiência intelectual e idosos com DA) para desempenhar tarefas nas quais há a interposição de um intervalo entre um estímulo antecedente e a emissão da resposta, como em tarefas de delayed matching to sample (DMTS) (e.g., Constantine \& Sidman, 1975; Costa, Schmidt, Domeniconi, \& de Souza, 
2013; Gutowski \& Stromer, 2003; Steingrimsdottir \& Arntzen, 2011a, b), dificuldade esta confirmada neste estudo.

Algumas pesquisas indicam que a dificuldade dos participantes com o atraso poderia ser melhorada com o ensino de uma "resposta pré-corrente", ou seja, o ensino de uma resposta a ser emitida pelo participante durante o intervalo, como, por exemplo, uma nomeação encoberta do estímulo visual em tarefas envolvendo estímulos dessa natureza (Constantine \& Sidman, 1975; Gutowski \& Stromer, 2003). Aparentemente, essa estratégia é bastante comum entre crianças em idade escolar, jovens e adultos saudáveis, e seria aprendida ao longo da vida em diferentes situações. No estudo de Arntzen (2006, Experimento 4), por exemplo, o pesquisador apresentava tarefas distratoras aos participantes durante o atraso em uma tarefa de DMTS, que impediam a emissão de respostas pré-correntes. Nesses casos, os jovens participantes apresentaram dificuldades no desempenho acurado da tarefa, diferentemente de quando as tarefas distratoras não eram apresentadas. De acordo com Gutowski e Stromer (2003) respostas pré-correntes, como a nomeação encoberta do estímulo, poderiam mediar o desaparecimento do estímulo antecedente e a emissão da resposta, desempenhando um papel suplementar entre ambos.

No caso de idosos com DA, é possível que a emissão espontânea desse tipo de pré-corrente seja afetada pela demência e, no caso da presente pesquisa, as dicas visuais poderiam desempenhar um papel suplementar na evocação da resposta de recontar a história recém-ouvida, exercendo o mesmo papel que pré-correntes encobertos. Os resultados negativos aqui encontrados, porém, sugerem que os estímulos visuais apresentados não funcionaram como discriminativos capazes de melhorar o desempenho dos idosos na tarefa proposta, talvez por não terem sido treinados como tal. 
Nos estudos de Bourgeois (1990; 1993), por exemplo, os idosos com DA, ao conversarem, utilizavam um caderno de registro com informações referentes ao tema da conversa (fotos e pequenas anotações sobre os temas). Esta dica visual serviu para deixar o discurso de idosos mais coerente. Estes estudos apresentaram bons resultados, como outros (e.g., Schryer \& Ross, 2013) provavelmente por quatro motivos. Primeiro, porque a exposição à tarefa pode ter tido o efeito de treino sobre como utilizar o apoio visual, condição ressaltada pela autora e por outros como fundamental para que a dica funcione. Segundo, porque a repetição da tarefa ao longo dos dias pode ter exposto os idosos aos efeitos reforçadores de sua utilização, como a atenção maior do interlocutor, a possibilidade de manter uma conversação por mais tempo e por se ver compreendido pela pessoa com quem interagia. Terceiro, porque a tarefa dos idosos dos estudos de Bourgeois era narrar episódios de suas próprias vidas, e não histórias que ouviram uma única vez. Finalmente, porque durante todos o procedimento o estímulo discriminativo que desencadeou a conversa era familiar ao participante, ou seja, tanto as fotos como as anotações no caderno de memória já tinham função evocativa estabelecida na história dos participantes. A utilização de dicas familiares para a narração de temas também familiares pressupõe que tais dicas já tenham uma função discriminativa prévia, não necessitando de treino. Se o participante não tem experiência prévia com a dica, esta não exercerá nenhum controle sobre o seu comportamento.

Em um estudo com crianças, realizado por Sella et al. (2015), também não foram encontradas evidências de que, sem treino adicional, objetos tridimensionais exerçam papel facilitador na tarefa de recontagem de histórias. Nesse estudo, o desempenho de crianças com 11 anos em uma tarefa de recontar histórias não foi favorecido pela dica visual. Esses resultados, assim como os da presente pesquisa, sugerem que estudos com dicas visuais devem ter como foco o controle de estímulos exigido, mas também as 
condições em que a dica será apresentada, o tipo de tarefa e o formato das dicas. É possível, portanto, que se o presente estudo tivesse fornecido um treino mais extenso e funcional para ensinar a função dos objetos tridimensionais, os participantes teriam feito maior uso desse tipo de dica, que poderia ter desempenhado, de fato, a função esperada.

Outra possibilidade, explorada no estudo de Silva e Yassuda (2009), seria o treino explícito de um pré-corrente encoberto para os idosos. Os autores pediam a idosos com declínio cognitivo e baixa escolaridade evocar encobertamente a imagem de objetos (e.g., uma mesa) e, em seguida, apresentavam a figura do objeto, pedindo que os idosos comparassem a figura apresentada e a imagem evocada. $\mathrm{O}$ treino exigia, gradualmente, a evocação de imagens mais complexas, como frases e pequenas histórias. A comparação do desempenho dos idosos em tarefas de recontagem de histórias antes e após o treino mostrou melhora significativa nos aspectos avaliados, sugerindo que esse tipo de estratégia tem efeitos positivos na recontagem de histórias. Esses resultados podem ter relação com o engajamento ativo dos participantes na estratégia, estabelecendo, de forma encoberta, um pré-corrente capaz de servir como discriminativo para a tarefa proposta.

Estratégias que envolvem o engajamento ativo de idosos em tarefas relacionadas à memória têm sido consideradas eficazes pela literatura (Small, 2012). Estudos futuros podem testar se a associação desse tipo de estratégia, associada ao treino de uso de dicas visuais, podem produzir melhora no desempenho de idosos em tarefas de recontagem de histórias.

Para além dos resultados até aqui discutidos, foram verificadas diferenças importantes no desempenho dos idosos com e sem comprometimento cognitivo na tarefa proposta. Apesar de idosos com ou sem DA tenderem a fornecer mais informações gerais sobre o conteúdo das histórias (macroestruturas) do que informações específicas ou detalhes (microestruturas), verificou-se que os idosos do GC emitiram esses elementos 
com maior frequência que idosos com DA em ambas condições (com e sem objetos). Nota-se, assim, que para ambos os grupos foi mais fácil fornecer informações referentes à ideia central da história do que aos detalhes da mesma. Parente et al., (1999) indicam que a maior ocorrência de macroestruturas, em comparação com microestruturas, é comum não apenas em idosos, mas também em adultos jovens. As autoras sugerem que adultos tendem a utilizar a estratégia de memorizar aspectos mais gerais de narrativas ouvidas em detrimento de detalhes.

Além disso, verificou-se que, apesar dos participantes com DA emitirem mais macroestruturas como os idosos saudáveis, as suas recontagens eram muito simplificadas e incompletas, por vezes comprometendo a própria compreensão da narrativa. Um exemplo é a narração feita por um dos participantes do GE sobre a história da jovem mulher: "Ela trabalhava num escritório e ela tinha medo de assalto. E ela se protegia, mas mesmo assim não adiantou. O pneu furou e precisou pegar o estepe do carro e aí ele trocou e depois largou ela" (P5 - GE). Esse relato é representativo do fato de que idosos do GE conseguiram recontar a história ouvida, mantendo aspectos semânticos consistentes, uma vez que o sentido da história é apresentado. Contudo, a descrição é desprovida de detalhes, o que já evidencia falhas do processo fonético-fonológico e semântico, comuns à DA (Szatloczki, et al., 2015). Apesar do desempenho de idosos com DA ser menos rico quando comparado com idosos saudáveis, é importante que se invista no desenvolvimento de estratégias que os ajudem a manter suas habilidades discursivas. A principal limitação deste estudo foi não garantir que as dicas visuais exercessem, de fato, função discriminativa e, portanto, apoio para a tarefa proposta, mas contribuiu com informações sobre os efeitos da demência sobre a recontagem de histórias por idosos. Pesquisas futuras devem investir em melhorar os procedimentos aqui apresentados, sobretudo em relação aos tipos de pistas visuais empregadas e ao tempo de 
exposição dos idosos à tarefa apresentada. A utilização de conteúdo mais significativo para os idosos, como relatos de situações correntes de seu dia a dia, ou relatos de notícias de sua cidade ou país, podem favorecer resultados mais positivos no uso de dicas visuais como apoio para recontagem de narrativas. 
Estudo 2 
O uso da técnica de fading out no recontar de hitórias por idosos com e sem Doença de Alzheimer

\section{Resumo}

O processo de neurodegeneração causado pela Doença de Alzheimer (DA) acarreta déficits na linguagem e dificulta a aprendizagem de novas informações, o que torna importante o estudo de procedimentos de reabilitação que favoreçam processos de aprendizagem. O Fading Out (FO), ou esvanecimento gradual de dicas, é um destes procedimentos, mas ainda pouco estudado em procedimentos com idosos com DA. O objetivo do estudo foi investigar se um procedimento de fading out progressivo de perguntas alteraria a produção de narrativas com apoio visual em idosos com DA. Participaram deste estudo 12 idosos, seis do grupo controle (CG), sem indicativos de comprometimento cognitivo; e seis do grupo experimental (GE), todos com indicativo de DA. O procedimento foi dividido em três fases. Na Fase 1 (Pré-Teste) e Fase 3 (PósTeste) foi apresentado aos participantes um conjunto de quatro cartões com imagens que, em sequência, representavam uma história. A tarefa era contar a história dos cartões. A Fase 2 foi dividida em três etapas. Em cada etapa foi apresentado um conjunto de três cartões, correspondentes a uma tirinha de história em quadrinhos. Inicialmente, o participante deveria contar a história dos cartões sem dicas; em seguida, os participantes deveriam recontar a história com o auxílio de perguntas feitas pela pesquisadora sobre cada cartão; finalmente, o participante deveria recontar a história inteira, sem dicas. As etapas diferenciavam-se pelo número de perguntas realizadas por cartão: na Etapa 1, foram feitas três perguntas por cartão; na Etapa 2, duas perguntas por cartão; e na Etapa 3 , uma pergunta por cartão. Os idosos do GC contaram histórias usando um número maior de palavras e com maior coerência que os idosos do GE. As perguntas não tiveram efeito no número de palavras emitidas pelos participantes de ambos os grupos. Contudo, o procedimento foi efeitovo para melhorar a coerência das histórias contadas pelos idosos do GE.

Palavras-Chaves: Doença de Alzheimer; Fading Out; Linguagem. 
The use of the fading out technique in retelling stories by elders with and without Alzheimer's disease

Abstract

The neurodegeneration process caused by Alzheimer's disease (AD) leads to deficits in the language and makes it difficult to learn new information, thus, it is important to propose rehabilitation procedures to elderly people that improve learning, which minimize possibility of errors. Fading Out (FO), or gradual removal of the stimulus, is one of these procedures. Thus, the objective of the study was to investigate whether a progressive fading out procedure of questions would alter the production of narratives with visual support. Twelve elderly, six in the control group (CG), that was composed by elderly individuals with no indication of cognitive impairment; and six in the experimental group (EG), formed by elderly individuals with Alzheimer's disease. The procedures were divided into three phases. In Phase 1 (Pre-Test) and Phase 3 (Post-Test) participants were presented with four pictures representing a story. Participants were asked to look at the cards and tell the story. Phase 2 was divided into three stages. In all the stages three cards were presented that represented a story, requested a narrative of the story, asked questions about each card and requested a new narration. The differences among the stages were by the number of questions asked per card: in Step 1, three questions were asked per card; in Step 2, two questions per card; and in Step 3, one question per card. The results showed that the elderly of the CG emit more words than the elderly of the EG during the narration and that the stories of the elderly of the GC present greater coherence. However, the procedure was effective in improving the coherence of the stories narrated by the elderly of the EG. The results are discussed in the paper.

Keywords: Alzheimer's disease; Fading Out; Language. 
A Doença de Alzheimer (DA) é um tipo de demência que afeta as funções cognitivas, como memória, atenção e linguagem. O avanço da demência provoca a intensificação dos déficits cognitivos e alterações orgânicas, como dificuldades na coordenação motora e falência dos órgãos (CID-10, 1999; DSM-V, 2014). Especificamente em relação às dificuldades de linguagem desses indivíduos, Soares, Brandão e Lacerda (2012) e Beilke e Pinto (2010) afirmam que diversos domínios linguísticos (como nomeação, descrição ou narração, por exemplo) são afetados pela DA, sendo que o estágio em que se encontra a demência é um fator relevante no grau de interferência no domínio linguístico afetado.

A fase inicial da DA, por exemplo, é caracterizada por falhas no processo de nomeação, no uso de termos gerais, como por exemplo chamar uma pessoa familiar do sexo feminino de mulher e não pelo nome próprio, e percepção dos erros na linguagem. Com o avanço da demência, a linguagem de pessoas com DA torna-se menos coesa, de forma que os indivíduos deixam de fazer uso das regras gramaticais e apresentam dificuldades para compreender a fala das demais pessoas. Nota-se uma redução na conversação até que o paciente chegue à fase de mutismo (Soares, et al., 2012).

As narrativas de idosos com DA têm sido caracterizadas como "vazias", marcadas por informações gerais sobre o assunto narrado e ausência de informações específicas, acréscimo de informações que não têm relação direta com o tema e necessidade de muitos turnos para que a narrativa seja concluída. Estas características da narrativa estão presentes na fase leve da doença e agravam-se com o avanço da mesma (Brandão \& Parente, 2011; Brandão, Parente, \& Peña-Casanova, 2008; Parente, Capuano, \& Nespoylous, 1999; Parente, Saboskinsk, Ferreira, \& Nespoulous,1999).

Brandão, Parente e Penã-Casanova (2010), por exemplo, selecionaram dois idosos com declínio cognitivo, sendo um com declínio moderado e outro com moderado-grave, 
para uma tarefa de narrativa com dicas visuais, que consistia em contar a história "Chapeuzinho Vermelho" com base em figuras referentes à história. Os resultados indicaram que ambos os participantes necessitaram de estratégias de comunicação para contar a história, sendo que o participante com declínio moderado necessitou de sete estratégias, enquanto que o com declínio moderado grave de onze. As estratégias utilizadas por ambos os participantes foram: "pedido de socorro", que refere-se a pedir um auxílio ao ouvinte a fim de verificar se a ideia está correta; "asserção da figura”, que refere-se a apontar para uma figura e depois fazer comentários sobre a mesma ou descrevê-la, e estratégias de "identificação da personagem”, em que aponta-se para um personagem com o objetivo de identifica-lo, mas não são fornecidas informações sobre o mesmo. No caso em análise, é preciso notar que a tarefa consistia na narração de uma história "popular", que provavelmente os participantes já tinham ouvido ou contado durante suas vidas, no entanto, isto não ajudou na narração. Este estudo permite concluir que a demência provoca alterações significativas no discurso, que se agravam com o avanço da doença.

O processo de produção ou déficits da linguagem, no entanto, não pode ser analisado de forma isolada, uma vez que tem ampla relação com os demais processos cognitivos, em especial a memória (Soares, et al., 2012). Beilke e Pinto (2010) afirmam que a construção de uma narrativa, por exemplo, depende de características da linguagem (como uso adequado dos verbos e encadeamento de palavras) e dos fatos que serão narrados que, por sua vez, dizem respeito à memória. Além disso, é importante considerar que o ponto de partida de uma narrativa também tem grande influência no desempenho dos idosos: contar uma história vivida no passado é diferente de narrar uma história ouvida há meia hora, o que, por sua vez, é diferente de contar uma história a partir de apoio visual (e.g., um conjunto de figuras sem legendas ou um livro de ilustrações). 
Brandão e Parente (2011) descrevem que os estudos sobre a narrativa de idosos com DA têm sido conduzidos de diferentes formas: alguns utilizam a apresentação de um input (quando se dá um estímulo, como um tema, por exemplo, e solicita-se que o idoso continue a narração) ou de forma natural (quando não há interferência de estímulos ambientais sobre a narração, ou seja, o interlocutor mantém uma conversa com o idoso que, por sua vez, não sabe do objetivo da pesquisa; logo, se o interlocutor fornece pistas ao idoso para facilitar a conversa isto acontece de forma natural e não controlada). As narrativas dos idosos trazem graves problemas de socialização para os idosos, o que causa isolamento social, assim, é preciso que pesquisadores se dediquem a estudos de intervenção da linguagem de idosos com DA com o intuito que melhorar a comunicação dos idosos e consequentemente diminuir o isolamento.

Estudos sobre intervenções no discurso de paciente com DA, de forma geral, têm como objetivo melhorar as narrativas dos idosos, tornando-as mais coerentes, a fim de melhorar as interações entre indivíduos com DA e seus familiares ou cuidadores. Assim, diferentes técnicas, como o Spaced Retrieval, o uso de Cadernos de Memória, os Grupos de Conversação e as orientações aos cuidadores são propostos como programas de reabilitação da linguagem, nesse aspecto (Bourgeois, 1990; 1993; Delfino \& Cachioni, 2016; Soares, et al., 2012; Soares, Soares e Caixeta, 2012).

Nos últimos anos, um número considerável de intervenções baseadas na teoria Analítico Comportamental para reabilitação de diversos repertórios de idosos com DA, inclusive verbais, têm sido publicados (Aggio, Ducatti, \& de Rose, 2018; Bourgeouis, 1990; 1993; Buchanan \& Fisher, 2002; Dixon, Becker, \& Sadowski, 2011; Gross, Fuqua, \& Merritt, 2013; Locke \& Mudford, 2010; Trahan, Donaldson, McNabney, \& Kahng, 2014). Essa produção, ainda inicial, é relevante pela tradição da área no desenvolvimento de procedimentos eficazes de ensino de repertórios verbais para diversas populações 
desafiadoras (Lucchesi \& Almeida-Verdu, 2017; Rique, Guerra, Borelli, Oliveira, \& Almeida-Verdu, 2017; Santos \& Almeida-Verdu, 2012), que têm como característica importante o arranjo de contingências de ensino que previnam ou que produzam baixa frequência de ocorrência de erros por parte dos participantes (a chamada aprendizagem sem erros) (de Souza \& de Rose, 2006; Melo, Hanna, \& Carmo, 2014).

Um dos procedimentos que garantem a aprendizagem com o mínimo de erros, é o procedimento denominado Fading (Esvanecimento ou Esmaecimento), que se refere à transferência do controle do responder de um estímulo para outro, ou pela introdução gradual do estímulo (Fading In) ou remoção gradual do estímulo (Fading Out). O procedimento de fading propõe que o treino seja iniciado com um estímulo de fácil discriminação e, à medida em que se garante que a discriminação foi estabelecida, o estímulo modifica-se (Catania, 1999, Terrace, 1963). O fading out de dicas, mais especificamente, refere-se à retirada gradual de dicas que podem ajudar na emissão do desempenho correto (Lear, 2004) e pressupõe o auxílio ao participante desde o início da aprendizagem para que ele apresente desempenho compatível com a tarefa. De modo geral, o procedimento se inicia com o fornecimento de uma dica completa; contudo, à medida que as tentativas avançam, e que o desempenho a ser ensinado se estabelece, parte da dica é retirada, até que, ao longo do processo, ocorre a retirada total da dica. Nesses casos a dica funciona como um estímulo discriminativo que auxilia na emissão do comportamento correto (Lear, 2004).

Diferentes estudos que utilizam o fading como procedimento de ensino têm apresentado bons resultados. O maior número de estudos que investigam o uso de fading refere-se à área educacional, contudo, há vários estudos que demonstram a eficácia do fading no contexto clínico (Bagaiolo \& Micheletto, 2004; Escobal, Araújo, \& Goyos, 2005; Hanna \& Ribeiro, 2005; Santos \& Souza, 2007). O procedimento de fading tem 
mostrado bons resultados para diferentes populações e problemas, inclusive para idosos com demência (Clare \& Jones, 2008; Haslam, Moss, \& Hodder, 2010).

O fading é um procedimento que minimiza a ocorrência de erros durante a aprendizagem por garantir que o processo de discriminação inicia com uma alta probabilidade de emissão do desempenho correto por parte do aprendiz. Iniciar a tarefa dessa forma é importante porque garante o estabelecimento de um nível inicial de desempenho, o que permite a modificação gradual do estímulo (e.g., a dica), à medida que as tentativas do procedimento avançam, não interferindo de forma prejudicial na aprendizagem. Um exemplo do procedimento de fading out de dica pode ocorrer no ensino de uma relação entre uma palavra e uma figura. Inicialmente, a figura é apresentada e o pesquisador dita o seu nome completo (e.g., "tomate"), pedindo que o participante repita. A dica, nesse caso, é o nome ditado da figura. Nas tentativas consecutivas o nome ditado vai sendo gradualmente retirado (e.g., inicialmente se retira a parte final da palavra ["toma"], depois a metade final da palavra ["tom"] e, finalmente, é apresentada apenas a sílaba inicial da palavra ["to"], antes da retirada completa da dica), enquanto se solicita o desempenho completo do participante. Gradualmente, portanto, o controle da emissão do nome da figura pelo participante vai se transferindo do modelo ditado pelo pesquisador para a própria figura que, finalmente, passa a evocar a palavra ensinada.

Procedimentos que previnem a ocorrência de erros são importantes para o ensino de diferentes habilidades verbais e não verbais para idosos com DA porque, além da ocorrência de erros desorganizar a aprendizagem (Hanna \& Ribeiro, 2005), o processo de demência prejudica a aprendizagem (DSM-V, 2014), como constatado em diferentes estudos com essa população (e.g., Camara, Ducatti, \& Schmidt, 2017; Ducatti \& Schmidt, 2016; Steingrimsdottir \& Arntzen, 2011). Apesar dos diversos estudos realizados sobre 
procedimentos de fading out de dicas na área de educação especial (Berkowitz, Sherry, \& Davis, 1971; Gomes, Varella, \& Souza, 2010), poucos são os estudos que estudam esse procedimento no ensino de repertórios verbais para idosos com demência. A maioria deles se refere ao procedimento como vanishing cue, e tem como objetivo o ensino de desempenhos de nomeação para idosos (Clare, Wilson, Cartes, \& Hogdes, 2002). Não foram encontrados estudos que estudaram o fading out como forma de melhorar o desempenho de idosos em tarefas narrativas, evocadas por estímulos visuais complexos, como cenas de uma história.

O objetivo geral deste estudo foi investigar se um procedimento de fading out progressivo de perguntas alteraria a produção de narrativa com apoio visual por idosos com DA. Os objetivos específicos foram: (a) comparar o desempenho de idosos saudáveis e com DA na tarefa, e o desempenho dos dois grupos consigo mesmos, antes e depois da introdução do procedimento de fading out; e (b) realizar uma análise qualitativa da produção do discurso destes idosos.

Considerando que os idosos com DA apresentam dificuldades em produzir narrativas, ainda que com apoio visual, esperava-se que a apresentação de dicas na forma de perguntas que aumentassem a discriminabilidade dos aspectos críticos das ilustrações componentes da história pudessem auxilia-los a organizar a narrativa da história. Além disso, esperava-se que o esvanecimento gradual das dicas (redução do número de perguntas ao longo do procedimento) não diminuísse a qualidade das descrições realizadas pelos idosos, de tal forma que as ilustrações, e não apenas as perguntas, controlassem a complexidade da narrativa (o número de palavras utilizadas para contar a história) e a sua coerência (continuidade do relato entre as figuras, de tal forma que a narrativa fizesse referência a cada um dos quadros, mas que formasse uma única história). 


\section{Método}

\section{Participantes}

Participaram deste estudo 12 idosos, que foram divididos em Grupo Comparação (GC) e Grupo Experimental (GE). Os participantes do GC foram três homens e três mulheres, com idade média de 76 anos e sem diagnóstico de comprometimento cognitivo. O resultado médio dos participantes do GC no Mini Exame do Estado Mental (MEEM) foi de 24,6 pontos e no Addenbrooke's Cognitive Examination-Revised (ACE-R) foi 68,3 pontos. Os participantes do GE foram cinco mulheres e um homem com idade média de 80,6 anos e com indícios de comprometimento cognitivo. Todas as mulheres tinham o diagnóstico da DA e o participante do sexo masculino tinha o diagnóstico de comprometimento cognitivo leve. O resultado médio no MEEM do GE foi de 16 pontos e no ACE-R foi de 39 pontos. A Tabela 1 apresenta dados de cada participante.

Os participantes de ambos os grupos eram alfabetizados e não demonstraram sintomas de depressão de acordo com a Escala de Depressão Geriátrica. Apenas um participante de cada grupo residia com a família; os demais moraram em Instituições de Longa Permanência para Idosos. Os critérios de exclusão da amostra foram (1) analfabetismo, (2) problemas de visão que comprometessem a observação dos estímulos visuais apresentados, (3) problemas de audição que prejudicassem a comunicação com a pesquisadora, e (4) indicativos de depressão. A pesquisa foi aprovada pelo Comitê de Ética da Faculdade de Filosofia, Ciências e Letras de Ribeirão Preto - USP (CAEE 41678015.4.0000.5407). 


\section{Tabela 1.}

Características gerais dos participantes do Estudo 2: idade, escolaridade, desempenho nos testes Mini Exame do Estado Mental (MEEM), Exame Cognitivo de Addenbrooke (ACER) e Escala de Depressão Geriátrica (GDS).

\begin{tabular}{|c|c|c|c|c|c|c|}
\hline Grupo & Participante & Idade & Escolaridade & MEEM & ACE-R & GDS \\
\hline \multirow{6}{*}{$\frac{\frac{0}{0}}{0}$} & $\mathrm{P} 1$ & 80 & FI & 28 & 57 & $\mathrm{~S} / \mathrm{D}$ \\
\hline & $\mathrm{P} 2$ & 83 & $\mathrm{FI}$ & 24 & 69 & $\mathrm{~S} / \mathrm{D}$ \\
\hline & $\mathrm{P} 3$ & 69 & SI & 27 & 73 & $\mathrm{~S} / \mathrm{D}$ \\
\hline & $\mathrm{P} 4$ & 68 & $\mathrm{SC}$ & 23 & 71 & $\mathrm{~S} / \mathrm{D}$ \\
\hline & P5 & 69 & $\mathrm{SC}$ & 22 & 71 & $\mathrm{~S} / \mathrm{D}$ \\
\hline & P6 & 87 & FI & 24 & 69 & $\mathrm{~S} / \mathrm{D}$ \\
\hline \multirow{6}{*}{ 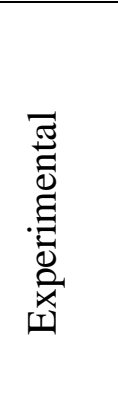 } & P11 & 80 & FI & 15 & 46 & $\mathrm{~S} / \mathrm{D}$ \\
\hline & $\mathrm{P} 12$ & 84 & FI & 14 & 20 & $\mathrm{~S} / \mathrm{D}$ \\
\hline & P13 & 89 & FI & 17 & 37 & $\mathrm{~S} / \mathrm{D}$ \\
\hline & P14 & 80 & FI & 11 & 26 & $\mathrm{~S} / \mathrm{D}$ \\
\hline & P15 & 70 & FI & 18 & 52 & $\mathrm{~S} / \mathrm{D}$ \\
\hline & P16 & 81 & FI & 21 & 53 & $\mathrm{~S} / \mathrm{D}$ \\
\hline
\end{tabular}

Nota: $\mathrm{P}=$ participante $\mathrm{FI}=$ Fundamental Incompleto. $\mathrm{SI}=$ Superior Incompleto. $\mathrm{SC}=$ Superior Completo. S/D = sem indicativos de depressão.

\section{Materiais e Situação Experimental}

Foi utilizado para o pré e pós-teste um conjunto de quatro cartões coloridos $(15 \mathrm{~cm} \mathrm{x}$ $10 \mathrm{~cm}$ ) do teste Sequência Lógica (Oficina da Linguagem) que retratavam uma história (o primeiro cartão tinha o desenho de um menino subindo em um cavalo e com um cachorro observando a cena; o segundo cartão era ilustrado com o menino sentado no cavalo e o cachorro rosnando para o mesmo; no terceiro cartão havia o cavalo assustado com o cachorro e empinando; e o quarto cartão mostrava o menino caído sobre o cão, o cavalo correndo e o cachorro observando). Esses cartões foram chamados no estudo de cartõesteste.

Para o procedimento propriamente dito, foram utilizadas três tirinhas de histórias em quadrinhos de Maurício de Souza (Turma da Mônica), cada uma formada por três 
quadrinhos (ver Tabela 2). Cada quadrinho foi ampliado $(25 \mathrm{~cm}$ x $22 \mathrm{~cm})$ e impresso em uma folha de tamanho A4. O critério de seleção dessas tirinhas era que todas fossem equivalentes quanto ao número de personagens (dois personagens por quadrinho) e ausência de diálogo entre os mesmos (o uso dos quadrinhos foi autorizado pela Assessoria de Comunicação - Maurício de Souza). Todas as sessões foram filmadas com uma filmadora da marca Sony Handycam, CDR-SR 20, HDD 80GB.

\section{Tabela 2.}

Estímulos utilizados no Estudo 2: tirinhas de história em quadrinhos da Turma da Mônica (Maurício de Souza) composta por três quadrinhos.

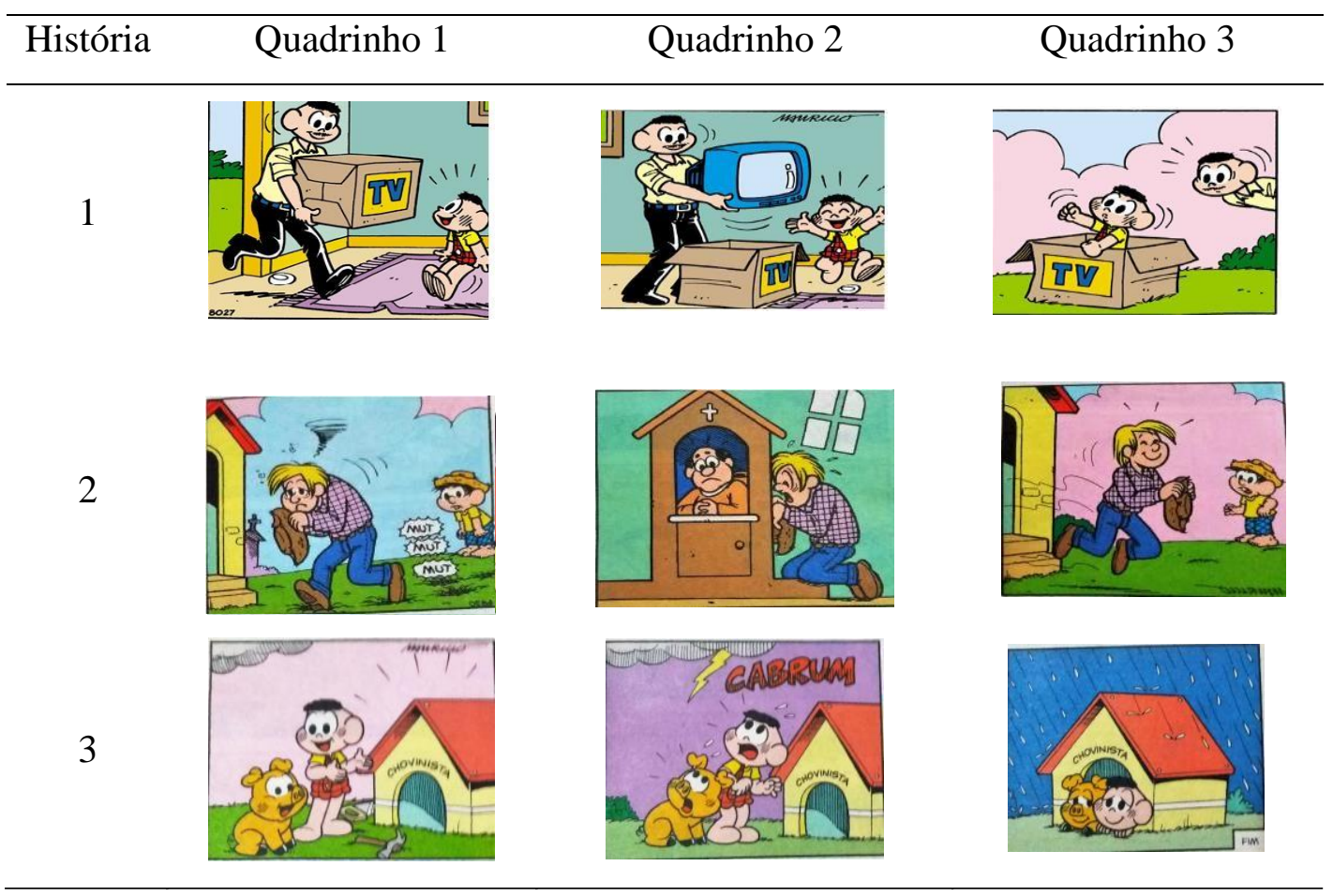

A coleta de dados ocorreu em uma sala da casa/instituição em que os participantes residiam. O local garantia o sigilo da pesquisa, a privacidade do participante e a ausência de sons externos que pudessem atrapalhar o procedimento. Os participantes foram posicionados em uma cadeira que estava na frente de uma mesa. A pesquisadora sentouse em uma cadeira do outro lado da mesa. A filmadora foi posicionada ao lado da pesquisadora e captava as imagens do participante. 


\section{Procedimento de Coleta de Dados}

O delineamento experimental utilizado foi o de pré e pós-teste, dividido em três fases: Fase 1 - Pré-Teste; Fase 2 - Intervenção (dividida em três etapas) e Fase 3 - PósTeste. Os participantes realizaram o procedimento individualmente. A descrição de cada fase do procedimento será feita na sequência.

Fase 1 - Pré-Teste: Inicialmente, foi colocado na frente do participante (a aproximadamente $30 \mathrm{~cm}$ ) os quatro cartões-teste, horizontalmente um ao lado do outro, na sequência da história, da esquerda para a direita. A pesquisadora então dizia, enquanto apontava para os cartões: "Olhe para cada um desses cartões e conte para mim a história que eles mostram”. A cada pausa maior de 10 segundos a pesquisadora perguntava: “ $O$ senhor (a senhora) terminou a história? Gostaria de acrescentar mais alguma coisa?”. A sessão era encerrada quando o participante avisasse que sua narrativa havia acabado: a pesquisadora dizia "Muito bem, obrigada!". Todo o desempenho do participante foi registrado em vídeo para posterior análise.

Fase 2 - Intervenção. As três etapas desta fase ocorreram em dias consecutivos. A cada etapa, antes e depois da introdução das perguntas sobre a história, era solicitado que o participante narrasse a história dos cartões e o seu desempenho era registrado em vídeo.

Etapa 1. O objetivo dessa etapa era fornecer dicas, na forma de perguntas, sobre os aspectos críticos de cada quadrinho componente da história e que deveriam ser discriminados para que fosse possível a construção de uma narrativa encadeada e coerente, e verificar se essas dicas teriam efeito sobre o desempenho posterior do participante na narrativa da história.

A sessão iniciava com a colocação dos três cartões componentes da história em quadrinho em frente ao participante (Conjunto A) sobre a mesa. Os cartões eram dispostos 
lado a lado, horizontalmente, na sequência da história, a aproximadamente $30 \mathrm{~cm}$ do participante. Em seguida, a seguinte instrução era apresentada, enquanto a pesquisadora apontava em direção aos cartões: "Olhe para cada um desses cartões e conte para mim a história que eles mostram”. Como na Fase 1, a pesquisadora aguardava a descrição do idoso e, a cada pausa maior que 10s, perguntava se havia algo a acrescentar. Após o término da narrativa, que servia como uma espécie de pré-teste para o desempenho do participante antes da introdução das dicas em forma de perguntas, a pesquisadora reiniciava a tarefa. Nessa etapa, a pesquisadora apontava para cada quadro da história e fazia três perguntas sobre a cena: uma delas pedia uma informação geral ("o que está acontecendo nessa cena?") e as outras duas eram referentes a detalhes da cena (“o que é isso na mão do homem?”; “o que o menino está fazendo dentro da caixa?”). Caso o participante respondesse de forma incorreta qualquer uma das perguntas, ou seja, se descrevesse a cena do quadrinho de forma não correspondente à ilustração, a pesquisadora descrevia a cena do quadrinho de forma correta. Após o participante responder as três perguntas sobre cada um dos quadros, a pesquisadora pedia para que ele contasse novamente a história que os cartões representavam (pós-teste do Conjunto A). Novamente, a cada pausa maior de 10s a pesquisadora perguntava se o participante gostaria de acrescentar mais alguma coisa à história e o critério de encerramento era $\mathrm{o}$ aviso do participante que indicasse que a narração havia terminado.

Etapa 2. Esta etapa seguiu a mesma estrutura da Etapa 1, com o Conjunto B de quadrinhos. Foram utilizados os mesmos procedimentos, instruções e critério de encerramento da Etapa 1, mas a pesquisadora fazia apenas duas perguntas sobre cada cartão, sendo uma pergunta geral ( "O que está acontecendo na cena?”) e outra específica (e.g., “Qual a expressão no rosto do menino?”). 
Etapa 3. Esta etapa seguiu a mesma estrutura das etapas anteriores (mesmos procedimentos e critérios), mas desta vez a pesquisadora fazia apenas uma pergunta sobre cada cartão (pergunta geral): “O que está acontecendo nessa cena?”. No dia seguinte à realização da Etapa 3, o participante realizava a Fase 3.

Fase 3 - Pós-Teste. Repetiu-se o mesmo procedimento da Fase 1, com o mesmo conjunto de cartões-teste.

\section{Procedimento de Análise de Dados}

Todas as descrições e respostas às perguntas emitidas pelos participantes foram transcritas na íntegra. A partir da transcrição, foram feitas duas análises: (a) levantamento de frequência de palavras empregadas na narração da história dos cartões-teste (Fases 1 e 3) e das histórias em quadrinhos (pré e pós-teste com cada conjunto de quadrinhos, em cada etapa), e (b) análise da coerência de cada narrativa, ou seja, análise de um fluxo compreensível.

Para a primeira análise, contabilizou-se o número de palavras emitidas pelos participantes individualmente nas Fases 1 e 3 e verificou-se a média de palavras emitidas. Em seguida foram comparados os dados entre grupos (GC-Fase1 x GE-Fase1 e GC-Fase 3 x GE-Fase 3). Posteriormente, foi realizada uma análise intragrupo com os dados obtido na Fase 1 e Fase 3 (GC-Fase1 x GC-Fase3 e GE-Fase1 x GE-Fase3). A análise estatística foi realizada por meio da ANOVA seguido pelo teste post-hoc de Newman-Keuls. Para o teste estatístico aplicado a diferença foi considerada significativa quando $p \leq 0,05$. Os dados foram apresentados como média \pm erro padrão da média $(\mathrm{EPM})$ e foram analisados usando o software Statistica 12 (StatSoft Inc., Tulsa, OK, USA).

Também foi contabilizado o número de palavras emitidos em cada narrativa da Fase 2. Foram comparadas as narrativas de cada grupo antes e após as perguntas e os 
dados foram analisados utilizando a ANOVA (exemplo: GC-Pré1 x GC-Pós1, GC-Pré2 x GC-Pós2 e GC-Pré3 x GC-Pós3) e comparados os desempenhos entre os grupos (exemplo: GC-Pré1 x GE-Pré1 e GC-Pós1 x GE-Pós1).

A análise da coerência das narrativas foi feita de forma qualitativa a fim de verificar a presença (ou não) de um relato contínuo e coerente com a história. Para isto, a pesquisadora realizou uma descrição das imagens, considerando os aspectos centrais de cada quadrinho que deveriam estar presentes no relato do participante a fim de que a história fosse contada de forma completa e com sentido. A descrição da pesquisadora foi apresentada a duas pessoas, estudantes de mestrado, a fim de estabelecerem um acordo sobre os elementos essenciais para a descrição. Assim, o relato dos participantes foi comparado ao modelo durante a realização das análises. Considerou-se que a narrativa era contínua e coerente quando havia: (a) menção do personagem central ou dos dois personagens, (b) descrição da ação do personagem central ou dos dois personagens e (c) a descrição do contexto geral da cena que favorecia a descrição das cenas seguintes, produzindo uma relação de "começo, meio e fim".

\section{Concordância entre Observadores}

Uma pessoa com formação em neurociência leu todas as transcrições referentes a todas as narrações dos participantes. Em seguida analisou os relatos para verificar lógica e coerência e descrição dos personagens. A concordância entre observadores foi de $85 \%$.

\section{Resultados}

Serão apresentados inicialmente os resultados da comparação entre os grupos e intragrupo. Em seguida serão apresentados os resultados referentes à análise qualitativa 
das narrativas dos idosos. A Figura 1 apresenta o desempenho dos idosos do GC e do GE em todas as fases do procedimento.

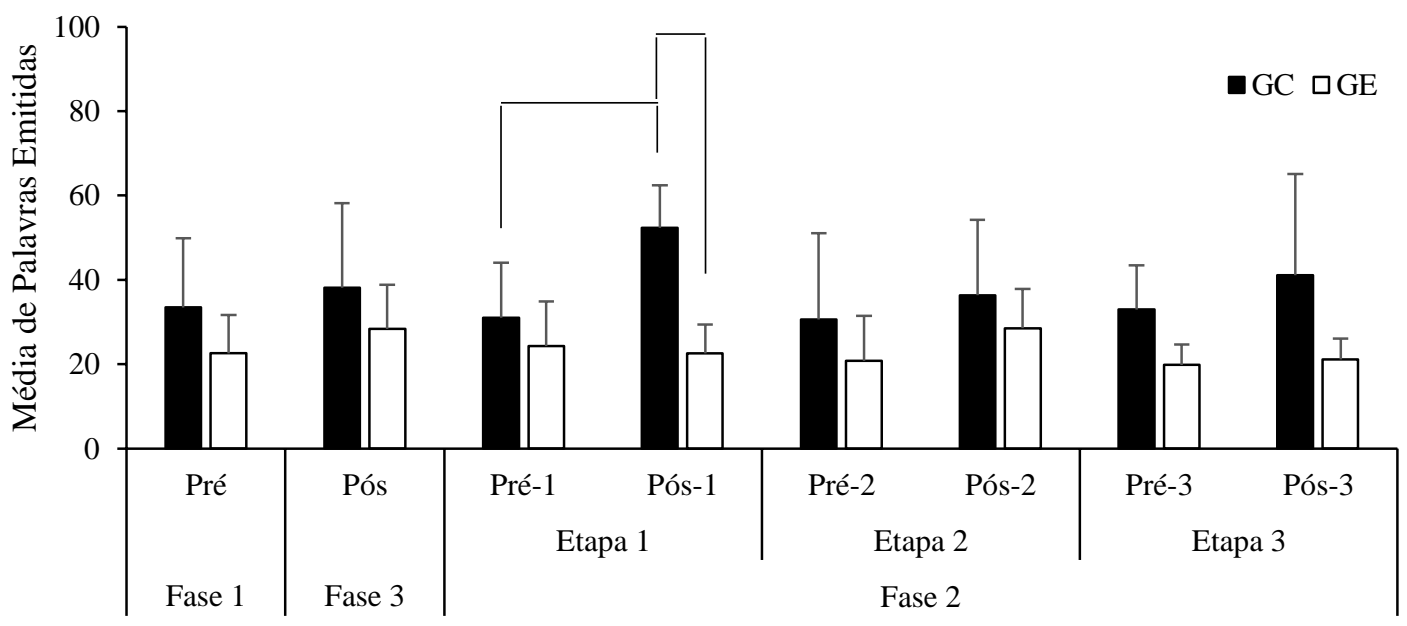

Figura 1. Número médio de palavras emitidas pelos participantes do Grupo Comparação (GC) e Grupo Experimental (GE) nas narrativas de histórias de cada uma das fases do procedimento.

De forma geral, é possível observar que em todas as fases os idosos do GC emitiram mais palavras nas suas narrativas que os idosos do GE. Observa-se, também, que os idosos do GC emitiram mais palavras nas condições de pós-teste em comparação ao pré-teste, tanto nas três etapas da Fase 2, quanto na Fase 3. O GE, por sua vez, emitiu maior número de palavras no pós-teste em suas narrativas, em comparação ao pré-teste, na Fase 3 e nas etapas 2 e 3 da Fase 2, mas de forma mais discreta que o GC.

Apesar dessas diferenças aparentes no desempenho dos grupos, a análise estatística entre os grupos, que comparou o desempenho de cada grupo na Fase 1 e Fase 3, indicou que não houve diferença estatística significativa na emissão de palavras em ambas condições (pré e pós) para os dois grupos $(\mathrm{GC}-[\mathrm{t}(10)=-1.20, \mathrm{p}=0.257]$ e GE [t $(10)=0.99, p=0.341])$. Ou seja, tanto os idosos do GC quanto o idosos do GE emitiram quantidade semelhante de palavras antes (Fase 1) e após (Fase 3) a intervenção (Fase 2). 
A análise estatística intragrupo da Fase 2 identificou diferença estatística no número de emissões de palavras apenas do GC na Etapa 1 [ $\mathrm{t}(10)=-3.17, \mathrm{p}=0.009]$ : nesta condição, os idosos do GC emitiram mais palavras no pós-teste em comparação ao préteste, mas o mesmo não se repetiu nas demais etapas do procedimento. Nas demais comparações intragrupo nas diferentes etapas, não foram observadas diferenças estatísticas, ou seja, apesar de se observar um aumento discreto do número de palavras emitidas pelos grupos nos pós-testes (em comparação ao pré-teste) das diferentes etapas da Fase 2, tal diferença não foi significativa.

A análise estatísticas entre grupos verificou se havia diferença estatística entre a emissão de palavras pelo GC e pelo GE. Os resultados indicaram que, ao comparar o desempenho dos dois grupos na Fase 1 e na Fase 3, não foram encontradas diferenças estatísticas. Verificou-se diferença estatística apenas no pós-teste da Etapa 1 (Fase 2) ([t $(10)=5.97, \mathrm{p}=0.0001])$, com o GC emitindo um número significativamente maior de palavras que o GE. As demais análises não indicaram diferenças significativas.

A Tabela 3 apresenta a análise da coerência das narrativas de histórias realizadas pelos participantes em todas as fases/etapas do procedimento. 
Tabela 3.

Análise da Coerência das Narrativas dos Idosos do Grupo Comparação (GC) e Grupo Experimental (GE).

\begin{tabular}{|c|c|c|c|c|c|c|c|c|c|}
\hline \multirow{3}{*}{ Grupos } & \multirow{3}{*}{ Participantes } & \multirow{3}{*}{$\begin{array}{c}\text { Fase } 1 \\
\text { Pré }\end{array}$} & \multirow{3}{*}{$\begin{array}{c}\text { Fase } 3 \\
\text { Pós }\end{array}$} & \multicolumn{6}{|c|}{ Fase 2} \\
\hline & & & & \multicolumn{2}{|c|}{ Etapa 1} & \multicolumn{2}{|c|}{ Etapa 2} & \multicolumn{2}{|c|}{ Etapa 3} \\
\hline & & & & Pré-1 & Pós-1 & Pré-2 & Pós-2 & Pré-3 & Pós-3 \\
\hline \multirow{6}{*}{ 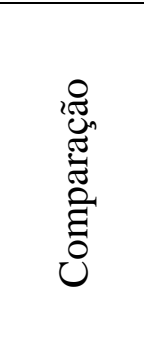 } & $\mathrm{P} 1$ & $S$ & $\mathrm{~S}$ & $\mathrm{~N}$ & $S$ & $\mathrm{~N}$ & $S$ & $\mathrm{~N}$ & $S$ \\
\hline & $\mathrm{P} 2$ & S & S & $\mathrm{N}$ & S & $\mathrm{N}$ & $S$ & $\mathrm{~N}$ & $S$ \\
\hline & P3 & S & $S$ & $S$ & S & S & $S$ & $\mathrm{~N}$ & $S$ \\
\hline & $\mathrm{P} 4$ & S & S & $\mathrm{N}$ & S & $\mathrm{N}$ & S & S & $S$ \\
\hline & P5 & $S$ & $S$ & $S$ & $S$ & $\mathrm{~S}$ & $S$ & $\mathrm{~S}$ & $S$ \\
\hline & P6 & $S$ & S & $\mathrm{N}$ & S & S & S & $\mathrm{N}$ & $\mathrm{S}$ \\
\hline \multirow{6}{*}{ 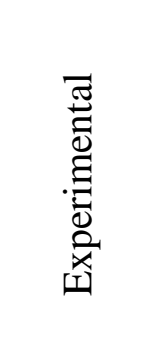 } & $\mathrm{P} 11$ & $\mathrm{~N}$ & $S$ & $\mathrm{~N}$ & $S$ & $\mathrm{~N}$ & $\mathrm{~N}$ & $\mathrm{~N}$ & $S$ \\
\hline & P12 & $\mathrm{S}$ & S & $\mathrm{N}$ & $\mathrm{N}$ & $\mathrm{N}$ & S & $\mathrm{N}$ & $\mathrm{S}$ \\
\hline & $\mathrm{P} 13$ & $\mathrm{~S}$ & $S$ & $\mathrm{~N}$ & $\mathrm{~N}$ & $\mathrm{~N}$ & $\mathrm{~N}$ & $\mathrm{~N}$ & $\mathrm{~N}$ \\
\hline & P14 & $\mathrm{S}$ & S & $\mathrm{N}$ & $\mathrm{S}$ & $\mathrm{N}$ & $\mathrm{S}$ & $\mathrm{N}$ & $\mathrm{S}$ \\
\hline & P15 & $\mathrm{S}$ & $S$ & $S$ & $\mathrm{~S}$ & $S$ & S & $\mathrm{N}$ & $\mathrm{S}$ \\
\hline & P16 & $\mathrm{N}$ & $S$ & $\mathrm{~N}$ & $\mathrm{~S}$ & $\mathrm{~N}$ & $\mathrm{~S}$ & $\mathrm{~N}$ & $\mathrm{~S}$ \\
\hline
\end{tabular}

Nota: S - Sim/Presença de Coerência; N - Não/Ausência de Coerência.

$\mathrm{Na}$ análise qualitativa das narrativas dos idosos do GC, observa-se que todos descreveram os cartões-teste com coerência, tanto na Fase 1 (pré-teste), quanto na Fase 3 (pós-teste). Além disto, observou-se não apenas manutenção da coerência da narrativa para esse grupo, como o aumento na riqueza de detalhes. Um exemplo dessa diferença pode ser observado no relato de P3. Na Fase 1 (Pré-teste), P3 fez a seguinte descrição: "Um garoto estava subindo a cavalo... Ele montou num cavalo e galopou. Depois o cavalo assustou e ele ficou amedrontado e quase caiu do cavalo e caiu. O cavalo sumiu.". Na Fase 3 (Pós-teste), aparticipante fez a seguinte narrativa: “O menino estava tentando subir no cavalo. Ele se esforçou muito. Ele conseguiu subir no cavalo e está andando normalmente... E foi... Depois um cachorro assustou o cavalo e o cavalo assustou o cachorro... O cachorro está avançando no cavalo e o menino está assustado e quase cai do animal. Depois ele cai.". Observa-se que no pós-teste P3 citou o cachorro (omitido no 
pré-teste), e acrescenta detalhes, como "ele se esforçou muito (...) e conseguiu subir no cavalo", "o cachorro está avançando no cavalo e o menino está assustado".

O desempenho dos idosos do GC foram mais variáveis na Fase 2, especialmente nos pré-testes. O participante P5 foi o único que apresentou uma narrativa com coerência no pré-teste de todas as etapas da Fase 2. O participante P3 realizou duas narrativas de pré-teste com coerência (Etapas 1 e 2); os participantes P4 e P6 apresentaram apenas uma narrativa com coerência nos pré-testes dessa Fase; e os demais participantes não fizeram narrativas com coerência no pré-teste de todas as etapas da Fase 2.

Os participantes P3 e P5 mantiveram a coerência das narrativas na Etapa 1 e os demais, apesar de não terem narrado uma história com coerência no pré-teste desta estapa, o fizeram no pós-teste. Por exemplo, P6 no pré-teste da Etapa 1 narrou: "Esse aqui é a pessoa carregando a tv. O do lado a pessoa tá com a tv já posta pra pôr no lugar e a outra pessoa apontando para alguma coisa, não sei. E agora, esse aqui, tem um com a mão fechada dizendo alguma coisa e o outro do lado reparando". No pós-teste dessa etapa, P6 relatou: “Esse aqui está carregando a caixa de tv e o menino está preocupado porque vai cair. O menino tá... Esse aqui, o pai, entrega a tv e o filho está contente e pedindo pra colocar a tv no lugar, no lugar próprio dela. E depois o menino vai brincar dentro da caixa: ou fazendo de carrinho ou fazendo de berço e o pai tá com cara de “cuidado”.

Na Etapa 2, metade dos participantes do GC (P3, P5 e P6) narraram história com coerência no pré e pós-teste; os demais participantes (P1, P2 e P4) narraram histórias coerentes apenas no pós-teste, ou seja, após intervenção. Na Etapa 3, apenas P4 e P5 narraram história coerentes nas duas situações de teste, contudo todos os demais apresentaram este desempenho após intervenção. Como exemplo, pode-se verificar o relato de P2: no pré-teste da Etapa 3 o participante relatou: "Chovinista eu nem sei oque 
é isso. É a casinha do cachorro. O menino foi pegar e depois ele entrou dentro da casa dele". Contudo, no Pós-3 o participante narrou da seguinte forma: "O menino foi passear com o cãozinho dele e o tempo começou a trovejar; e começou a chover. Então eles entraram na casinha dele”.

Os idosos do GE também apresentaram desempenho variado. Na Fase 1, quatro dos seis idosos (P12, P13, P14 e P15) narraram histórias coerentes. Na Fase 3, todos os idosos narraram a história dos cartões-teste com coerência. O participante P15, por exemplo, na Fase 1 emitiu um relato coerente, mas simples: "Ele está montando a cavalo e começou a andar. O cachorro não gostou muito. O cavalo também não gostou e deu um ponta pé nele, então ele caiu e machucou." . No entanto, após a intervenção, o P15 narrou a história de forma mais completa: "O menino está subindo no cavalo pra cavalgar. O cachorro está abanando o rabinho pra ele. Ele montou no cavalo e o cachorro rosnou. Aí o cavalo empinou pra dar uma patada nele (aponta para o cachorro) e o cachorro ficou pi pi pi... Ai o homem caiu do cavalo e o cavalo foi embora."

O participante P14, por exemplo também apresenta um relato mais completo após a intervenção. Na Fase 1 o participante relata a história da seguinte forma: “Ele está andando com o cavalo... Depois ele caiu, né?!"; e no Fase 3, narra: "Ele está montado no cavalo e o cachorro esta brabo. (Silêncio). O cavalo está dando coice e agitado nele e por isto o menino caiu do cavalo."

Ao longo da Fase 2, apenas P15 apresentou narrativas com coerência nos prétestes das Etapas 1 e 2; todos os demais participantes apresentaram narrativas sem coerência em todos os pré-testes. Após a intervenção (pós-testes), pelos menos quatro dos seis idosos apresentaram narrativas coerentes das histórias, demonstrando melhora nesse aspecto após a intervenção. O participante P13 foi o único que não apresentou coerência em suas narrativas, nem no pré e nem no pós-teste das três etapas da Fase 2. 


\section{Discussão}

O objetivo geral deste estudo foi investigar se um procedimento de fading out progressivo de dicas (na forma de perguntas) alteraria a produção de narrativas com apoio visual de idosos com DA, em comparação a um grupo de idosos saudáveis. As medidas empregadas para avaliar essas mudanças foram o número de palavras utilizadas pelos idosos antes e após a intervenção em uma tarefa de narrativa de história (Fases 1 e 3), e ao longo das diferentes etapas da intervenção (Fase 2). A segunda medida foi a análise da coerência das narrativas realizadas em todas as fases do procedimento.

Os resultados obtidos indicaram que o procedimento foi eficaz, especialmente para alterar a qualidade da narrativa dos idosos (sua coerência): a maioria dos participantes dos dois grupos passou a narrar histórias com maior coerência nos pós-testes das etapas da Fase 2 depois da apresentação de dicas (perguntas) sobre a descrição das cenas componentes das histórias. Ao menos aparentemente, o efeito das dicas se manteve mesmo com a sua retirada gradual, uma vez que dois idosos do GE que apresentaram uma narrativa sem coerência no pré-teste, apresentaram uma narrativa coerente no pós-teste. Além disso, mesmo uma única pergunta na Etapa 3 da Fase 2 foi suficiente para melhorar a coerência da narrativa da história de todos os idosos do GC e de cinco dos seis idosos do GE. Em relação à medida quantitativa utilizada (frequência de palavras), apesar de se observar um maior número de palavras nas narrativas dos idosos do GC em comparação aos do GE, na comparação entre pré e pós-teste, essas diferenças não foram significativas. Pode-se concluir, então, que o procedimento foi eficaz para melhorar a produção do discurso narrativo dos idosos, o que pode indicar um caminho promissor na intervenção sobre esse tipo de repertório verbal de pacientes com DA.

Muitos estudos utilizam a frequência de palavras emitidas em tarefas de descrição de uma figura para caracterizar o discurso de idosos saudáveis e com DA, e de idosos 
com DA em diferentes estágios da doença. O estudo de Lira, Minett, Bertlucci e Ortiz (2014), por exemplo, comparou o desempenho de idosos controle (saudáveis) e com DA na tarefa de descrição de uma figura e verificou que o grupo controle emitiu maior frequência de palavras em comparação aos idosos com DA (mas, não houve diferença nessa medida entre idosos com DA de diferentes níveis de comprometimento - leves e moderados). Outros estudos que utilizaram essa mesma medida em tarefas de descrição de figuras, no entanto, não verificaram diferenças entre idosos controle e com DA (Bschor, Kühl, \& Reischies, 2001; Feyereisen, Berrewaerts, \& Hupet, 2007; Nicholas \& Brookshire, 1993), o que indica que não há consenso na literatura sobre se o número de palavras empregadas por idosos em uma tarefa de descrição é uma medida capaz de diferenciá-los.

A tarefa de descrição de figuras, no entanto, é diferente da tarefa de narrar uma história à partir de uma sequência de figuras, tarefa empregada no presente estudo. A descrição de sequências de ações que se relacionam entre si e que constituem um “acontecimento" único (a narrativa de uma história, portanto) requerem que o participante não apenas fique sob controle das cenas individuais, mas que relacione os fatos retratados em cada cena e estabeleça relações entre esses eventos (Drummond et al., 2015). Nesse sentido, seria possível supor que a frequência de palavras fosse uma medida de interesse nesse tipo de tarefa.

Poucos estudos, porém, propõem a análise dessa medida, como na presente pesquisa. Drummond et al. (2015) utilizaram a frequência de palavras (entre várias outras medidas) para caracterizar as diferenças de desempenho de idosos saudáveis e com demência, na narração de uma história a partir de um conjunto de sete cartões (a "História do acidente de carro"). Nesse estudo, não foram verificadas diferenças significativas no número de palavras utilizadas por idosos saudáveis e idosos com DA para narrar a história 
(nem no tempo utilizado pelos dois grupos para fazer a narrativa), da mesma forma que no presente estudo. $\mathrm{O}$ conjunto de pesquisas que investigam descrições de figuras e narrativas de histórias a partir de figuras sequenciais, assim como os resultados do presente estudo, indicam, portanto, que a frequência de palavras utilizadas em tarefas verbais que envolvam descrição de estímulos visuais complexos (e.g., um cenário ou uma sequência de imagens que constituem uma história) não é uma medida que diferencia idosos saudáveis e com DA. Adicionalmente, o presente estudo indica que essa medida também não é um bom marcador para verificar efeitos de intervenções sobre o discurso narrativo de idosos com DA.

Estudar e intervir sobre o discurso narrativo de idosos com DA tem importância prática. Contar histórias é uma tarefa importante, pois permite o relato daquilo que aconteceu com o outro e consigo mesmo, podendo ser fundamental, por exemplo, na descrição de uma doença. Estudar a narração de uma história a partir de estímulos visuais pode ajudar a entender, por um lado, eventuais dificuldades associadas à DA na execução dessa tarefa e, por outro, tipos de intervenção que podem atuar sobre essas dificuldades. Nesse sentido, o presente estudo propôs, também, a análise da coerência da narrativa, como outros estudos da literatura (Drummond et al., 2015).

Vários estudos têm descrito as dificuldades de idosos com DA na produção de discursos narrativos evocados por apoio visual, especialmente em relação à coerência (Lima, Brandão, Parente, \& Peña-Casanova, 2014; Lira, Ortiz, Campanha, Bertolucci, \& Minett, 2011; Toledo et al., 2018). Lima et al. (2014), por exemplo, analisaram a coerência de uma narrativa de idosos com e sem DA a partir de uma sequência de 12 figuras retratando a história "Chapeuzinho Vermelho". A coerência foi avaliada pela análise das proposições dos idosos ao longo da narrativa: se as proposições descreviam as ideias principais do tópico (diretamente relacionadas à história - coerência global) e a 
conexão semântica entre as proposições (se uma proposição tinha ou não relação com a proposição anterior - coerência local). Os autores verificaram que os escores de coerência global e local dos indivíduos com DA foram significativamente mais baixos que os dos idosos controle. Drummond et al. (2015) também compararam a coerência do discurso narrativo de idosos com e sem DA, por meio da análise da estrutura narrativa das histórias (presença ou não do evento inicial da história, seu desenvolvimento e desfecho) e da coerência global (avaliada pelo número de macroproposições e de microproposições na história). O estudo concluiu que os idosos com DA, em comparação aos controles, apresentaram dificuldades com a coerência global de suas narrativas, produzindo um número menor de macroproposições e histórias menos completas.

O presente estudo também analisou a coerência da narrativa dos idosos. Para isso, definiu operacionalmente o que chamou de coerência: a presença (ou não) da citação de todos os personagens retratados em cada quadro (cena), a descrição das ações realizadas pelos personagens (ou apenas personagem central) em cada cena e a descrição do contexto geral de cada cena, em relação ao quadrinho anterior/seguinte e ao seu desfecho. Esse tipo de definição é importante para que se possa identificar de forma mais clara os desempenhos requeridos dos idosos na tarefa e formas específicas de intervenção sobre esses desempenhos. A partir dessa definição, de modo geral não foram verificadas diferenças entre idosos controle e com DA na comparação entre o pré e o pós-teste: dois dos idosos com DA não apresentaram uma narrativa coerente no pré-teste (enquanto todos os idosos controle narraram a história com coerência no pré e no pós-teste); e todos os idosos dos dois grupos apresentaram narrativas coerentes no pós-teste. Além disso, a maioria dos idosos controle e com DA apresentaram narrativas sem coerência nos prétestes da Fase 2, e com coerência nos pós-testes (as exceções no pós-teste eram do GE). Isso indica que a análise proposta (assim como a tarefa) não diferenciaram os idosos dos 
dois grupos em relação à coerência da narrativa, nem nas medidas de pré-teste, nem nas medidas de pós-teste. Por outro lado, diferentemente das demais pesquisas que analisam a coerência das narrativas de idosos com DA, e têm caráter descritivo e apenas retratam as dificuldades de idosos com DA na tarefa, os resultados obtidos no presente estudo sugeriram a efetividade do procedimento de fading out de dicas para a melhora da coerência das narrativas, dentro dos parâmetros estudados.

Os resultados deste estudo demonstram a dificuldade dos idosos na tarefa narrativa, não apenas em termos de coerência, mas também em termos de produção de detalhamentos, uma vez que os idosos do GE apresentaram, nas condições de pré-teste, narrativas mais pobres em comparação aos seus resultados dos pós-testes e ao GC. Tais resultados corroboram os achados de Brandão et al. (2010), Bourgeois (1990; 1993) e Soderlund, Cronqvist, Norberg, Ternested, e Hansebo (2016), mas vão além: indicam que os idosos com DA podem ser sensíveis a intervenções que possam melhorar a qualidade de seu discurso.

É importante procurar entender de que forma o procedimento proposto atuou sobre a melhora da coerência das narrativas dos idosos. Uma possível explicação para as dificuldades encontradas pelos idosos nos pré-testes da Fase 2 pode estar relacionada aos aspectos que, de fato, controlaram a narrativa dos participantes. É possível que os participantes tenham construído suas narrativas com base em aspectos irrelevantes de cada cena, ou podem ter descrito cada cartão de forma independente, ou ainda, podem ter apresentado uma inspeção insuficiente de cada cena, o que pode tê-los impedido de realizar uma descrição lógica, coesa e detalhada da história. Apesar do número de cenas apresentadas aos participantes em cada história ser pequena (três), cada cena era colorida e com muitos detalhes (diferentemente dos cartões-teste empregados nas Fases 1 e 3), o que exigia que o idoso identificasse os aspectos críticos em cada quadro, que 
contribuiriam para a formulação de uma narrativa que, por sua vez, dependia da sequência das três cenas. Portanto, apesar da sequência de imagens servir como um apoio importante para a narrativa dos idosos (o que seria uma vantagem sobre narrativas de dependem de aspectos auditivos, como recontar histórias ouvidas, ou narrativas autobiográficas - Lima et al., 2014) os idosos tinham que discriminar eventos relevantes e irrelevantes de cada cena para construir a narrativa.

Neste sentido, no procedimento testado as perguntas (dicas) podem ter aumentado a discriminabilidade dos eventos relevantes de cada imagem, direcionando a inspeção visual dos idosos de cada cena. Com isso, cada pergunta, ao mesmo tempo em que colocava a narrativa do idosos sob controle de um tópico trazido pela pesquisadora (o personagem, sua ação ou o que "ocorria” em cada cena), também colocava o desempenho verbal do participante sob controle da própria cena, o que, por sua vez, aparentemente contribuiu para que o participante fizesse uma narrativa sequencial, ao invés de apenas descrever cada cena de forma independente. A isso se chama transferência de controle de estímulos, uma característica do procedimento de fading out (Catania, 1999; Terrace, 1963).

Além disso, apesar de não se ter observado o efeito das dicas entre as diferentes etapas da Fase 2 (i.e, o desempenho dos idosos no pré-teste das etapas 2 e 3 não melhorou em função da apresentação das dicas nas etapas anteriores), a retirada gradual das perguntas mostrou que, ao final, apenas uma pergunta geral sobre cada cena teve o efeito de melhorar a coerência da narrativa dos participantes. $O$ estudo aqui apresentado, no entanto, não é capaz de esclarecer se a apresentação desde o início de apenas uma única dica (pergunta) para cada cena seria suficiente para produzir a melhora verificada no desempenho dos idosos, o que demanda investigações posteriores. 
Diferentes estudos têm mostrado o efeito do fading out na aprendizagem de desempenhos verbais por idosos com demência (Clare, et al., 2000; Clare \& Jones, 2008; Grandmaison \& Simard, 2003; Haslam, Moss, \& Hodder, 2010). Esses estudos, no entanto, testam intervenções sobre desempenhos muito específicos, como nomear figuras ou faces. A proposta do presente estudo estende o uso do fading out para uma tarefa mais complexa, mas são necessários outros estudos para que seja possível afirmar sua utilidade no desempenho de idosos nessa tarefa. A replicação deste estudo com um número maior de idosos pode ajudar a esclarecer em que medida o uso de dicas na forma de perguntas pode realmente melhorar a coerência e a complexidade de narrativas com apoio visual por idosos, o que pode ser importante no campo da reabilitação cognitiva.

A DA é uma condição orgânica que faz com que tarefas simples se tornem mais complexas, devido à degeneração do sistema nervoso que lesa áreas cerebrais responsáveis pela aprendizagem. Sabe-se que a recuperação total das áreas lesadas não é possível, o que faz com que o desenvolvimento de técnicas de reabilitação seja necessário para minimizar os danos e adiar o avanço da doença (Jang, et al., 2015; Kumar, Singh \& Ekavali, 2015). Estudos que avancem neste sentido podem representar uma contribuição importante para a qualidade de vida de idosos com DA. 
Estudo 3 
Desempenho de idosos com Doença de Alzheimer em tarefas de nomeação após procedimentos de Spaced Retrieval e Fading Out

\section{Resumo}

A Doença de Alzheimer (DA) é um transtorno neurocognitivo que afeta principalmente a memória e a linguagem. Diferentes procedimentos de ensino têm sido testados para auxiliar a preservação e/ou recuperação dessas funções de idosos. O Spaced Retrieval (SR) e Fading Out (FO) têm sido utilizados para auxiliar estes pacientes a aprender ou recuperar relações entre estímulos, mas ainda não há consenso na literatura sobre as diferenças dessas técnicas em termos de eficácia. O objetivo deste estudo foi comparar a eficácia dos procedimentos SR e FO no ensino de nomeação de figuras para idosos com DA. Participaram oito idosos com indicativos de DA, de ambos os sexos, idade entre 65 e 89 anos. Todos os participantes aprenderam dois conjuntos de sete relações nomefigura, cada conjunto por um procedimento diferente (condição de ensino SR ou FO) delineamento de medidas repetidas. A ordem das condições foi balanceada entre os participantes. Após um pré-teste de nomeação de figuras, no qual foram selecionadas aquelas que os participantes não nomearam, foram conduzidos os procedimentos de ensino. Na condição SR, era apresentada uma figura e falado seu nome; na sequência, era solicitado que o participante nomeasse a figura (“O que é isso?"), em intervalos progressivamente maiores. Na condição FO, era apresentada uma figura e falado o nome da mesma, de forma simultânea. Nas tentativas seguintes, era apresentado para o participante a figura e era falado apenas parte de seu nome (apresentações de partes progressivamente menores do nome da figura, até a ausência da dica). Ao final de cada treino, foi conduzido um pós-teste de nomeação das figuras ensinadas e um pós-teste geral com todas as figuras foi aplicado ao final das duas condições. Os dois procedimentos foram eficazes para ensinar a nomeação das palavras, uma vez que os idosos nomearam corretamente no mínimo metade das figuras de cada conjunto, e mantiveram tal desempenho na fase de manutenção. Não foram encontradas diferenças significativas entre os desempenhos finais dos idosos nas duas condições. Os resultados fortalecem os achados sobre a eficácia de intervenções para ensino de desempenho de nomeação para idosos com DA e demonstram a importância do FO como um procedimento de ensino rápido.

Palavras-Chaves: Nomeação de figuras; Spaced Retrieval; Fading Out; Doença de Alzheimer; Idosos. 
Performance of elderly with Alzheimer's disease in appointment tasks after Spaced Retrieval and Fading Out procedures

\begin{abstract}
Alzheimer's disease (AD) is a neurocognitive disorder that mainly affects memory and language. Different teaching procedures have been tested to assist the preservation and / or recovery of these functions of the elderly. Spaced Retrieval (SR) and Fading Out (FO) have been used to help these patients to learn or recovery relationships between stimuli, but there is no consensus in the literature about the differences between these techniques in terms of effectiveness. The objective of this study was to compare the efficacy of SR and $\mathrm{FO}$ procedures to teaching elderly with $\mathrm{AD}$ to name figures. Eight elderly individuals with AD signs of both sexes, aged between 65 and 89 years, participated. All participants learned two sets of seven name-figure relationships, each set by a different procedure (SR or FO teaching condition) - delineation of repeated measures. The order of conditions was balanced between participants. After a pre-test of naming figures, in which were selected those figures that the participants were not able to named, the teaching procedures were conducted. In SR condition, a figure was displayed and its name was spoken; in the sequence, the participant was asked to name the figure ("What is this?") at progressively larger intervals. In FO condition, a figure was displayed and the name was spoken simultaneously. In subsequent attempts, the figure was presented to the participant and only part of his name was spoken (presentations of progressively smaller parts of the figure's name until the absence of the tip). At the end of each training, a post-test of naming of the taught figures was conducted and a general post-test with all the figures was applied at the end of the two conditions. The two procedures were effective in teaching the naming of the words, since the elderly correctly named at least half of the figures of each set, and maintained such performance in the maintenance phase. No significant differences were found between the final performance of the elderly in both conditions. The results strengthen the findings on the efficacy of interventions for naming performance education for elderly with $\mathrm{AD}$ and demonstrate the importance of $\mathrm{FO}$ as a rapid teaching procedure.
\end{abstract}

Keywords: Appointment of figures; Spaced Retrieval; Fading Out; Alzheimer's disease; Aged. 


\section{Introdução}

A Doença de Alzheimer (DA) é um Transtorno Neurocognitivo que acarreta prejuízos nas funções cognitivas, em especial na memória e na linguagem (DSM-V, 2014). Não há cura para DA, mas tratamentos farmacológicos e a reabilitação neuropsicológica auxiliam na manutenção das funções cognitivas, assim como no ensino de desempenhos que se deterioraram por conta do comprometimento da memória (Folch, et al., 2018; Rodakowski, Saghafi, Butters, \& Skidmore, 2015; Rojas, et al., 2013; Salamone, Caraci, Leggio, Fedotova, \& Drago, 2011).

Idosos com DA apresentam dificuldades de nomear pessoas conhecidas e com quem convivem diariamente, assim como objetos familiares (Dixon, Becker, \& Sadowski, 2012; Ducatti \& Schmidt, 2016). Essas dificuldades causam problemas na interação social de idosos com DA, que vão desde o constrangimento por não conseguir dizer o nome de um familiar, até a dificuldade em fazer solicitações relacionadas às suas necessidades básicas ou manter um discurso coerente em função de lacunas na narrativa decorrentes de dificuldades no uso de palavras adequadas.

Muitos procedimentos de ensino têm se mostrado eficazes para melhorar o desempenho de idosos com DA em tarefas que envolvem diferentes tipos de repertório verbal e o comportamento de lembrar (Provencher; Bier, Audet, \& Gagnon, 2008; Bourgeois, 1990; 1993; Camara, Ducatti, \& Schmidt, 2017; Clare, et al, 2000; Ducatti \& Schmidt, 2016; Haslam, Moss \& Hodder, 2010). De forma específica, a literatura científica tem feito referência a procedimentos que garantam a aprendizagem ou recuperação de desempenhos verbais com o mínimo de erros ("aprendizagem sem erro" - errorless learning" - EL) para intervir em diferentes desempenhos ditos "cognitivos" de idosos saudáveis e com demência (Aggio \& Domeniconi, 2012; Camara, et al, 2017; Ducatti \& Schmidt, 2016; Dunn \& Clare, 2007; Haslam \& Hodder, 2012; Steingrimsdottir 
\& Arntzen, 2011; 2011b). A característica desses procedimentos é prevenir ou reduzir a probabilidade de que os indivíduos cometam erros durante o processo de aprendizagem (Hopper et al., 2013), garantindo que a resposta correta seja emitida ou escolhida em função de dicas de diferentes tipos (Lear, 2004). Dois procedimentos desse tipo e que têm sido estudado em intervenções com idosos com DA são o fading out de dicas (também referido como esvanecimento de dicas ou, em inglês, vanishing cues) e a recuperação espaçada (spaced retrieval - SR).

O SR é um procedimento desenvolvido por Landauer e Bjork (1978) com base em resultados de estudos anteriores que mostraram a eficácia da repetição para a aprendizagem. Os dados mostravam não só a importância da repetição, mas também o papel do intervalo entre as tentativas e de respostas ativas por parte dos aprendizes. Assim, Landauer e Bjork (1978) expandiram essa ideia e propuseram um procedimento em que o indivíduo era exposto à oportunidade de emitir o desempenho que estava sendo ensinado, em tentativas sequenciais cujo intervalo deveria aumentar progressivamente.

Camp (1989) adaptou essa técnica para o trabalho com idosos com demência e, na sequência, vários outros estudos foram desenvolvidos a fim de verificar a eficácia do SR na melhora de diferentes repertórios de pacientes com comprometimento cognitivo, em especial para a reabilitação de desempenhos que dependiam da memória em pacientes com DA (e.g., Cherry \& Simmons-D’Gerolamo, 2005; Creighton, Van der Ploeg, \& OConnor, 2013; Fridriksson, Holland, Beeson, \& Marrow, 2011; Jang, Lee, \& Yoo, 2015; Kelly \& O’Sullivan, 2015). De modo geral, o SR consiste em apresentar um estímulo visual (e.g., uma foto) juntamente com um estímulo verbal que tem alguma relação com aquele (e.g., um nome: "Celso"). Nas tentativas seguintes, o estímulo visual (a foto) é apresentado e é solicitado ao participante a emissão da resposta verbal (o nome). As tentativas prosseguem com este formato, mas ocorrem em intervalos progressivamente 
maiores. De modo geral, a técnica tem se mostrado bastante eficaz para o ensino de diferentes desempenhos (Creighton, Van der Ploeg, \& O’Conner, 2013), e por isso o SR tem se tornado uma técnica de referência para o ensino de diferentes tipos de repertório para pessoas com DA.

Hawley (2002), por exemplo, utilizou o procedimento SR para ensinar relações face-nome para idosos com DA e testar a generalização das relações ensinadas. Os seis idosos com DA moderada participantes aprenderam a relacionar tais estímulos ao longo de seis sessões de ensino, que ocorreram em um período de duas semanas. Além de relações entre nomes e faces, Hopper et al. (2013), em um artigo de revisão, descreveram o uso do SR para ensino de diferentes atividades de vida diária, reconhecimento e uso de calendário, nomeação de figuras e objetos, recordação do nome de remédios, uso de aparelhos eletrônicos, entre outras aplicações.

Outra estratégia frequentemente utilizada para ensino de diferentes habilidades relacionadas à linguagem é o fading out (esvanecimento) de dicas (FO). O ensino por FO envolve o fornecimento inicial de dicas para a realização de uma determinada tarefas, com o progressivo e sistemático esvanecimento ou retirada dessas dicas à medida que a aprendizagem vai se estabelecendo (Glisky, Schacter, \& Tulving, 1986). Nos estudos em que a dica é verbal, o FO é realizado pela omissão progressiva de partes da palavra (falada ou escrita). Por exemplo, se uma relação nome-figura está sendo ensinada (e.g., a palavra ditada "tomate" e sua respectiva figura), inicialmente apresenta-se a figura e a palavra ditada inteira e pede-se que o participante repita a palavra. Nas tentativas seguintes, a figura é apresentada concomitantemente a apenas parte da palavra (e.g., "toma", "tom”, "to" e finalmente "t"), até que a dica é inteiramente omitida.

De modo geral, poucas pesquisas têm testado exclusivamente o FO com pacientes com DA (e.g., Mimura \& Komatsu, 2010; Provencher, Bier, Audet, \& Gagnon, 2008). É 
mais comum que o FO seja empregado nas pesquisas em conjunto com outras técnicas para ensino de diferentes repertórios para pacientes com DA (e.g., Clare et al., 2000; Clare, Wilson, Carter, Roth, \& Hodges, 2002; Haslam, Moss, \& Hodder, 2010; Thivierge, Simard, Jean, \& Grandmaison, 2008). Em todos esses estudos, a associação de FO com outras técnicas se mostrou eficaz no ensino dos desempenhos-alvo.

Apesar de se reconhecer que, na prática, a combinação de várias estratégias de ensino para os idosos com DA é importante para contemplar ou contornar as dificuldades específicas que eles apresentam, estudos de intervenção que fazem essa combinação tendem a dificultar a compreensão da contribuição individual de cada técnica para o ensino de habilidades específicas (Haslam et al., 2010). Além disso, nas últimas duas décadas muitas pesquisas têm se dedicado ao estudo dos efeitos do SR, demonstrando sua eficácia e até mesmo sua superioridade em comparação com outras técnicas (e.g., Haslam, Hodder, \& Yates, 2011), o que tem feito com que esta técnica seja reconhecida como uma importante ferramenta nas intervenções com idosos. Por outro lado, o FO, apesar de ter uma longa história de aplicação na educação especial (Alves, de Assis, Kato, \& Bruno, 2011; Berkowitz, Sherry, \& Davis, 1971; Boyle \& Hughes, 1994; Sidman, \& Stoddard, 1967; Souza, Verdu, Bevilacqua, 2013), tem ainda sido pouco testado com idosos com DA e, por isso, ainda há pouco suporte empírico sobre sua eficácia com essa população (Hopper et al., 2013).

Tendo em vista a necessidade de se compreender a efetividade de diferentes técnicas de ensino/recuperação de repertórios verbais em idosos com DA, a fim de dar suporte a profissionais que atuam na recuperação de diferentes repertórios verbais desses indivíduos, o objetivo deste estudo foi comparar o desempenho de idosos com DA em uma tarefa de nomeação de figuras, após aprendizagem feita por meio do ensino por Spaced Retrieval (SR) e Fading Out (FO). 


\section{Método}

\section{Participantes}

Participaram deste estudo oito idosos (sete mulheres), de ambos os sexos, alfabetizados, com idade média de 79 anos (mediana 84,5 anos), e indicativos de Doença de Alzheimer (DA). Cinco participantes residiam em uma Instituição de Longa Permanência para Idosos e três residiam em suas casas com seus familiares. Os idosos foram divididos aleatoriamente em dois grupos, apenas como forma de balancear a ordem das condições de ensino. O G1 era formado por quatro mulheres, com idade média de 80 anos, cujo o escore médio no MEEM foi de 13 pontos (mediana 13); e o G2 por três mulheres e um homem, com idade média de 79 anos, cujo escore médio no MEEM foi de 16 pontos (mediana 15,5). Os testes estatísticos não revelaram diferenças entre idade e desempenho no MEEM entre os grupos. Nenhum dos participantes apresentou diagnóstico de depressão, de acordo com a Escala de Depressão Geriátrica (Yesavage, et al., 1983). Os critérios de exclusão da amostra foram (1) analfabetismo, (2) déficits visuais, de linguagem e audição significativos, que comprometessem a comunicação com a pesquisadora, (3) indicativos de depressão, e (4) indicativo de DA em fase moderada (participantes com MEEM igual ou inferior a 10 pontos). Informações detalhadas dos participantes estão na Tabela 1.

Outros dois idosos, alfabetizados, sem indicativos de depressão, alterações significativas de visão e audição, e sem comprometimento cognitivo também participaram do estudo. Um deles, um homem de 86 anos, cujo escore no MEEM foi 18 pontos; e o outro uma mulher de 70 anos, com escore no MEEM de 26 pontos. Esses idosos realizaram apenas a tarefa de nomeação das figuras a fim de garantir que as figuras a serem utilizadas eram comuns e de fácil identificação. 


\section{Tabela 1.}

Características gerais dos idosos participantes do Estudo 3: idade, escolaridade, desempenho nos testes Mini Exame do Estado Mental (MEEM) e Escala de Depressão Geriátrica (GDS).

\begin{tabular}{cccccc}
\hline Grupos & Participante & Idade & Escol. & MEEM & GDS \\
\hline \multirow{3}{*}{ G1 } & P1 & 89 & FI & 13 & S/D \\
& P2 & 83 & FI & 12 & S/D \\
& P3 & 65 & FI & 14 & S/D \\
& P4 & 86 & FI & 13 & S/D \\
& P11 & 90 & FI & 21 & S/D \\
& P12 & 65 & FI & 12 & S/D \\
& P13 & 80 & FI & 14 & S/D \\
& P14 & 81 & FI & 17 & S/D
\end{tabular}

Nota: $\mathrm{P}=$ participante; $\mathrm{FI}=$ Fundamental Incompleto; $\mathrm{S} / \mathrm{D}=$ sem indicativos de depressão.

\section{Materiais, Equipamentos e Situação Experimental}

Para a realização deste estudo foram utilizados 122 cartões de figuras do teste ABFW (Andrade, Befi-Lopes, Fernandes, \& Wertzner, 2000), que são empregados nas provas de vocabulário e fonologia do instrumento. Tais cartões contêm imagens coloridas impressas em um fundo branco, com dimensões de 12 x $21 \mathrm{~cm}$. As imagens são relacionadas a diferentes categorias, como animais, alimentos, meios de transporte, móveis e utensílios, vestuários, locais, brinquedos e instrumentos. Utilizou-se também uma Filmadora SONY Handycam, CDR-SR 20, HDD 80GB e folhas de registro.

Durante todo o procedimento, a coleta de dados foi realizada individualmente com cada participante, em um ambiente em que ambos, participante e pesquisador pudessem ficar posicionados um em frente ao outro, separados por uma mesa, que serviu de apoio para os cartões. A filmadora foi posicionada ao lado do participante a fim de registrar as 
respostas de nomeação do mesmo durante a tarefa. Toda a coleta aconteceu em um local reservado na instituição em que o idoso residia, o que permitiu o sigilo e privacidade durante a coleta.

\section{Procedimento de Coleta de Dados}

Foi realizado um delineamento de medidas repetidas (Cozby, 2006), no qual todos os participantes passaram pelas duas condições de ensino, com contrabalanceamento da ordem de apresentação das condições entre os participantes. O procedimento de ensino foi dividido em três fases, descritas na sequência.

Fase 1 - Avaliação Inicial. Essa fase teve como objetivo avaliar se e como o participante nomeava as imagens impressas nos cartões, e selecionar as imagens que ele não conseguia nomear a fim de utiliza-las na fase seguinte. Foram apresentadas aos participantes, individualmente, todos os 122 cartões, um por vez, e foi pedido que eles olhassem cada imagem e falassem o nome da mesma. O procedimento foi repetido duas vezes, em dias distintos. Considerou-se que o participante não sabia o nome das figuras impressas nos cartões quando o mesmo não nomeava a figura em nenhuma das duas apresentações. Ao final, foram selecionados 21 cartões, sete referentes a figuras que os participantes nomearam corretamente e 14 cartões referentes a imagens que os participantes não nomearam em nenhuma das apresentações (os cartões a serem utilizados nas fases seguintes, portanto, podiam variar entre os participantes. Os cartões utilizados eram referentes a objetos, tais como: geladeira, relógio, estátua e abajur.). Metade dos cartões que os participantes não sabiam nomear foram utilizados no ensino na condição FO e os demais na condição de ensino SR. A escolha dos cartões para cada condição de ensino foi feita por sorteio. 
Fase 2 - Ensino de Nomeação. A nomeação das figuras impressas nos cartões foi feita por meio dos procedimentos de FO e SR. Os participantes do G1 aprenderam as sete primeiras relações nome-figura por meio do FO e os demais cartões por SR; a ordem das condições foi inversa para o G2.

Condição de ensino por $\mathbf{F O}$. O ensino por FO iniciava com a seguinte instrução: "Eu irei mostrar para o(a) senhor(a) um cartão que tem uma figura desenhada e irei falar o nome desta figura. Em seguida, o(a) senhor(a) deve repetir esse nome. Nós faremos isto duas vezes. Em seguida, eu irei falar apenas parte do nome da figura, mas o(a) senhor(a) deve falar o nome completo da figura. A cada tentativa, eu irei diminuir a quantidade de silabas da palavra, porém o(a) senhor(a) deve falar a palavra inteira. Ao final, eu não irei falar palavra, mas o senhor deve dizer o nome da figura que eu estou mostrando. ”. A cada tentativa, se o participante falasse o nome da figura de forma correta, a pesquisadora dizia "Isso, é esse mesmo o nome" e seguia para a próxima tentativa; caso o participante errasse, a pesquisadora falava: "Não está correto" e repetia a tentativa. Cada correção aconteceu até cinco vezes. Se o participante continuasse errando, o ensino de tal palavra era suspenso e iniciava-se o ensino da próxima palavra. O ensino por FO iniciou-se com a apresentação de $100 \%$ da palavra, seguida de $75 \%, 50 \%, 25 \%$ e $0 \%$ da palavra, o que significa que, para cada palavra, foram organizadas quatro níveis de dicas. Considerando, por exemplo, a palavra "relógio", a mesma foi ensinada da seguinte forma: nas tentativas de $100 \%$ da palavra foi dito "relógio"; nas tentativas de $75 \%$ da palavra, "relógi"; nas tentativas de 50\%, "reló"; nas tentativas de $25 \%$ "re"; e nas tentativas de $0 \%$, nada foi dito. Foram conduzidas três tentativas com a dica $100 \%$, três sem dicas $(0 \%)$; para cada um dos demais tipos de dicas, foram apresentadas duas tentativas. No total, cada relação era ensinada em 12 tentativas (sem contar os eventuais procedimentos de correção necessários). 
Após a finalização do ensino de todas as sete relações nome-figura, foi realizado um teste de nomeação. Para isto, os sete cartões foram apresentados ao participante, um após o outro, e foi pedido que ele os nomeasse (“Que figura é essa?”). Essa apresentação final dos cartões foi feita no dia em que foi encerrado o treino, após a última tentativas de ensino, por duas vezes, em sequência, sem consequências diferenciais para acertos ou erros.

Condição de ensino por SR. O procedimento de ensino por SR também iniciava com a apresentação da instrução: "Eu irei mostrar para o(a) senhor(a) um cartão com uma imagem e irei falar o nome desta imagem. $O($ a) senhor (a) deve repetir a palavra logo em seguida. Depois, de tempos em tempos, eu irei pedir para o(a) senhor(a) me falar o nome da imagem que aparece no cartão". Na primeira tentativa, o cartão era apresentado e a pesquisadora dizia o seu nome; logo em seguida, pedia que o participante dissesse o nome da figura (e.g., "Esse é o relógio; qual o nome dessa figura?"). Como no ensino por FO, o ensino de cada relação era composto por 12 tentativas, que eram espaçadas no tempo: a segunda tentativa aconteceu 1s após a apresentação da palavra; as demais tentativas eram apresentadas em períodos progressivamente maiores entre as tentativas: $2 \mathrm{~s}, 4 \mathrm{~s}, 8 \mathrm{~s}, 16 \mathrm{~s}, 32 \mathrm{~s}, 1$ minuto (min), $2 \mathrm{~min}, 4 \mathrm{~min}, 8 \mathrm{~min}, 17 \mathrm{~min}$ e $34 \mathrm{~min}$. Cada tentativa começava com a pergunta da pesquisadora: “Qual o nome dessa figura?”. Entre as tentativas, a pesquisadora realizava com o participante alguma atividade que o mesmo julgasse interessante, como conversar, ouvir música ou realizar pintura. Se o participante nomeasse corretamente a figura, a pesquisadora dizia "Correto" e voltava a realizar a atividade. Caso o participante errasse a palavra, a pesquisadora dizia "Não está correto", falava o nome correto da palavra, pedia para que ele nomeasse a imagem, e a tentativa seguinte ocorria na duração do intervalo anterior àquele em que o erro foi cometido. Por exemplo, se o participante não soubesse nomear a figura na tentativa com intervalo de 
32s, a pesquisadora fazia a correção e a próxima tentativa ocorria após 16s da correção. Após o término do ensino das sete relações palavra-figura, todos os cartões foram reapresentados, um após o outro, por duas vezes, e foi pedido para que o participante nomeasse cada figura impressa nos cartões (teste de nomeação). Este procedimento era conduzido após o ensino da última relação. Os desempenhos dos participantes (corretos ou incorretos) nesse teste não foram consequenciados diferencialmente.

Fase 3 - Avaliação Final. Essa fase teve como objetivo avaliar a manutenção da aprendizagem de nomeação das figuras e aconteceu um dia após a finalização da Fase 2. Para tanto, foram selecionados sete cartões que os participantes demonstraram saber nomear na Fase 1 (cartões controle) e os 14 cartões utilizados nos dois procedimentos. Os cartões foram misturados e apresentados, um por vez, ao participante. A pesquisadora apenas pediu para que o idoso olhasse a imagem e falasse seu nome. A mesma sequência de 21 cartões foi apresentada duas vezes consecutivas e não houve correções ou consequências diferenciais para acertos e erros.

\section{Procedimento de Análise de Dados}

Foram analisados os desempenhos dos participantes no teste de nomeação realizado ao final de cada procedimento da Fase 2, e na Fase 3 (nessa fase, apenas com os cartões que foram ensinados na Fase 2). Os participantes tinham duas tentativas de nomeação de cada uma das setes figuras, em cada fase. Para cada acerto foi computado um (1) ponto. Erros não foram pontuados. A pontuação máxima possível era 14 em cada procedimento.

Para comparar diferenças nos desempenhos dos participantes nos dois procedimentos de ensino em ambas as fases, realizou-se a análise estatística por meio da ANOVA, seguido pelo teste post-hoc de Newman-Keuls. Para o teste estatístico aplicado 
a diferença foi considerada significativa quando $p \leq 0,05$. Os dados foram apresentados como média \pm erro padrão da média $(\mathrm{EPM})$ e foram analisados usando o software Statistica 12 (StatSoft Inc., Tulsa, OK, USA).

\section{Concordância entre Observadores}

Um segundo juiz com formação em Psicologia assistiu 50\% dos vídeos dos testes de nomeação (Fases 2 e 3) a fim de verificar a resposta emitida pelos participantes e comparar com o registro da pesquisadora. A concordância foi de $100 \%$.

\section{Resultados}

O ensino das palavras por meio do procedimento FO para todos os participantes, independentemente da ordem de apresentação das condições, aconteceu em quatro dias. Em cada um dos três primeiros dias foram ensinadas duas relações palavra-figura; no quarto dia foi ensinada uma relação e realizado o teste de nomeação das figuras ensinadas. O ensino das palavras por meio do SR para todos os participantes também aconteceu em quatro dias, sendo que em cada um dos três primeiros foram ensinadas duas relações e no último foi ensinada a última relação e realizado teste de nomeação dos sete cartões. $\mathrm{O}$ tempo médio de ensino de cada relação do procedimento de FO foi de 30 minutos, enquanto que o tempo médio de duração de SR foi de 70 minutos. O procedimento de correção foi utilizado para todos os participantes, pelo menos em uma das condições. Para o procedimento de $\mathrm{FO}$, quatro participantes necessitaram de uma a duas correções; no SR, todos os participantes necessitaram de uma a quatro correções.

A Figura 1 apresenta a média de nomeações corretas de todos os participantes (G1 e G2) nos testes de nomeação realizados nas duas condições de ensino (FO e SR) e nas duas fases: logo após o ensino e na manutenção (realizado logo após a finalização das 
duas condições). O número máximo de acertos por participante era 14 para cada condição (duas apresentações de cada um dos sete cartões). A média de nomeações corretas no teste de nomeação da Fase 2 na condição de ensino por FO foi de 9,25 e na condição SR foi de 9,5. A média de nomeações corretas na Fase 3 foi de 7,8, tanto na condição FO quanto na condição SR. A análise estatística revelou que não houve diferença estatística entre o número de palavras nomeadas na fase de ensino em comparação à fase de manutenção tanto na condição de $\mathrm{FO}(\mathrm{P}=0,16)$ quanto na $\mathrm{SR}(\mathrm{P}=0,14)$, ou seja, as palavras ensinadas para todos os participante por meio de FO mantiveram-se estáveis no repertório dos participantes; e o mesmo aconteceu com as palavras ensinadas por SR.

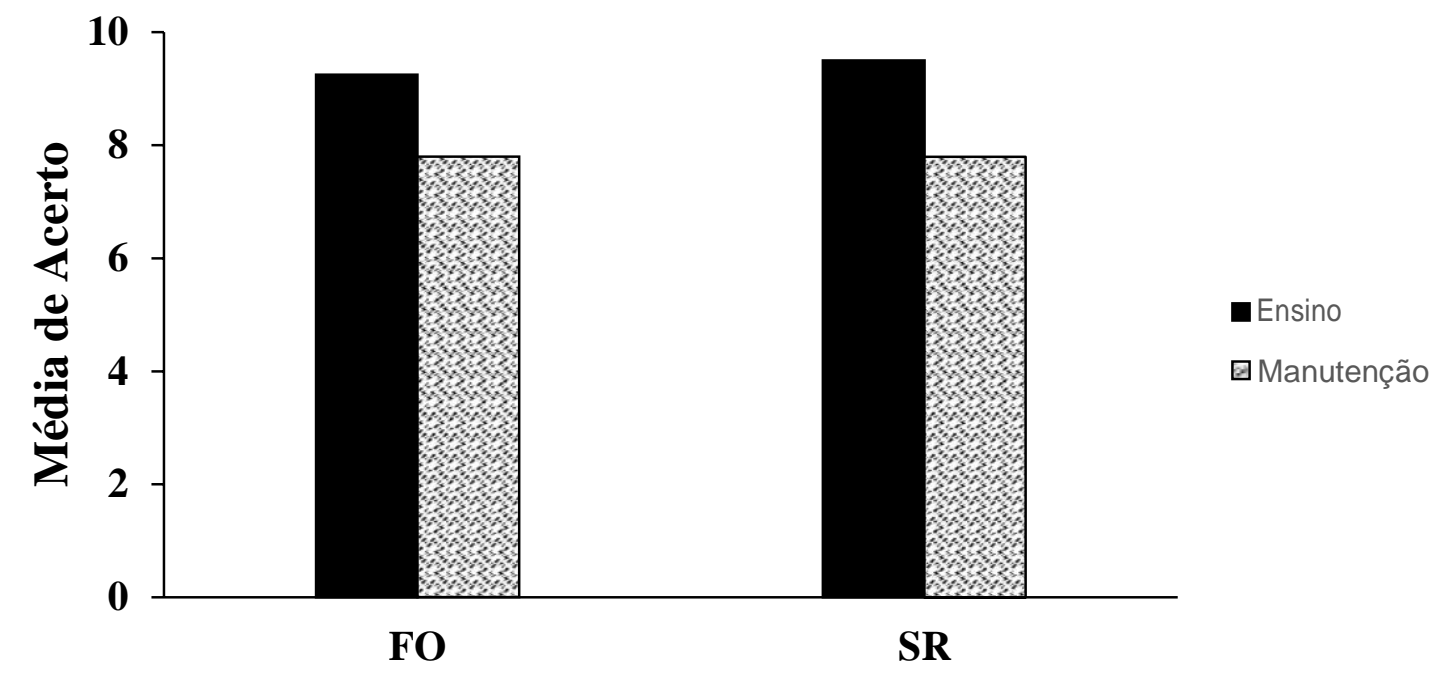

Figura 1: Média de acertos de todos os participantes nas duas condições de ensino (FO e SR) nos testes de nomeação de figuras realizados nas Fase 2 e 3.

A Figura 2 apresenta o número de acertos de cada participante no teste de nomeação que aconteceu ao término da Fase 2, para cada condição de ensino. Os participantes do G1 a realizaram primeiro condição de ensino por FO e depois por SR, enquanto os participantes do G2 inciaram pela condição de ensino por SR e passaram, em seguida, pela condição FO. O número máximo de acertos possíveis por condição era 14. 


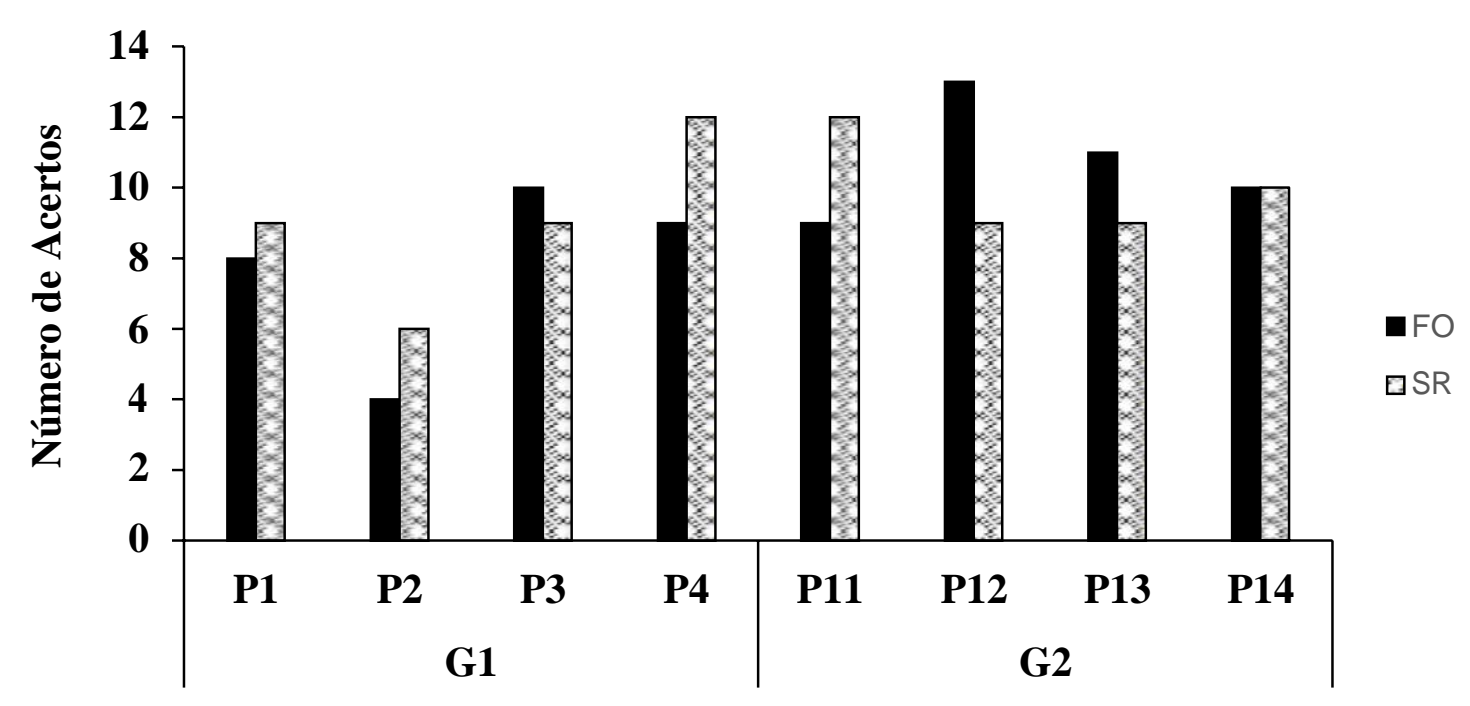

Figura 2: Número de acertos dos participantes individuais nos testes de nomeação da Fase 2 na condição de ensino por Fading Out (FO) e por Spaced Retrievel (SR). Os participantes do G1 iniciaram pela condição de ensino FO e os do G2 por SR.

Observa-se na Figura 2 que, com exceção de P2, todos os participantes realizaram nomeações corretas em pelo menos metade das tentativas. Três participantes do G1 (P1, P2 e P4) demonstraram melhor desempenho no teste de nomeação após o ensino por SR (segunda condição), em comparação ao ensino por meio de FO. A vantagem do SR sobre o FO foi observada em apenas um participante do G2 (P11). Nesse grupo, os participantes P12 e P13 demonstraram melhor desempenho em FO e P14 demonstrou o mesmo desempenho em ambos procedimentos de ensino. A análise estatística, porém, não identificou diferença significativa entre os desempenho dos participantes nos dois testes de nomeação, indicando que ambos os procedimentos promoveram níveis semelhantes de aprendizagem da nomeação $(\mathrm{p}=0,4)$. A média de acertos dos participantes no teste de nomeação da Fase 2 foi de 7,72 após FO e 9,0 após SR para o G1; e de 10,75 após FO e 10 após $\mathrm{SR}$, para o $\mathrm{G} 2$.

A Figura 3 apresenta o desempenho individual dos participantes na Fase 3 (teste de manutenção de nomeação). Apesar de, na Fase 3, ter sido testado o desempenho de 
nomeação dos participantes para todas as figuras ensinadas e para as figuras controle, pode-se considerar como "manutenção de aprendizagem" apenas o desempenho dos participantes em relação aos cartões ensinados na primeira condição de ensino (FO para G1 e SR para G2), que ocorreu, em média, cinco dias antes da realização da Fase 3.

No G1, que iniciou o treino com o procedimento de FO e em seguida realizou o treino de nomeção por meio do SR, os participantes P1, P2 e P3 apresentaram um número maior de nomeações corretas dos cartões que foram ensinados por FO (entre sete e dez), em comparação àqueles ensinados por SR (entre duas e sete). Os participantes do G2, que iniciaram o treino por meio do procedimento de SR, seguido pelo FO, apresentaram desempenhos oposto: P11, P12 e P13 apresentaram melhor desempenho com as figuras ensinadas por meio de SR (entre oito e 11) do que por meio de FO (entre sete e nove). O participante P14 demonstrou desempenho igual em ambas as condições (10 acertos). Observa-se, com isto que, com exceção de P4 e P14, todos os participantes apresentaram número maior de acertos em relação às figuras aprendidas por meio da primeira condição de ensino a que foram expostos. Apesar dessas diferenças, a análise estatística realizada demonstrou que não há diferenças significativas no desempenho de retenção daquilo que foi aprendido por FO em comparação ao que foi aprendido por $\operatorname{SR}(F(1,12)=2,4682$; $\mathrm{p}=0,11)(\mathrm{F}(1,12)=1,0716 ; \mathrm{p}=0,39)$. Os idosos de ambos os grupos nomearam todas as imagens "controle". 


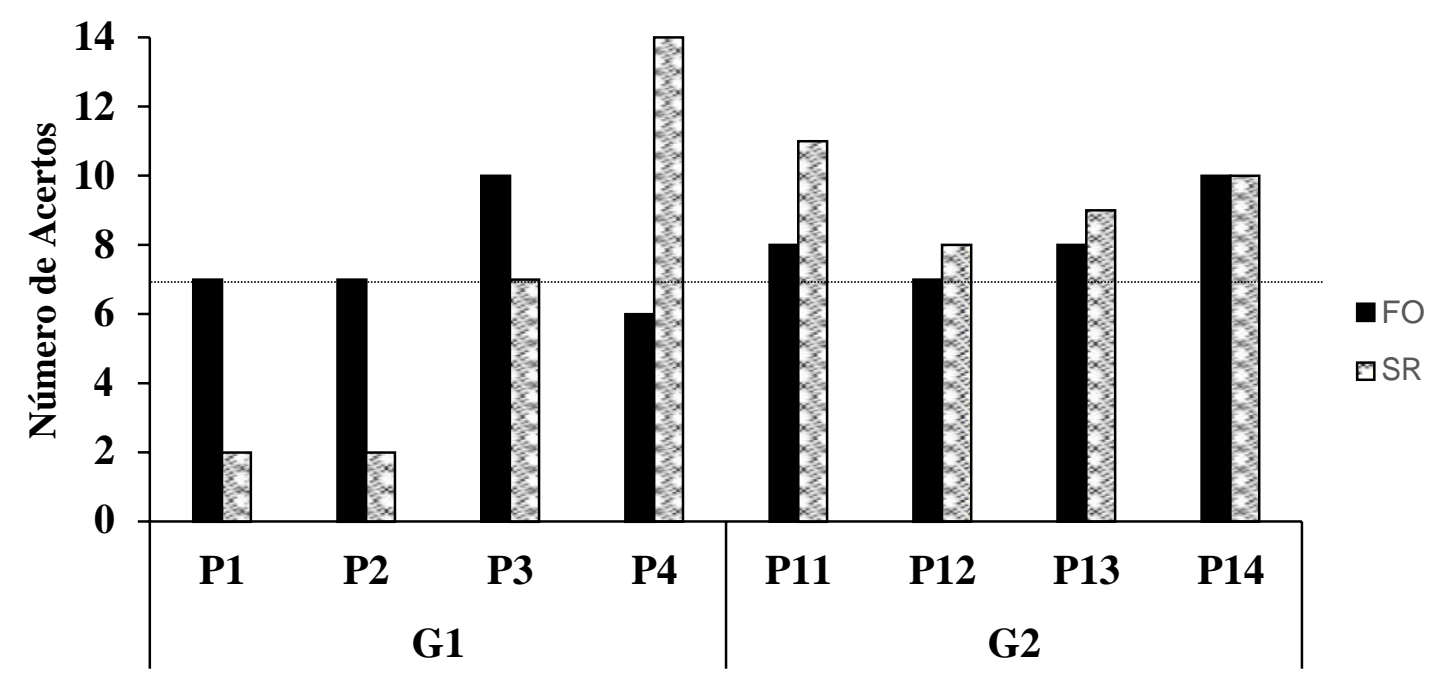

Figura 3: Número de acertos dos participantes individuais nos testes de nomeação da Fase 3 na condição de ensino por Fading Out (FO) e por Spaced Retrievel (SR).

A média de acertos dos idosos do G1 na Fase 3 (manutenção) foi 7,5 para as palavras ensinas por meio de FO e 6,25 para as palavras ensinadas por SR. A média de acertos dos idosos do G2 foi 8,25 em FO e 9,5 em SR.

\section{Discussão}

O objetivo deste estudo foi comparar a aprendizagem/recuperação do desempenho de nomeação de figuras por meio dos procedimentos de SR e de FO de dicas, em pacientes com indicativos de DA. De forma geral, observou-se que ambos os procedimentos foram eficazes em promover o desempenho de nomeação das figuras ensinadas, uma vez que os participantes mostraram desempenho semelhante nos testes conduzidos logo após o ensino (Fase 2) e na manutenção (Fase 3), tanto para as palavras aprendidas por FO como por SR.

Esses resultados remetem a duas considerações importantes. Uma delas refere-se à própria eficácia individual dos procedimentos testados. A segunda, aos motivos pelos quais esses procedimentos foram eficientes em produzir a aprendizagem/recuperação de 
repertório aqui descrita, que podem estar relacionados: (a) ao fato dos dois procedimentos de ensino escolhidos ( $\mathrm{SR}$ e FO) poderem ser considerados como procedimentos que previnem a ocorrência de erros; (b) os estímulos selecionados para a pesquisa poderem ter favorecido a aprendizagem por serem considerados "familiares", a despeito dos idosos não conseguirem nomeá-los; e (c) a tarefa consistia na recuperação de um repertório que provavelmente estava instalado no repertório verbal do participante, mas que foi "perdido" devido à DA.

Diferentes estudos têm comparado procedimentos de ensino para diversos desempenhos de idosos com DA. O SR, em especial, tem recebido muita atenção na comparação com outros procedimentos (Anderson, Arens, Johnson, \& Coppens, 2001; Provencher, et al., 2008; Cherry \& Simmons-D’Gerolamo, 2005; Haslam et al., 2011), e em associação com outras técnicas (Benigas \& Bourgeois, 2016; Lekeu, Wojtasik, Van der Linden, \& Salmon, 2002; Loewenstein, Acevedo, Czaja, \& Duara, 2004; Thivierge et al, 2008). O FO tem sido menos explorado pela literatura e, em geral, é utilizado em associação com outras técnicas (e.g., Clare et al., 2000; Clare, et al., 2002; Haslam et al., 2010). Não foram encontrados, no entanto, estudos que comparassem de forma direta o SR e o FO.

Os resultados obtidos no presente estudo corroboram os achados destas pesquisas citadas e de outras que também demonstram a eficácia de ambos os procedimentos testados (Provencher, et al., 2008; Bourgeois, et al., 2003; Clare, et al., 2000; Gradmaison \& Simard, 2003; Haslam, Moss, Hodder, 2010; Haslam, et al., 2011; Hawley, et al., 2008). No entanto, o presente estudo não demonstrou que um procedimento é superior ao outro em termos de resultados na aprendizagem ou na manutenção do desempenho aprendido. Esse resultado é importante especialmente se se considerar que, apesar dos resultados terem sido similares, pode haver uma vantagem no uso do FO em comparação 
com o SR pelo tempo de duração de cada sessão de ensino. Apesar de cada relação ter sido ensinada em um conjunto de 12 tentativas programadas (sem contar as tentativas de correção), o tempo médio de ensino de cada relação na condição FO foi menos da metade do tempo dispendido no ensino de cada relação na condição SR. Em termos práticos, isso representa um ganho considerável ao se pensar em intervenções planejadas com idosos em ambientes institucionais ou em consultórios. A escolha de quais procedimentos devem ser utilizados, em que contextos e para quais repertórios específicos ainda é um tema em discussão (Haslam et al., 2010). Os resultados aqui apresentados são uma contribuição aos esforços em construir evidências que possam nortear os profissionais nessas escolhas.

No entanto, também é preciso considerar um conjunto de fatores que podem ter concorrido, não apenas para que não tenham sido encontradas diferenças entre os procedimentos, mas também para que a aprendizagem tenha ocorrido de forma similar. O primeiro deles é que, tanto o FO quanto o SR podem ser considerados procedimentos que previnem a ocorrência de erros, o que tem sido referido pela literatura como uma condição de ensino importante para a aprendizagem (Melo, Hanna, \& Carmo, 2014).

Procedimentos para a aprendizagem sem erro têm sido utilizados com diferentes populações, em diferentes contextos e, de forma geral, têm sido eficazes para a aprendizagem (e.g., Medeiros, Antonakopoulou, Amorin, \& Righetto, 1997; Melchiori, de Souza, de Rose, 1992; Souza \& de Rose, 2006). A caraterística desses procedimentos é o ensino gradual dos repertórios, garantindo ao máximo a ocorrência de desempenhos bem-sucedidos por parte dos participantes (Melo \& Hanna, 2014). O SR, por exemplo, caracteriza-se por ser um procedimento de ensino em que o participante é apresentado ao modelo de desempenho requerido (e.g., a resposta de nomeação) e que tal desempenho é requerido de forma repetida, em intervalos inicialmente muito curtos e que se expandem à medida em que as respostas corretas são emitidas. Com isso, são apresentadas 
oportunidade frequentes de responder (estímulos discriminativos), que evocam o desempenho esperado que, por sua vez, é consequenciado diferencialmente em esquema contínuo (Catania, 1999). O espaçamento gradual da apresentação da ocasião para responder favorece o fortalecimento do desempenho, assim como a garantia da correção imediata de eventuais erros e diminuição do espaçamento entre as tentativas quando da ocorrência de uma resposta incorreta.

No procedimento de FO ocorre a "transferência do controle do responder" (Catania, 1999) da palavra ditada pela pesquisadora para a figura em si: inicialmente, o participante deveria apenas repetir o nome correto da figura (emissão de uma resposta verbal idêntica ao estímulo verbal emitido pela pesquisadora); na sequência, e à medida em que a dica verbal era retirada, o participante deveria falar o nome da figura sob controle da dica e da figura; finalmente, esperava-se que apena a apresentação da figura evocasse a resposta correta (e, nesse sentido, ocorria a transferência do controle do responder). Da mesma forma que no SR, o feedback imediato do desempenho do participante, bem como a retirada gradual da dica e a garantia de correção de respostas incorretas são parte do que se caracteriza como procedimento de ensino sem erro.

Outro fator que pode ter contribuído para a aprendizagem dos desempenhos dos participantes desse estudo é a natureza familiar dos estímulos empregados. Nos trabalhos anteriormente descritos, assim como neste estudo, os idosos foram expostos a tarefas de nomeação, pois aprenderam a relação "face-nome" de pessoas ou objetos, respectivamente. Contudo, nos estudos de Provencher, et al., (2008), Haslam, et al. (2008) e Haslam e Hodder (2010), os idosos aprenderam a nomear imagens de pessoas com quem não tinham contato, ou seja, aprenderam algo novo e neste estudos, os idosos aprenderam a nomear imagens de objetos comuns a seu dia-a-dia, como relógio ou geladeira, ou 
melhor, a tarefa não propôs a aprendizagem de algo novo, mas sim o reestabelecimento de uma relação que foi perdida em função da DA.

Muitas pesquisas ensinam desempenhos e/ou relações novas (Steingrimsdottir \& Artzen, 2011a; 2011b), enquanto outras se concentram em recuperar desempenhos que antes da DA faziam parte do repertório dos indivíduos (Camara, Ducatti \& Schmidt, 2017; Dixon, Becker, \& Sadowski, 2011; Ducatti \& Schmidt, 2016; Souza, 2011). Apesar de não haver estudos comparando esses dois tipos de aprendizagem, é preciso considerar que certamente há processos e implicações diferentes nesses dois tipos de atividades. Assim, talvez o grau de familiaridade das imagens ensinada pode ter contribuído para que o SR, no presente estudo, não tenha se mostrado superior ao FO, pois os idosos não aprenderam algo totalmente novo; eles foram expostos a uma situação de recuperação de repertório. Assim, talvez o SR seja superior aos demais procedimentos quando aquilo que é ensinado refere-se a uma aprendizagem totalmente nova.

Goulart, Delage, Rico e Brino (2013) definem aprendizagem como a emissão de um comportamento que nunca esteve no repertório comportamental do indivíduo, ou seja, um comportamento novo ou um comportamento modificado, que foi instalado no repertório comportamento do indivíduo com determinada topografia, mas que modificouse com alguma variável. A aprendizagem pode ser mais fácil ou difícil a depender do procedimento utilizado para ensinar e dos estímulos envolvidos no ensino, assim, os bons resultados deste estudo podem ter ocorrido porque os procedimentos utilizados facilitaram a recuperação de um repertório. Independentemente dessa questão, porém, é preciso considerar que a recuperação de repertórios perdidos em função da DA é um objetivo de reabilitação importante e que os resultados aqui apresentados são de grade interesse. 
Todos os estudos que propõem o ensino de estímulos familiares, como a relação face-nome ou a execução de atividades relacionadas à vida diária, como atender um telefone, têm interesse em auxiliar os pacientes a manter a independência no seu cotidiano. Esse objetivo é fundamental em termos práticos e, nesse sentido, a pesquisa de formas de intervenção rápidas e eficientes é um objetivo muito importante na área de reabilitação de idosos com DA. Além disso, a utilização de estímulos familiares também parece favorecer a aprendizagem de outros tipos mais complexos de relação entre estímulos (Artzen, 2012; O’Connor, Rafferty, Barnes-Holmes, \& Barnes-Holmes, 2009).

Em termos de condições de intervenção, é preciso considerar, também, que ambos os procedimentos de aprendizagem sem erro garantiam que o estímulo discriminativo (imagem) que controlou a resposta de nomeação fosse apresentado de forma direta, sem a presença de estímulos concorrentes ou que pudessem interferir no controle do comportamento. Assim, na situação experimental de ambas as condições de intervenção os estímulos discriminativos foram apresentados sozinhos (e não entre outros, como na tarefa de emparelhamento ao modelo, por exemplo), o que favoreceu com o que participante ficasse sob controle do estímulo específico e emitisse a resposta adequada. Outros procedimentos de ensino, em especial o de tentativa e erro, pode não controlar tão bem o responder, porque apresentam os estímulos-alvo (discriminativos) juntamente com estímulos “incorretos” na situação (estímulos delta), o que pode dificultar a aprendizagem dos idosos, como já verificado em outros estudos (e.g., Steingrimsdottir \& Arntzen, 2011).

O presente estudo apresenta algumas limitações que podem ser superadas em estudos futuros. Uma delas é a ausência de tarefas de generalização, ou seja, não foram apresentados aos idosos objetos tridimensionais referentes às figuras ensinadas para a realização de um teste de nomeação generalizada. Além disso, é importante que se 
verifique a manutenção da aprendizagem em intervalos maiores de tempo, com medidas de follow up mais longas.

Deve-se considerar também que apesar dos bons resultados que a literatura científica apresenta sobre o FO e, especialmente, sobre o SR, todos os estudos utilizam objetos familiares para os procedimentos de ensino, ensinam relações face-nome ou um comportamento que o idoso deseja emitir, mas não consegue mais (Dunn \& Clare, 2007; Hawley, et al., 2008). Por um lado, essas medidas são importantes porque ensina-se algo funcional para o idoso mas, por outro, não esclarecem se os procedimentos também são eficazes para o ensino de habilidades mais complexas, como falar endereços ou dar informações pessoais, que favoreceria uma orientação temporal mais adequada. Tarefas dessa natureza devem ser estudadas em pesquisas futuras, ampliando o conhecimento atual sobre técnicas para ensino de repertórios específicos para idosos com DA.

O presente estudo indicou que não há diferenças, em termos de resultados obtidos, entre os procedimentos de ensino por FO e por SR no ensino do desempenho de nomeação. No entanto, por ser um procedimento mais rápido, o FO apresenta uma vantagem de ordem prática sobre o SR, no ensino de dessa habilidade. Comparações entre esses procedimentos de ensino relacionadas a outros desempenhos devem ser ainda pesquisadas. Considerando que o número de idoso têm aumentado em todo o mundo e que cada vez mais nota-se também os crescentes casos de demência, em especial a DA, torna-se importante o desenvolvimento de procedimentos de intervenção (para as funções cognitivas e/ou comportamentos modificados pela demência), uma vez que este é o meio pelo qual o idoso pode recuperar informações de sua vida que são alteradas ou destruídas devido a demência e obter assim melhor qualidade de vida. 
Considerações finais 
O objetivo geral deste trabalho foi investigar o efeito de diferentes tipos de estratégias de intervenção (apoio visual, FO e SR) sobre a produção de diferentes desempenhos de falante (reprodução de narrativas ouvidas, narrativa de uma história com apoio visual - uma história em quadrinhos - e nomeação de figuras), em idosos com diagnóstico de DA leve (em fase inicial). Os resultados mostraram que o objetivo geral do trabalho foi atingido, uma vez que os três estudos propostos forneceram dados sobre o efeito das estratégias de intervenção investigadas sobre os diferentes desempenhos de falante investigados. De forma geral, os resultados do Estudo 1 indicaram que o apoio visual fornecido não foi eficiente para a melhora na reprodução de uma narrativaouvida; os resultados do Estudo 2 indicaram que as dicas (perguntas) melhoraram a qualidade das narrativas dos idosos com DA; e os resultados do Estudo 3 mostraram igual eficácia do FO e do SR para o ensino de nomeação de figuras, com uma vantagem prática do FO sobre o SR (tempo de aplicação).

Muitos estudos têm descrito Programas de Estimulação Cognitiva (PEC) para idosos com demência (e.g., Apóstolo, et al., 2013; Botino, et al., 2002; Castro, 2011; Costa, 2012; Da-Silva et al., 2013; Gonçalves, 2012; Melo, 2008; Ramos, Mónico, Parreira, Fonseca, \& Dixe, 2017; Tavares, 2007). O PEC nada mais é do que a aplicação de diferentes técnicas com o objetivo de estimular, recuperar ou aprimorar as funções cognitivas (Castro, 2011; Costa, Bertola, \& Malloy-Diniz, 2017). De forma geral, os estudos que propõem programas de reabilitação cognitiva seguem a mesma estrutura, que consiste na identificação da queixa, avaliação do sujeito, descrição da intervenção e aplicação da mesma, e avaliação após a intervenção (Monteiro, Grove, \& Fuentes, 2013). Este modelo parece ser eficiente, uma vez que avalia o idoso antes e depois da intervenção e verifica o impacto na queixa. 
No entanto, a dificuldade dos PECs consiste no fato de não haver um modelo estruturado de intervenção e de que a proposta de muitas técnicas juntas não permite a análise da contribuição de cada uma delas para os resultados obtidos. Jean, Bergeron, Thivierge, e Simard (2010) destacam isto em uma revisão sistemática sobre PEC para idosos com comprometimento cognitivo. Os autores identificaram 15 artigos sobre este tema e afirmaram que os dados obtidos demonstram a eficácia dos PEC, contudo, ressaltam que os estudos não demonstraram padrão em relação ao tamanho da amostra, tipo de metodologia, formato da intervenção (em grupo ou individual) e técnica utilizada e por isto advertem que é preciso haver um consenso a respeito do melhor direcionamento a fim de promover diretrizes que possivelmente melhorariam esta modalidade de tratamento não farmacológico e identificariam as melhores técnicas para auxiliar a reabilitação dos pacientes com e sem demência.

A Análise do Comportamento, por sua vez, tem longa tradição no desenvolvimento de procedimentos de ensino de diversos tipos de repertório, inclusive aqueles incluídos na literatura nas chamadas "funções cognitivas", incluindo aqui os repertórios verbais. As pesquisas sob esta orientação teórica enfatizam que os procedimentos de ensino devem ser utilizados no contexto das necessidades de cada paciente, avaliadas por meio da Análise Funcional, que é uma ferramenta eficiente, tanto para identificar as necessidades de intervenção e as variáveis de controle implicadas nessas necessidades, quanto para indicar as intervenções que podem produzir mudanças que melhorem a qualidade de vida dos idosos com DA e de seus cuidadores (McCurry \& Drossel, 2011). Partindo desse pressuposto, talvez a questão mais importante em procedimentos de reabilitação de idosos com DA não seja a definição de protocolos rígidos, aplicáveis a todos os pacientes, mas sim o desenvolvimento de procedimentos de 
ensino com fortes evidências de eficácias, que possam ser utilizados pelos profissionais na formulação de programas individualizados para idosos com DA.

Procedimentos de ensino, como o FO e o SR, têm demonstrado eficácia na recuperação dos déficits causados pela demência, contudo é importante ressaltar a necessidade de se ampliar a pesquisa no ensino de habilidades funcionais para idosos, aquelas necessárias para manutenção de sua independência e autonomia. Por um lado, entende-se a necessidade de se realizar pesquisas básicas, com repertórios bem delimitados, a fim de se esclarecer questões relativas aos processos envolvidos nas perdas decorrentes da demência, como é o caso dos estudos de Steingrimsdottir e Arntzen (2011, 2011b, 2015, 2017), além de se testar procedimentos de ensino em habilidades simples, cujo controle de variáveis seja adequado (e.g., Dixon et al., 2011). Por outro, é importante ampliar as pesquisas sobre desempenhos de idosos em situações cotidianas, que lhes permitam melhorar sua interação social e a execução de tarefas do dia a dia, utilizandose de estímulos e situações significativas para os idosos. Se a demência já é uma condição que dificulta a aprendizagem, testar procedimentos utilizando estímulos familiares aos idosos pode garantir, como ganho adicional ao conhecimento científico, benefícios diretos aos idosos.

As pesquisas realizadas com a população idosa, em especial a população com DA, têm mostrado que eles são sensíveis a diferentes contingências de ensino e aprendem novos comportamentos (verbais ou não verbais), desde que as condições antecedentes e consequentes sejam programadas de forma adequada (Aggio \& Domeniconi, 2012; Goyos, et al., 2012; Haydu \& Morais, 2009; Haydu, Omote, Vicente, Aggio, \& Paula, 2009; Sartori, 2008; Souza, 2011; Steingrimsdottir \& Arntzen, 2011; 2011b).

No caso da presente pesquisa, os três repertórios investigados, apesar de poderem ser descritos como "repertórios verbais", têm diferentes variáveis de controle. O 
desempenho de recontar uma história ouvida, por exemplo, focalizado no Estudo 1, requer que o indivíduo fique sob controle de uma narrativa oral, que tem uma sequência específica, marcada por um conjunto de personagens ou eventos que se sucedem e que conduzem a um desfecho. Após ouvir a narrativa, o comportamento de recontar a história demanda que o indivíduo não apenas fique sob controle da sequência de eventos descritos na história, mas que emita as palavras correspondentes a esses eventos (e.g, referir-se aos personagens como "velho homem" e "menino") e que cada trecho/fato narrado seja ocasião para a narrativa do próximo, como em uma cadeia de respostas (Catania, 1999). Narrar uma história em quadrinhos, por outro lado (Estudo 2), apesar de topograficamente se assemelhar ao desempenho anterior, é um comportamento sob controle de estímulos diferente e demanda um conjunto de comportamentos distintos. $\mathrm{O}$ indivíduo precisa inspecionar cada ilustração, identificando os aspectos críticos de cada uma, que se relacionam ao quadro anterior e/ou seguinte. Em seguida, ou concomitantemente, precisa ficar sob controle de alterações que ocorrem nas cenas a cada quadrinho, de forma que o conjunto de quadrinhos forme uma história encadeada. Finalmente, para narrar a história, o indivíduo precisa emitir as palavras correspondentes aos personagens, objetos e ações presentes nos diferentes quadros (tatear), para o encadeamento dos eventos retratados em cada figura.

Esse tipo de análise é importante por mostrar os diversos tipos de controle envolvidos em cada tipo de repertório verbal complexo, e por indicar os tipos de contingências de ensino que devem ser planejadas nas intervenções. Sem essa análise, corre-se o risco de implementar procedimentos que aparentemente "não dão certo" ou não se mostram eficientes, não pelo seu formato, mas porque não são atendem às condições específicas dos comportamentos que estão sendo estudados. Goyos, et al. (2012) afirmam que as intervenções comportamentais destinadas a idosos apresentam 
resultados tão bons quanto as intervenções realizadas em outras populações. Isto sugere que a condição biológica, i.e, a demência, apesar de produzir prejuízos no desempenho dos idosos, não é um impedimento ao desenvolvimento de intervenções, mas que é a análise minuciosa dos objetivos da intervenção que indicarão os melhores procedimentos a serem adotados.

Ainda é necessário que muitos estudos sejam realizados. Necessita-se compreender melhor as variáveis ambientais que controlaram os déficits apresentados por idosos com DA, assim como as variáveis ambientais e procedimentos de ensino que poderiam auxiliar na recuperação desses déficits, melhorando assim as condições e a qualidade de vida de idosos acometidos por transtornos neurocognitivos. 
Referenneias 


\section{Referências}

Aggio, N. M., \& Domeniconi, C. (2012). Formação e manutenção de classes de estímulos equivalentes: um estudo com participantes da terceira idade. Acta Comportamentalia, 20, 29-43.

Aggio, N. M., Ducatti, M. de Rose, J. C. (2018). Cognition and language in dementia patients: Contributions from behavior analysis. Behavioral Interventions, 33, 1-14. doi: 10.1002/bin.1527.

Alves, K. R. S., de Assis, G. J. A., Kato, O. M., \& Bruno, A. L. de F. (2011). Leitura recombinativa após procedimentos de fading in de sílabas das palavras de ensino em pessoas com atraso no desenvolvimento cognitivo. Acta Comportamentalia, 19(2), 183-203.

Alzheimer's Disease International. Relatório sobre a doença de Alzheimer no mundo. (2009).

American Psychiatric Association. (2013). Diagnostic and statistical manual of mental disorders (5th ed.). Washington, DC: Author.

Anderson, J., Arens, K., Johnson, R., \& Coppens, P. (2001). Spaced retrieval vs. memory tape therapy in memory rehabilitation for dementia of the Alzheimer's type. Clinical Gerontologist, 24(1-2), 123-140. doi: 10.1300/J018v24n01_09

Andrade, C. R. F.; Béfi-Lopes, D. M.; Fernandes, F. D. M.; Wertzner, W. H. ABFW: Teste de linguagem infantil nas áreas de Fonologia, Vocabulário, Fluência e Pragmática. Carapicuiba (SP): Pró-Fono, 2000. 90 p.

Andrade, S. M., Mendonça, C. T. P. L., Pereira, T. C. L., Fernandez-Calvo, B., Araújo, R. C. N., \& Alves, N. T. (2016). Adjuvant transcranial direct current stimulation for treating Alzheimer's disease: A case study. Dementia \& Neuropsychologia, 10(2), 156-159. doi.org/10.1590/S1980-5764-2016DN1002013

Arntzen, E. (2006). Delayed matching to sample: Probability of responding in accord with equivalence as a function of different delays. The Psychological Record, 56, 135-167. doi: 10.1007/BF03395541.

Arntzen, E. (2012). Training and testing parameters in formation of stimulus equivalence: methodological issues. European Journal of Behavior Analysis, 13, 123-135. doi: 10.1080/15021149.2012.11434412.

Ash, S., Moore, P., Vesely, L., \& Grossman, M. (2007). The decline of narrative discourse in Alzheimer's disease. Brain and Language, 103(1/2), 181-182. doi: 10.1016/j.bandl.2007.07.105.

Azevedo, P. G., Landim, M. E., Fávero, G. P., \& Chiappetta, A. L. M. L. (2009). Linguagem e memória na doença de Alzheimer em fase moderada. Revista CEFAC, 12(3), doi: 10.1590/S1516-18462010005000001.

Bagaiolo, L. F. \& Micheletto, N. (2004). Fading e exclusão: aquisição de 
discriminações condicionais e formação de classes de estímulos equivalente. Temas em Psicologia, 12 (2), 168-185.

Balota, D. A., Duchek, J. M., Sergent-Marshall, S. D., \& Roediger, H. L., III. (2006). Does expanded retrieval produce benefits over equal-interval spacing? Explorations of spacing effects in healthy aging and early stage Alzheimer's disease. Psychology and Aging, 21, 19-31. doi: 10.1037/0882-7974.21.1.19.

Barbosa, C. M. O., \& Martin, J. I. G. (2012). Ajudas externas à memória na intervenção em pessoas idosas com comprometimento mnésico. Psicologia: Reflexão e Crítica, 25(2), 320-329. doi: 10.1590/S0102-79722012000200014

Baumgart, M., Snyder, H. M., Carrillo, M. C., Fazio, S., Kim, H., \& Johns, H. (2015). Summary of the evidence on modifiable risk factors for cognitive decline and dementia: a population-based perspective. Alzheimer \& Dementia, 11, 718-126, doi: 10.1016/j.jalz.2015.05.016

Beilke, H. M. B. \& Pinto, R. do C. N. (2010). A narrativa na Demência de Alzheimer: reorganização da linguagem e das "memórias" por meio de práticas dialógicas. Estudos linguísticos, 39(2), 557-567.

Benigas, J. E., \& Bourgeois, M. (2016). Using spaced retrieval with external aids to improve use of compensatory strategies during eating for persons with dementia. American journal of speech-language pathology, 25(3), 321-334. doi: 10.1044/2015_AJSLP-14-0176

Berkowitz, S., Sherry,P. J., \& Davis, B. A. (1971). Teaching self-feeding skills to profound retardates using reinforcement and fading procedures. Behavior Therapy, 2(1), 62-67.

Beydoun, M. A., Beydoun, H. A., Gamaldo, A. A., Teel, A., Zonderman, A. B., \& Wang, Y. (2014). Epidemiologic studies of modifiable factors associated with cognition and dementia: Systematic review and meta-analysis. Public Health, 14: 643. doi: 10.1186/1471-2458-14-643.

Bourgeois, M. S. (1990). Enhancing conversations skills in patients with Alzheimer's disease using a prosthetic memory aid. Journal of Applied Behavior Analysis, 23, 29-42. doi: 10.1901/jaba.1990.23-29

Bourgeois, M. S. (1993). Effects of memory aids on the dyadic conversations of individuals with dementia. Journal of Applied Behavior Analysis, 26, 77-87. doi: 10.1901/jaba.1993.26-77

Bourgeois, M. S., Camp. C., Rose. M., Blanche, W., Malone, M., Carr, J., et al (2003). A comparison of training strategies to enhance use of external aids by persons with dementia. Journal of Communication Disorders, 36(5), 361-378. doi: 10.1016/S0021-9924(03)00051-0

Boyle, J. R. \& Hughes, C. A. (1994). Effects of self-monitoring and subsequent fading of external prompts on the on-task behavior and task productivity of 
elementary students with moderate mental retardation. Journal of Behavior Education, 4: 439, 439-457. doi: 10.1007/BF01539544

Brandão, L. (2005). Perfil discursivo e interativo de pessoas com Doença de Alzheimer. Tese de Doutorado. Universidade Federal do Rio Grande do Sul.

Brandão, L., Castelló, F. G., van Dijk, T. A., Parente, M. A. M. P., \& Peña-Casanova, J. (2009). Cognition and discourse production in Alzheimer's disease: using informative prompts. Psychology \& Neuroscience, 2(2), 99-107. doi: 10.3922/j.psns.2009.2.006.

Brandão, L., \& Parente, M. A. de M. P. (2011). Doença de Alzheimer e a aplicação de diferentes tarefas discursivas. Psicologia: Reflexão e Crítica, 24 (1), 161-169.

Brandão, L., Parente, M. A. M. P., \& Peña-Casanova, J. (2008). Turnos e atos de fala do interlocutor de pessoas com doença de Alzheimer. Revista Virtual de Estudos da Linguagem, 6 (11), 1-32.

Brandão, L., Parente, M. A. M. P., \& Penã-Casanova, J. (2010). Estratégias comunicativas de pessoas com doença de Alzheimer. Psicologia: Reflexão e Crítica, 23 (2), 308-316.

Brasil, Lei no 10.741, de $1^{\text {o }}$ de outubro de 2003. Estatuto do Idoso. Brasília.

Brucki, S. M. \& Nitrini, R. (2008). Cancellation task in very low educated people. Archives of Clinical Neuropsychology 15(6), 495-513. doi: 10.1016/j.acn.2007.11.003

Bschor, T., Kühl, K. P., \& Reischies, F. M. (2001). Spontaneous speech of patients with dementia of the Alzheimer type and mild cognitive impairment. International psychogeriatrics, 13(3), 289-298. doi: 10.1017/S1041610201007682.

Buchanan, J, A., Christenson, A., Houlihan, D., \& Ostrom, C. (2011). The role of behavior analysis in the rehabilitation of persons with dementia. Behavior Therapy, 42, 9-12. doi: 10.1016/j.beth.2010.01.003.

Buchanan J. A, \& Fisher, J. E. (2002). Functional assessment and noncontingent reinforcement in the treatment of disruptive vocalization in elderly dementia patients. Journal of Applied Behavior Analysis, 35(1), 99-103. doi: 10.1901/jaba.2002.35-99.

Burlá, C., Pessini, L., Siqueira, J. E., \& Nunes, R. (2014). Envelhecimento e doença de Alzheimer: Reflexões sobre autonomia e o desafio do cuidado. Revista Bioética, 22(1), 85-93. doi: 10.1590/S1983-80422014000100010.

Caixeta, L., \& cols. (2012). Doença de Alzheimer. Artmed: Porto Alegre.

Caxieta, L. (2012) Evolução do conceito de doença de Alzheimer. In L. Caxieta, \& cols. (Eds.), Doença de Alzheimer (pp. 21-29). Artmed: Porto Alegre. 
Caixeta, L. (2012). Como diagnosticar a doença de Alzheimer? In: Caixeta, L., \& cols. (2012). Doença de Alzheimer, p. 97-113, Artmed: Porto Alegre.

Camara, M. R., Ducatti, M., \& Schmidt, A. (2017). Identity matching to sample and exclusion performance in elderly with and without neurocognitive disorders. Behavior Interventions, 32(4), 326-340. doi: 10.1002/bin.1487

Camp, C. J. (1989). Facilitation of new learning in Alzheimer's disease. In G. Gilmore and M. Whitehouse (eds.), Memory and Aging: Theory, Research and Practice (pp. 212-225). New York: Springer Publishing.

Caramelli, P. \& Barbosa, M. T. (2002). Como diagnosticar as quatro causas mais frequentes da demência?. Revista Brasileira de Psiquiatria, 24(Supl I), 7-10.

Carpenter, S. K., Cepeda, J. N., Roher, D., Kang, S. H. K., \& Pashler, H. (2012). Using spacing to enhance diverse forms of learning: review of recent research and implications for instruction. Educational Psychology Reserarch, 24(3), 369-378. doi: $10.1007 / \mathrm{s} 10648-012-9205-\mathrm{z}$

Cataldo, J. K., Prochaska, J.J., \& Glantz, S. A. (2010). Cigarette smoking is a risk factor for Alzheimer's disease: An analysis controlling for tobacco industry affiliation. In: Jourmal Alzheimers Disease, 19, p. 465-480. doi: 10.3233/JAD-2010-1240.

Catania, A. C. (1999). Aprendizagem: comportamento, linguagem e cognição. Artmed.

Cera, L. M., Ortiz, K. Z., Bertolucci, P. H. F., \& Minett, T. S. C. (2011). Manifestações da apraxia de fala na doença de Alzheimer. Revista da Sociedade Brasileira de Fonoaudiologia, 16(3), 337-343. doi: 10.1590/S1516-80342011000300016.

Classificação de transtornos mentais e de comportamento da CID-10: descrições clínicas e diretrizes diagnósticas [CID-10]. (1993). Porto Alegre, Artmed.

Clare, L. \& Jones, R. S. (2008). Errorless learning in the rehabilitation of memory impairment: a critical review. Neuropsychology Reviw, 18 (1), 1-23. doi: 10.1007/s11065-008-9051-4.

Clare, L., Wilson, B. A., Carter, G., Breen, K., Gosses, A., \& Hodges, J. R. (2000). Intervening with everyday memory problems in dementia of Alzheimer type: an errorless learning approach. Journal of Clinical and Experimental Neuropsychology, 22(1), 132-146. doi: 10.1076/1380-3395(200002)22:1;1$8 ;$ FT132.

Clare, L., Wilson, B. A., Carter, G., Roth, I., \& Hodges, J. R. (2002). Relearning facename associations in early Alzheimer's disease. Neuropsychology, 16(4), 538.

Clemente, R. S. G. \& Ribeiro-Filho, S. T. (2008). Comprometimento cognitivo leve: aspectos conceituais, abordagem clínica e diagnóstica. Revista do Hospital Universitário Pedro Ernesto, 7, 68-77. 
Chen, J. H., Lin, K.P., \& Chen, Y. C. (2009). Risk factors for dementia. Journal of the Formosan Medical Association, 10, 754-764. doi: 10.1016/S0929-6646(09)604022.

Cherry, K. E., \& Simmons-D'Gerolamo, S. S. (2005). Long-term effectiveness of spaced-retrieval memory training for older adults with probable Alzheimer's disease. Experimental Aging Research, 31, 261-289. doi: 10.1080/03610730590948186.

Constantine, B., \& Sidman, M. (1975). Role of naming in delayed matching-to-sample. American Journal of Mental Deficiency, 79, 680-689.

Costa, M. V., Bertola, L., \& Malloy-Diniz, L. F. (2017). Intervenções cognitivas em geriatria. In: Teixeira, A. L., Diniz, B. S., \& Malloy-Diniz, L. F. (2017). Psicogeriatria na prática clínica, p. 141-167. Pearson: São Paulo.

Costa, A. R. A., Schmidt, A., Domeniconi, C., \& de Souza, D. G. (2013). Emparelhamento com o modelo simultâneo e atrasado: Implicações para a demonstração de equivalência de estímulos por crianças. Temas em Psicologia, 21(2), 469-482. doi: 10.9788/TP2013.2-13

Cozby, P. C. (2006). Métodos de pesquisa em ciência do comportamento. Editora AUAS: São Paulo.

Creighton, S. A.; Ploeg, E. S. V. der., O’Connor, D. W. (2013). A literature review of spaced-retrieval interventions: a direct memory intervention for people with dementia. International Psychogeriatrics, 1-21. doi:10.1017/S1041610213001233

De Felice, F. G., Ferreira, S. T. (2014). Inflammation, defective insulin signaling, and mitochondrial dysfunction as common molecular denominators connecting type 2 diabetes to Alzheimer disease. Diabetes, 63, 2262-2272. doi: 10.2337/db13-1954.

Delfino, L. L. \& Cachioni, M. (2016). Estratégias comunicativas de cuidadores de idosos com demência: uma revisão sistemática. Jornal Brasileiro de Psiquiatria, 65(2), 186-95. doi: 10.1590/0047-2085000000122.

de Rose, J. C. (1993). Classes de estímulos: implicações para uma análise comportamental da cognição. Psicologia: Teoria e Pesquisa, 9, 283-303.

de Rose, J. C., \& Bortoloti, R. (2007). A equivalência de estímulos como modelo do significado. Acta comportamentalia., 15, 83-102.

Di Paula, M., Spatella, G., \& Caltagirone, C. (2010). In vivo structural neuroanatomy of corpus callosum in Alzheimer's Disease and Mild Cognitive Impairment using different MRI techniques: a review. Journal of Alzheimer's Disease, 20(1), 67-95. doi: 10.3233/JAD-2010-1370

Dijkstra, K., Bourgeois, M. S., Allen, R. S., \& Burgio, L. D. (2004). Conversational coherence: Discourse analysis of older adults with and without dementia. Journal of Neurolinguistics, 17(4), 263-283. doi: 10.1016/S0911-6044(03)00048-4. 
Dixon, M., Becker, J. C., \& Sadowski, K. A. (2011). Applying Skinner's analysis of verbal behavior to persons with dementia. Behavior Therapy, 42, 120-126. doi: 10.1016/j.beth.2010.05.002

Drummond, C., et al. (2015). Deficits in narrative discourse elicited by visual stimuli are already present in patients with mild cognitive impairment. Frontiers in aging neuroscience, 7, 96. doi: 10.3389/fnagi.2015.00096.

Ducatti, M., \& Schmidt, A. (2016). Learning conditional relations in elderly people with and without neurocognitive disorders. Psychology \& Neuroscience, 9, 240-254. doi: doi.org/10.1037/pne0000049.

Dunn, J., \& Clare, L. (2007). Learning face-name associations in early-stage dementia: Comparing the effects of errorless learning and effortful processing. Neuropsychological Rehabilitation, 17(6), 735-754. doi: 10.1080/09602010701218317.

Enhelhardt, E.,Brucki, S. M. T., Cavalcanti, J. L. S. \& Cols. (2005) Tratamento da doença de alzheimer: recomendações e sugestões do departamento científico de neurologia cognitiva e do envelhecimento da academia brasileira de neurologia. Arquivos de Neuro-Psiquiatria, 63, 1104-1112.

Erkes, J., Raffard, S., Meylemans, T. (2009). Spaced-retrieval inpatients with Alzheimer's disease. Critical review and clinical applications. Psychol Neuropsychiatr, 7(4), 275-286. doi: 10.1684/pnv.2010.0188.

Escobal, G., Araújo, E. A. C., \& Goyos, C. (2005). Escolha e desempenho no trabalho de adultos com deficiência mental. Revista Brasileira de Educação Especial, 11 (3), 335-372. doi: 10.1590/S1413-65382005000300004.

Ferreira, P. C., Piai, K. de A., Takayanagui, A. M. M., \& Segura-Muñoz, S. I. (2008). Alumínio como fator de risco para doença de Alzheimer. Revista Latino-Americana de Enfermagem, 16(1), 151-157. doi: 10.1590/S0104-11692008000100023

Forlenza, O. V. (2005). Tratamento farmacológico da doença de Alzheimer. Revista de Psiquiatria Clinica, 32(3), 137-148. doi: 10.1590/S0101-60832005000300006

Feyereisen, P., Berrewaerts, J., \& Hupet, M. (2007). Pragmatic skills in the early stages of Alzheimer's disease: an analysis by means of a referential communication task. International journal of language \& communication disorders, 42(1), 1-17. doi: 10.1080/13682820600624216.

Folch, J., et al. (2018). Review of the advances in treatment for Alzheimer disease: strategies for combating -amyloid protein. Neurología, 33(1), 47-58. doi: 10.1016/j.nrleng.2015.03.019.

Fridriksson, J., Holland, A., Beeson, P., \& Morrow, L. (2011). Spaced retrieval treatment of anomia. Aphasiology, 19(2), 99-109. doi: 10.1080/02687030444000660. 
Gallagher, S. M., \& Keenan, M. (2009). Stimulus equivalence and the mini mental status examination in the elderly. European Journal of Behavior Analysis, 10, 159165. doi: 10.1080/15021149.2009.11434316.

Gallucci-Neto, J., Tamelini, M. G., \& Forlenza, O. V. (2005). Diagnóstico diferencial das demências. Revista de Psiquiatria Clínica, 32(3), 119-130. doi: 10.1590/S010160832005000300004

Glisky, E. L., Schacter, D. L., \& Tulving, E. (1986). Learning and retention of computer-related vocabulary in memory-impaired patients: Method of vanishing cues. Journal of Clinical and Experimental Neuropsychology, 8(3), 292-312. doi: 10.1080/01688638608401320.

Gomes, C. G. S., Varella, A. A. B., \& de Souza, D. das G. (2010). Equivalência de Estímulos e Autismo: Uma Revisão de Estudos Empíricos. Psicologia: Teoria e Pesquisa, 26 (4), 729-737

Goulart, P. R. K.; Delage, P. E. G. A.; Rico, V. V.; Brino, A. L. de F.. (2012). Aprendizagem. In: Maria Marta Costa Hübner, Márcio Borges Moreira (Orgs.). Temas clássicos da psicologia sob a ótica da análise do comportamento. 1 ed. Rio de Janeiro, 20-31.

Goyos, C., Rossit, R. A. S., Elias, N. C., Escobal, G., \& Chereguini, P. (2009). Análise do comportamento e o estudo do envelhecimento humano: revisão dos estudos de aplicação. Revista Brasileira de Análise do Comportamento, 5(2), 1-20. doi: 10.18542/rebac.v5i2.927

Gradmaison, E. \& Simard, M. (2003). A critical review of memory stimulation programs in Alzheimer's disease. The Journal of Neuropsychiatry and clinical neurosciences., 15(2),130-44. doi: 10.1176/jnp.15.2.130.

Grinberg, L. T., Suemoto, C. K., Leite, R. E. P., Ferretti, R. E. de K., \& Farfel, J. M. (2012). Neuropatologia da doença de Alzheimer. In: Caixeta, L., \& cols. (2012). Doença de Alzheimer, p. 127-226, Artmed: Porto Alegre.

Gross, A. C., Fuqua, R. W., \& Merritt. T.A. (2013). Evaluation of verbal behavior in older adults. The Analysis of Verbal Behavior, 29(1), 85-99.

Guimarães, L. \& Lazzaratti, C. (2017). Doença de Alzheimer e diabetes mellitus tipo 2: relações metabólicas e neurodegenerativas. Revista Perspectiva: Ciência e Saúde, 2(1), 113-123.

Gutierrez, B. A.O., Silva, H. S., Guimarães, C., \& Campino, A. C. (2014). Impacto econômico da doença de Alzheimer no Brasil: É possível melhorar a assistência e reduzir custos? Ciência e Saúde Coletiva, 19(11), 4479-4486. doi: 10.1590/1413812320141911.03562013 .

Gutowski, S. J., \& Stromer, R. (2003). Delayed matching to two-picture samples by individuals with and without disabilities: An analysis of the role of naming. Journal of Applied Behavior Analysis, 36, 487-505. doi: 10.1901/jaba.2003.36-487 
Hamdam, A. C. (2008). Avaliação neuropsicológica na doença de Alzheimer e no comprometimento cognitivo leve. Psicologia Argumento, 26(52), 183-192.

Hanna, E. S. \& Ribeiro, M. R. (2005). Autocontrole: um caso especial de comportamento de escolha. In: Rodrigues, J. A. \& Ribeiro, M. R. (Orgs.) Análise do Comportamento: Pesquisa, Teoria e Aplicação, 175-187, Artmed: São Paulo.

Haslam, C., Moss, Z., \& Hodder, K. (2010). Are two methods better than one? Evaluating the effectiveness of combining errorless learning with vanishing cues. Journal of Clinical and Experimental Neuropsychology, 32(9), 973-85. doi: 10.1080/13803391003662686.

Haslam, C., Hodder, K. I., \& Yates, P. J. (2011). Errorless learning and spaced retrieval: how do these methods fare in healthy and clinical populations? Journal of Clinical Experimental Neuropsychology. 33(4), 432-447. doi: 10.1080/13803395.2010.533155.

Hawley, K. S. (2002). Spaced-retrieval effects on name-face recognition in older adults with probable Alzheimer's disease. Thesis. Faculty of the Louisiana State University.

Hawley, K. S. \& Cherry, K. E. (2004). Spaced-Retrieval effects on name-face recognition in older adults with provavle Alzheimer's disease. Behavior Modification, (28)2, 276-296. doi: 10.1177/0145445503259283

Hawley, K. S., Cherry, K. E., Boudreaux, E. O., \& Jackson, E. M. (2008). A comparison of adjusted spaced retrieval versus a uniform expanded retrieval schedule for learning a name-face association in older adults with probable Alzheimer's disease. Journal of Clinical and Experimental Neuropsychology, 30, 639-649.

Haydu, V. B., \& Morais, L. P. (2009). Formação, manutenção e recuperação de relações equivalentes em adultos da terceira idade. Psicologia Argumento, 27 (59), 323-336.

Hochhalter, A. K., Bakke, B. L., Holub, R. J., \& Overmier, J. B. (2004). Adjusted spaced retrieval training: A demonstration and initial test of why it is effective. Clinical Gerontologist, 27, 159-168. doi: 10.1300/J018v27n01_12.

Hopper, T., et al., (2013). An evidence-based systematic review on cognitive interventions for individual with dementia. American Journal of Speech-Language Pathology, 22, 126-145. doi: 10.1044/1058-0360(2012/11-0137)

Instituto Brasileiro de Geografia e Estatística [IBGE]. (2009). Indicadores sociodemográficos e de saúde no Brasil. Estudos \& Pesquisa: informações demográficas e socioeconômicas. Rio de Janeiro.

Instituto Brasileiro de Geografia e Estatística (IBGE). (2016). Síntese de indicadores sociais: uma análise das condições de vida da população brasileira. Estudos \& Pesquisa 
Jackson, O. (2011). Demência senil e comprometimento cognitivo. In T. L. Kauffman (Ed.), Manual de reabilitação geriátrica (pp. 112-116). Guanabara, 2011.

Jang, J. S., Lee, J. S., \& Yoo, D. H. (2015). Effects of spaced retrieval training with errorless learning in the rehabilitation of patients with dementia. Journal of Physical Therapy Science, 27(9), 2735-2738. doi: 10.1589/jpts.27.2735.

Kane, R. L., Ouslander, J. G., \& Abrass, T. B. (2004). O paciente geriátrico: demografia, epidemiologia e utilização dos serviços de saúde. In R. L. Kane, J. G. Ouslander, \& T. B. Abrass (Eds), Geriatria Clínica. Rio de Janeiro.

Kelly, M. E. \& O’Sullivan, M. (2015). Strategies and techniques for cognitive rehabilitation: manual for healthcare professionals working with individuals with cognitive impairment.

Kintsch, W., \& van Dijk, T. (1978). Toward a model of context comprehension and production. Psychologial Review, 25(5), 363-394. doi: 10.1037/0033295X.85.5.363.

Klekocuik, S. Z., Saunders, N. L., Summers, M. J. (2016). Diagnosing mild cognitive impairment as a precursor to dementia: fact ou fallacy? The Australian Psychological Society, p. 1-8. doi:10.1111/ap.12178.

Kumar, A., Singh, A. \& Ekavali, (2015). A review on Alzheimer's disease pathophysiology and its management: an update. Pharmacological Reports, 67(2), 195-203. doi: 10.1016/j.pharep.2014.09.004. Epub 2014 Sep 22.

Landauer, T. K., \& Bjork, R. A. (1978). Optimum rehearsal patterns and name learning. In M. Gruneberg, P. E. Morris, \& R. N. Sykes (Eds.), Practical aspects of memory (pp. 625-632). London: Academic Press.

Lear, K. (2004). Ajuda e dicas. In. Lear, K. (2004). Ajude-nos a aprender: um programa de treinamento em ABA. Parte I. Toronto: 2. ed.

Lekeu, F., Wojtasik, V., Van der Linden, M., \& Salmon, E. (2002). Training early Alzheimer patients to use a mobile phone. Acta Neurology Belgium, 102, 114-121

Loewenstein, D. A., Acevedo, A., Czaja, S. J., \& Duara, R. (2004). Cognitive rehabilitation of mildly impaired Alzheimer disease patients on cholinesterase inhibitors. American Journal of Geriatric Psychiatry, 12, 395-402. doi: 10.1176/appi.ajgp.12.4.395.

Lima, T. M., Brandão, L., Parente, M. A. M. P., \& Peña-Casanova, J. (2014). Alzheimer's disease: cognition and picture-based narrative discourse. Revista CEFAC, 16(4), 1168-1177. doi: 10.1590/1982-021620147513

Lira, J. O., Minett, T. S. C., Bertolucci, P. H. F., \& Ortiz, K. Z. (2014). Analysis of word number and content in discourse of patients with mild to moderate 
Alzheimer's disease. Dementia \& Neuropsychologia, 8(3), 260-265. doi: 10.1590/S1980-57642014DN83000010

Lira, J. O., Ortiz, K. Z., Campanha, A. C., Bertolucci, P. H. F., \& Minett, T. S. C. (2011). Microlinguistic aspects of the oral narrative in patients with Alzheimer's disease. International Psychogeriatrics, 23(3), 404-412. doi: 10.1017/S1041610210001092.

Locke, J. M, \& Mudford, O. C. (2010). Using music to decrease disruptive vocalizations in a man with dementia. Behavioral Interventions, 25(3), 253-260. doi: 10.1002/bin.309.

Lucchesi, F. D. M. \& Almeida-Verdu, A. C. M. (2017). Ensino de componentes da linguagem a usuários de implante coclear: revisão da literatura. Revista CEFAC, 19(6), 855-867. doi: 10.1590/1982-021620171965717

Mansur, L. L., Carthery, M. T., Caramelli, P., \& Nitrini, R. (2005). Linguagem e cognição da doença de Alzheimer. Psicologia: Reflexão e Crítica, 18(3), 300-307. doi: 10.1590/S0102-79722005000300002.

Manual diagnóstico e estatístico de transtornos mentais [DSM-V]. (2014). Porto Alegre, Ed. Artes Médicas.

Massoud, F. \& Gauthier, S. (2010). Update on the Pharmacological Treatment of Alzheimer's Disease. Current Neuropharmacology, 8(1), 69-80. doi: 10.2174/157015910790909520.

McCurry, S. M. \& Drossel, C. (2011). Treating dementia in context: a step-by-step gruide to working with individuals and families. APA Books, $1^{\text {a }}$ ed.

Medeiros, J. F., Antonakopoulu, A., Amorim, K., \& Righetto, A. C. (1997). O uso da discriminação condicional no ensino da leitura e escrita. Temas em Psicologia, 5(1), 23-32.

Melchiori, L. E., de Souza, D. G., \& de Rose, J. C. (1992). Aprendizagem de leitura por meio de um procedimento de discriminação sem erros (exclusão): uma replicação com pré-escolares. Psicologia: Teoria e Pesquisa, 8 (1), 101-111.

Melo, R. M. de, Hanna, E. S., \& Carmo, J. dos S. (2014). Ensino sem erro e aprendizagem de discriminação. Temas em Psicologia, 22(1), 207222. doi.org/10.9788/TP2014.1-16.

Mimura, M., \& Komatsu, S. I. (2010). Factors of error and_effort in memory intervention for patients with Alzheimer's disease and amnesic syndrome. Psychogeriatrics, Psychogeriatrics, 10(4), 179-186. doi: 10.1111/j.14798301.2010.00339.x.

Monteiro, L. de C., Crove, P., \& Fuentes, D. (2012). Reabilitação neuropsicológica. In: Malloy-Diniz, L. F., Fuentes, D., \& Consenza, R. (Org). Neuropsicologia do Envelhecimento: uma abordagem multidimensional. Artmed: Porto Alegre, 348- 
359.

Nicholas, L. E., \& Brookshire, R. H. (1993). A system for quantifying the informativeness and efficiency of the connected speech of adults with aphasia. Journal of Speech, Language, and Hearing Research, 36(2), 338-350.

O’Connor, J., Rafferty, A., Barnes-Holmes, D., \& Barnes-Holmes, Y. (2009). The role of verbal behavior, stimulus nameability, and familiarity on the equivalence performaces of autistic and normally developing children. The Psychological Record, 56, 53-74.

Ortiz, K. Z. \& Bertolucci, P. H. F. (2005). Alterações de linguagem nas fases iniciais da doenças de Alzheimer. Arquivos de Neuropsiquiatria, 63(2-A), 311-317

Papaléo Netto, M. (2007). Gerontologia: a velhice e o envelhecimento em visão globalizada. Atheneu. São Paulo.

Parahyba, M. I. \& Simões, C. C. da S. (2006). A prevalência da incapacidade funcional em idosos no Brasil. Ciências e Saúde Coletiva, 11(4), 967-974.

Parente, M. A. P. M., Capuano, A., \& Nespoylous, J. L., (1999). Ativação de modelos mentais no recontar de histórias por idosos. Psicologia: Reflexão e Crítica, 12(1), 157-172.

Parente, M. A. M. P., Saboskinsk, A. P., Ferreira, E., \& Nespoulous, J. L. (1999). Memória e compreensão da linguagem no envelhecimento. Estudos Interdisciplinares do Envelhecimento, 1, 57-76.

Plassman, B. L., Williams, J. W. Jr, Burke, J. R., Holsinger, T., Benjamin, S. (2010) Systematic review: factors associated with risk for and possible prevention of cognitive decline in later life. Annals of Internal Medicine, 153, 182-193. doi: 10.7326/0003-4819-153-3-201008030-00258.

Pessoa, R. M. de P., Faria, S. M. de, Morais, D. de, \& Chagas, M. H. N. (2016). Da demência ao transtorno neurocognitivo maior: aspectos atuais. Revista Ciências em Saúde, 6(4), 1-13. doi: 10.21876/rcsfmit.v6i4.606

Petersen, R. C., Smith, G. E.,Warin, S. C., Ivnik, R. J., Kokmem, E., \& Tangelos, E. R. (1997). Aging, memory, and mild cognitive impairment. International Psychogeriatrics, 9(1), 65-69.

Pinkston, E.M. \& Linsk, N. L. (1984). Behavioral family intervention with the impaired elderly. Gerontologist, 24(6), 576-583.

Prince, M., Prina, M., Guerchet, M., Albanese, E., et al. (2014) World Alzheimer Report: Dementia and Risk Reduction. Alzheimer's Disease International (ADI), London.

Provencher, V., Bier, N., Audet, T., \& Gagnon, L. (2008). Errorless-based techniques can improve route finding in early Alzheimer's disease: a case study. American 
Journal of Alzheimer's Disease \& Other Dementias, 23(1), 47-56. doi: 10.1177/1533317507307228.

Ramos, A. A. \& Hamdam, A. C. (2016). Avaliação neuropsicológica na Doença de Alzheimer e Demência Frontotemporal: critérios nosológicos. Interação em Psicologia, 18(3), 391-197. doi: 10.5380/psi.vl8i3.47039

Rique, L. D., Guerra, B. T., Borelli, L. M., Oliveira, A. P. de., \& Almeida-Verdu, A. C. M. (2017). Revista CEFAC, 19(2), 289-296. doi: 10.1590/1982-021620171928516

Rodakowski, J., Saghafi, E., Butters, M. A., \& Skidmore, E. R. (2015). Nonpharmacological interventions for adults with mild cognitive impairment and early stage dementia: an update scoping review. Molecular Aspects of Medicine, 43, 3853. doi: 10.1016/j.mam.2015.06.003

Rojas, G. J., Villar, V., Iturry, M., Harris, P., Serrano, C. M., Herrera, J. A., \& Allegri, R. F. (2013). Efficacy of a cognitive intervention program in patients with mild cognitive impairment. International Psychogeriatrics, 25(5), 825-831. doi:10.1017/S1041610213000045.

Salamone, S., Caraci, F., Leggio, G. M., Fedotova, J., \& Drago, F. (2011). New pharmacological strategies for treatment of Alzheimer's disease: focus on disease modifying drugs. British Journal of Clinical Pharmacology, 73(4), 504-517. doi: 10.1111/j.1365-2125.2011.04134.x

Sando SB, Melquist S, Cannon A, Hutton M, Sletvoid O, Saltvedt I, et al. Risk-reducing effect of education in Alzheimer's disease. Int J Geriatr Psychiatry 2008;23:115662.

Santos, J. V. \& Souza, C. B. A. de (2007). Categorização de verbalizações do processo terapêutico e o operante intraverbal. Revista Brasileira de Terapia Comportamental e Cognitiva, 9(2), 261-275.

Santos, S. de L; R. dos, \& Almeida-Verdu, A. C. M. (2012). Leitura em uma criança surda após equivalência de estímulos. Psicologia em Revista, 18(2), 209-226. doi: 10.5752/P.1678-9563.2012v18n2p209

Schryer, E., \& Ross, M. (2013). The use and benefits of external memory aids in older and younger adults. Applied Cognitive Psychology, 27, 663-671. doi: 10.1002/acp.2946.

Sella, A. C., Bandini, C. S. M., Bandini, H. H. M., Ribeiro, D. M., \& Vieira, H. C. (2015). Effects of picture prompts on story retelling performance in typically developing children. Psicologia: Reflexão e Crítica, 28, 397-403. doi: 10.1590/1678-7153.201528220.

Sidman, M. (2012). Techniques for describing and measuring behavioral changes in Alzheimer's patients. European Journal of Behavior Analysis, 14(1), 141-149. 
Sidman, M. \& Stoddard, L. T. (1967). The effectiveness of fading in programming a simultaneous form discrimination for retarded children. Journal of the Experimental Analysis of Behavior, 10, 3-15.

Silva, H. S. \& Yassuda, M. S. (2009). Memory training for older adults with low education: Mental images versus categorization. Educational Gerontology, 35, 890905. doi: 10.1080/03601270902782487.

Skinner, B. F. \& Vaughan, M. E. (1985). Viva bem a velhice: aprendendo a programar a sua vida. Tradução: Neri, A. L. Summus: São Paulo.

Small, J. A. (2012). A new frontier in spaced retrieval memory training for persons with Alzheimer's disease. Neuropsychological Rehabilitation, 22(3), 329-361. doi: 10.1080/09602011.2011.640468

Soares, C. D., Brandão, L., \& Lacerda, M. C. (2012). Linguagem e discurso na Doença de Alzheimer. In L. Caxieta et al., (Eds.), Doença de Alzheimer (pp. 21-29). Artmed: Porto Alegre.

Soares, V. L. D., Soares, C. D., \& Caxieta, L. (212). Reabilitação neuropsicológica: prática. In: L. Caxieta et al.. (Eds.), Doença de Alzheimer (pp. 21-29). Artmed: Porto Alegre.

Soderlund, M., Cronqvist, A., Noberg, A., Ternestedt, B-M., \& Hansebo, G. (2016). Conversations between persons with dementia disease living in nursing homes and nurses - qualitative evaluation of an intervention with the validation method. Scandinavian Journal of Caring Sciences, 30, 37-47. doi: 10.1111/scs.12219.

Souza, D. G. de \& Rose, J. C. de. (2006). Desenvolvendo programas individualizados para o ensino de leitura. Acta Comportamentalia, 14(1), 77-98.

Souza, F. S. de. (2011). O ensino de discriminações condicionais para idosos com comprometimento cognitivo. Dissertação, Pontifícia Universidade Católica, São Paulo.

Souza, F. C. de, Verdu, A. C.A, \& Bevilacqua, M. C. (2013). Ecoico e nomeação de figuras em crianças com deficiência auditiva pré-lingual com implante coclear. Acta Comportamentalia, 21(3), 273-283.

Souza, L. C. de, Rocha, N. P., Teixeira, A. L., \& Caramelli, P. (2017). Doença de Alzheimer. In: Teixeira, A. L., Diniz, B. S., \& Malloy-Diniz, L. F. (2017). Psicogeriatria na prática clínica, p. 141-167. Pearson: São Paulo.

Soares, V. L. D., Soares, C. D., \& Caixeta, L. (2012). Métodos de avaliação neuropsicológica no diagnóstico da doença de Alzheimer. In: Caixeta, L., \& cols. (2012). Doença de Alzheimer, p. 175-188, Artmed: Porto Alegre.

Steingrimsdottir, H. S., \& Arntzen, E. (2011a). Using conditional discrimination procedures to study remembering in an Alzheimer's patient. Behavioral Intervention, 26, 179-192. doi: 10.1002/bin.334 
Steingrimsdottir, H. S., \& Arntzen, E. (2011b). Identity matching in a patient with Alzheimer's disease. American Journal of Alzheimer's Disease \& Other Dementias, 26(3), 247-253. doi: 10.1177/1533317511402816

Sternberg, R. J. (2010). Psicologia Cognitiva. Porto Alegre: Artes Médicas

Studar-Neto, A. \& Nitrini, R. (2016). Subjetive cognitive decline: the first clinical manifestation of Alzheimer's disease? Dementia Neuropsychoogial, 10(3), 170177. doi: 10.1590/S1980-5764-2016DN1003002

Szatloczki, G., Hoffmann, I., Vincze, V., Kalman, J., \& Pakaski, M. (2015). Speaking in Alzheimer's disease, is that an early sign? Importance of changes in language abilities in Alzheimer's disease. Frontiers in Aging Neuroscience, 7, 1-7. doi: 10.3389/fnagi.2015.00195.

Taveira, R. B. R., Taveira, D. L. R., \& Caixeta, L. (2012). Abordagens não farmacológicas na doença de Alzheimer. In: Caixeta, L., \& cols. (2012). Doença de Alzheimer, p. 353-367, Artmed: Porto Alegre.

Teixeira, C. V. L., Gobbi, L. T. B., Corazza, D. I., Stella, F., Costa, J. L. R., \& Gobbi, S. (2012). Non-pharmacological interventions on cognitive functions in older people with mild cognitive impairment (MCI). Archives of Gerontology and Geriatrics, 54, 175-180. doi:10.1016/j.archger.2011.02.014.

Terrace, H. S. (1963). Discrimination learning with and without "errors" 1. Journal of the experimental analysis of behavior, 6(1), 1-27.

Thivierge, S., Simard, M., Jean, L., \& Grandmaison, E. (2008). Errorless learning and spaced retrieval techniques to relearn instrumental activities of daily living in mild Alzheimer's disease: a case report study. Neuropsychiatric Disease and Treatment, 4(5), 987-999.

Toledo, C. M., Aluísio, S. M., dos Santos, L. B., Brucki, S. M. D., Trés, E. S., de Oliveira, M. O., \& Mansur, L. L. (2018). Analysis of macrolinguistic aspects of narratives from individuals with Alzheimer's disease, mild cognitive impairment, and no cognitive impairment. Alzheimer's \& Dementia: Diagnosis, Assessment \& Disease Monitoring, 10, 31-40. doi: 10.1016/j.dadm.2017.08.005

Trahan, M. A., Donaldson, J. M., McNabney, M., \& Kahng, S. (2014). The influence of antecedents and consequences on the occurrence of bizarre speech in individuals with dementia. Behavioral Interventions, 29 (4), 286-303. doi: 10.1002/bin.1393.

United Nations Population Fund (2000).Setting the scene.In United Nations Population Fund.Aging in the Twenty-First Century: a celebration and a challenge.

Vale, F. de A. C. de., Corrêa-Neto, Y., Bertolucci, P. H. F., Machado, J. C. B., Silva, D. J. da, Allam, N., Balthazar, M. L. F. (2011). Tratamento da doença de Alzheimer. Dementia Neuropsychology, 5(I), 34-48. 
Verhaeghen, P., Marcoen, A., \& Gossens, L., (1992). Improving memory performance in the aged through mnemonic training: a meta-analytic study. Psychology and Aging, 7(2), 242-251.

Vieira, R. T. \& Caixeta, L. (2012). Epidemiologia da doença de Alzheimer. In: Caixeta, L., \& cols. (2012). Doença de Alzheimer, p. 353-367, Artmed: Porto Alegre.

Wilson, B.A. (1996). Reabilitação das Deficiências Cognitivas. In: Nitrini, R.; Caramelli, P.; Mansur, L.L. Neuropsicologia das Bases Anatômicas à Reabilitação. Clínica Neurológica HCFMUSP, São Paulo, 314-43.

World Health Organization (2002). Saúde mental: nova concepção, nova esperança. Relatório mundial da saúde. Tradução Gabinete de Tradução Climepsi Editores

World Health Organization (WHO). (2005). Envelhecimento Ativo: uma política de saúde. Tradução de Suzana Gontijo. Brasilia: OPAS.

World Health Organization (WHO). (2015). Relatório Mundial de Envelhecimento e Saúde.

Yang, Y. \& Song, W. (2013). Molecular links between Alzheimer's disease and diabetes mellitus. In: Neuroscience, 250, 140-150

Yesavage, et al., (1983). Development and validation of a geriatric depression screening scale: a preliminary report. Journal of Psychiatric Research, 17(1):37-49. 
Anexos 


\section{Anexos A - Parecer de Aprovação do Comitê de Ética em Pesquisa}

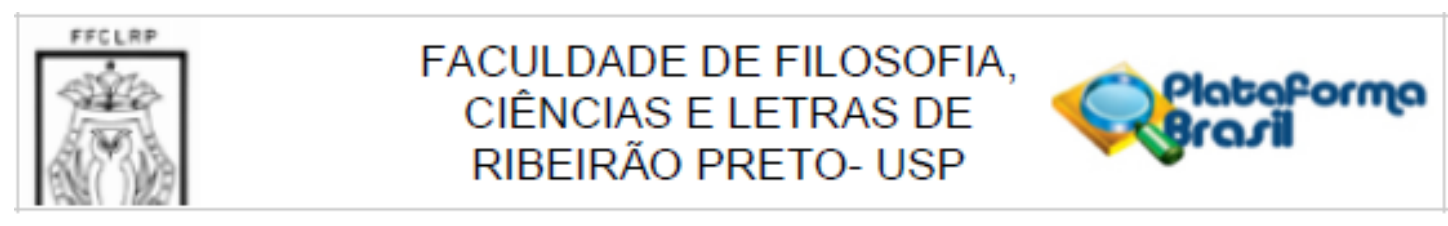

\section{PARECER CONSUBSTANCIADO DO CEP}

\section{DADOS DO PROJETO DE PESQUISA}

Título da Pesquisa: ESTUdOS SOBRE A PRODUÇÃO DE DISCURSO EM IDOSOS COM DEMÊNCIA DE ALZHEIMER NA FASE INICIAL

Pesquisador: Mariana Ducatti Almeida

Área Temática:

Versão: 2

CAAE: 41678015.4 .0000 .5407

Instituição Proponente: Faculdade de Filosofia, Ciências e Letras de Ribeirão Preto- USP

Patrocinador Principal: Financiamento Próprio

\section{DADOS DO PARECER}

Número do Parecer: 1.089 .819

Data da Relatoria: 21/05/2015

Apresentação do Projeto:

vide parecer anterior.

Objetivo da Pesquisa:

vide parecer anterior.

Avaliação dos Riscos e Beneficios:

vide parecer anterior.

Comentários e Considerações sobre a Pesquisa:

Tendo por base, os comentários já feitos em relação à pesquisa, concernentes à sua relevância, sublinha-se aqui que a finalidade das filmagens, assim como o destino final das mesmas, foi agora esclarecida, explicitando-se que essas compõem o método de coleta de dados, sendo que, ao final das observações das mesmas, com as transcrições literais das falas dos idosos - registradas nas sessões de intervenção previstas na pesquisa -, as filmagens devem ser destruidas.

No mais, a pesquisadora também esclareceu as questões relativas ao recrutamento dos idosos que serão convidados a participar da pesquisa. Nos casos dos idosos que apresentam autonomia intelectual para decidir pela própria participação, a esses será feito o pedido de colaboração,

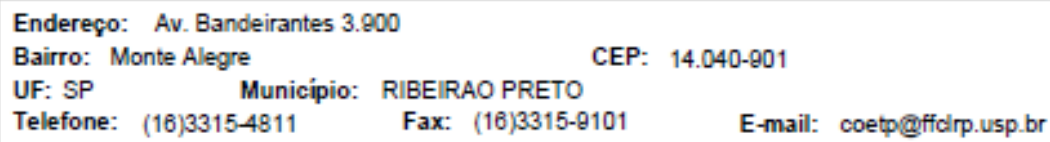




\section{FACULDADE DE FILOSOFIA, CIÊNCIAS E LETRAS DE RIBEIRÃO PRETO- USP

Contnuaçăo do Parecer: 1.089.819

diretamente, verbalmente e por escrito. Nos casos em que o idoso não apresenta mais essa autonomia, devido à sua condição, embora se proceda de modo a considerar sua declaração verbal, relativa à vontade ou não de participar da pesquisa, a pesquisadora declara que deverá também obter o consentimento de um responsável pelo idoso, seja esse a pessoa que tem sua curatela, seja esse um familiar.

Consideraçôes sobre os Termos de apresentação obrigatória:

Os Termos de Consentimento Livre e Esclarecido foram revistos e reapresentados.

Os dois modelos, um dirigido ao próprio participante, no caso dos idosos com capacidade para decidir livremente sobre a participação na pesquisa, e um dirigido a um responsável, no caso dos idosos que não possuam mais esta condição.

Esses documentos são similares e ambos trazem todas as informações necessárias e encontram-se redigidos de forma acessivel.

Recomendações:

Não há recomendações.

Conclusões ou Pendências e Lista de Inadequações:

Considerando que os pontos que mantinham o projeto em pedência foram revistos e promoveram reelaboração dos documentos, pensa-se que o mesmo pode agora ser aprovado no Comitê.

Situação do Parecer:

Aprovado

Necessita Apreciação da CONEP:

Não

RIBEIRAO PRETO, 01 de Junho de 2015

Assinado por:

Marina Rezende Bazon

(Coordenador)

Endereço: Av. Bandeirantes 3.800

Bairro: Monte Alegre

UF: SP Município: RIBEIRAO PRETO

Telefone: (16)3315-4811 Fax: (16)3315-9101 E-mail: coetp@iffelrp.usp.br 
Anexo B - Mini Exame do Estado Mental

\section{Mini Exame do Estado Mental}

\section{Orientação espacial (0-5 pontos):}

Em que dia estamos?

Ano:

Semestre:

Mês:

Dia:

Dia da Semana:

\section{Orientação espacial (0-5 pontos):}

Onde estamos?

Estado:

Cidade:

Bairro:

Rua:

Local:

\section{Linguagem ( $0-3$ pontos):}

Siga a ordem:

(1) Pegue esse papel com a mão direita.

(2) Dobre-o no meio.

(3) Coloque-o no chão.

\section{Linguagem (1 ponto):}

Escrever num papel a ordem "Feche os Olhos" e pedir para o participante ler e executar.

\section{Linguagem (1 ponto):}

Pedir para o entrevistador escrever uma frase completa.

\section{Repita as palavras ( $0-3$ pontos):}

Caneca; Tijolo; Tapete

\section{Linguagem (1 ponto):}

Cópia do desenho:

\section{Cálculo (0-5 pontos):}

4.a Se de 100 fossem tirados 7 quanto restaria? E se tirarmos mais 7?

(Repetir o procedimento por cinco vezes)

4b. Soletre a palavra MUNDO de trás pra frente.

O-D-N-U-M

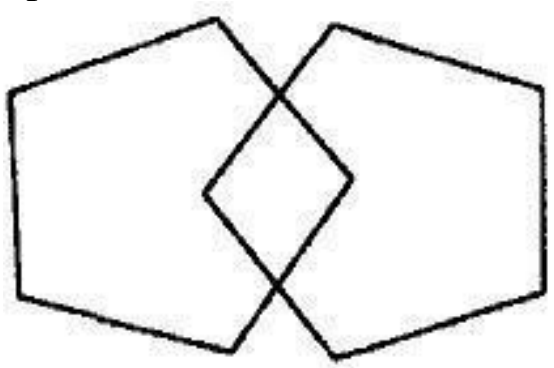

Verificar se todos os lados estão preservados e se os lados da intersecção formam um quadrilátero. Tremor e rotação podem ser ignorados.

\section{Memorização ( $0-3$ pontos):}

Falar as palavras ditadas anteriormente (Caneca; Tipojo; Tapete).

\section{Linguagem (0-2 pontos):}

Mostrar um relógio e uma caneta e pedir para o entrevistador nomeá-los.

\section{Linguagem (1 ponto):}

Repetir a frase: "Nem aqui, nem ali, nem lá." 
Anexo C - Escala de Depressão Geriátrica

ESCALA GERIÁTRICA DE DEPRESSÃO ${ }^{1}$

(Yesavage, 1983)

PACIENTE:

DATA DA AVALIAÇÃO: AVALIADOR:

1. Você está satisfeito com sua vida?

2. Abandonou muitos de seus interesses e atividades?

3. Sente que sua vida está vazia?

4. Sente-se freqüentemente aborrecido?

5. Você tem muita fé no futuro?

6. Tem pensamentos negativos?

7. Na maioria do tempo está de bom humor?

8. Tem medo de que algo de mal vá lhe acontecer?

9. Sente-se feliz na maioria do tempo?

10. Sente-se freqüentemente desamparado, adoentado?

11. Sente-se freqüentementeintranqüilo?

12. Prefere ficar em casa em vez de sair?

13. Preocupa-se muito com o futuro?

14. Acha que tem mais probl de memória que os outros?

15. Acha bom estar vivo?

16. Fica freqüentemente triste?

17. Sente-se inútil?

18. Preocupa-se muito com o passado?

19. Acha a vida muito interessante?

20. Para você é difícil começar novos projetos?

21. Sente-se cheio de energia?

22. Sente-se sem esperança?

23. Acha que os outros têm mais sorte que você?

24. Preocupa-se com coisas sem importância?

25. Sente freqüentemente vontade de chorar?

26. É difícil para você concentrar-se?

27. Sente-se bem ao despertar?

28. Prefere evitar as reuniões sociais?

29. É fácil para você tomar decisões?

30. O seu raciocínio está tão claro quanto antigamente?

\begin{tabular}{|c|c|c|}
\hline Sim & ( & ) Não \\
\hline ) $\operatorname{Sim}($ & ) Nã & \\
\hline Sim & ( & ) Não \\
\hline ) Sim & ( & ) Não \\
\hline Sim & ( & ) Não \\
\hline ) Sim & ( & ) Não \\
\hline ) $\mathrm{Sim}$ & ( & ) Não \\
\hline ) Sim & ( & ) Não \\
\hline ) $\mathrm{Sim}$ & ( & ) Não \\
\hline ) $\operatorname{Sim}()$ & Não & \\
\hline ) Sim & ( & ) Não \\
\hline ) Sim & ( & ) Não \\
\hline ) $\mathrm{Sim}$ & ( & ) Não \\
\hline $\operatorname{Sim}() N$ & & \\
\hline ) $\mathrm{Sim}$ & ( & ) Não \\
\hline Sim & ( & ) Não \\
\hline ) Sim & ( & ) Não \\
\hline ) Sim & ( & ) Não \\
\hline ) $\mathrm{Sim}$ & ( & ) Não \\
\hline ) Sim & ( & ) Não \\
\hline ) Sim & ( & ) Não \\
\hline ) Sim & ( & ) Não \\
\hline ) Sim & ( & ) Não \\
\hline ) Sim & ( & ) Não \\
\hline ) Sim & ( & ) Não \\
\hline ) Sim & ( & ) Não \\
\hline $\operatorname{Sim}($ & Não & \\
\hline ) Sim & ( & ) Não \\
\hline ) $\mathrm{Sim}$ & ( & ) Não \\
\hline ) $\mathrm{Sim}$ & ( & ) Não \\
\hline
\end{tabular}

\footnotetext{
${ }^{1}$ Pontuação: 0 quando for diferente da resposta em negrito 1 quando for igual à resposta em negrito

Total $>10=$ suspeita de depressão
} 
Apêndices 


\section{Apêndice 1 - Termo de Autorização}

\section{TERMO DE AUTORIZAÇÃO}

Meu nome é Mariana Ducatti Almeida e estou realizando uma pesquisa de doutorado que tem como título "Estudos sobre a produção de discurso em idosos com demência de Alzheimer", sob orientação da profa. Dra. Andréia Schmidt, professora da Pós-Graduação em Psicobiologia da Universidade de São Paulo. Nessa pesquisa, estamos estudando maneiras de ajudar idosos que tenham diagnóstico de Doença de Alzheimer (DA) em estágio inicial a melhorar a produção de seu discurso. Para isso, desenvolvemos três métodos para investigar o efeito de diferentes tipos de tipas sobre a produção de discursos com DA. Esse procedimento é feito em passos, com auxílio de uma pasta de atividades e um computador, ao longo de vários dias. A duração total de cada método é de quatro meses aproximadamente, sendo que as sessões de ensino serão feitas de segunda a sexta-feira, por aproximadamente 30 minutos com cada idoso.

Para selecionar os idosos que participarão da pesquisa, precisaremos fazer uma avaliação de memória e da cognição (a capacidade dele se localizar no tempo e no espaço e de responder algumas questões de raciocínio lógico), por meio de dois testes, chamados de Mini Exame do Estado Mental e Exame Cognitivo de Addenbrooke (ACE-R). Além disso, precisamos avaliar se esses idosos apresentam depressão, por meio da Escala de Depressão Geriátrica, e também avaliar a linguagem e nomeação de figuras por meio do protocolo Montreal-Toulouse de Exame Linguístico de Afasia, versão M1-Alpha e Subteste Discurso Conversacional, da Baterial Montreal de Avaliação da Comunicação (MAC). Os resultados de todos esses testes serão disponibilizados para os idosos e/ou seu responsável.

A pesquisa não envolverá nenhum custo, assim como não haverá nenhuma remuneração, nem para o participante e nem para a instituição. Da mesma forma, não há riscos previsíveis para a participação dos idosos. A identidade de todos os participantes e da instituição não será divulgada e os resultados da pesquisa serão usados exclusivamente para fins científicos, ou seja, para o desenvolvimento de estratégias que possam ajudar pessoas idosas que apresentem problemas na produção de discurso.

Garantimos que o participante, seu familiar e responsável da instituição poderão ter acesso aos dados da pesquisa ou esclarecimentos sobre a mesma em qualquer momento que desejarem, bastando, para isso, entrar em contato com as pesquisadoras por 
meio do telefone abaixo descrito, ou pessoalmente, uma vez que a coleta de dados ocorrerá na instituição em que os idosos estiverem vinculados. Caso autorize o desenvolvimento dessa pesquisa em sua instituição, por gentileza assine o termo de autorização abaixo. Desde já, agradecemos a sua atenção e disponibilidade.

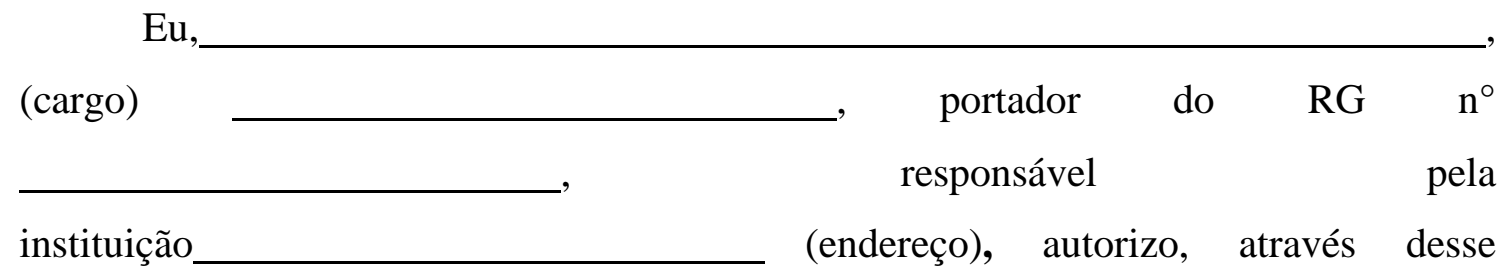

documento, que sejam realizados neste local todos os procedimentos acima descritos da pesquisa "Estudos sobre a produção de discurso em idosos com demência de Alzheimer", sob responsabilidade de Mariana Ducatti Almeida. Declaro que fui esclarecido(a) sobre esses procedimentos e que tenho sob minha guarda uma cópia desse termo de autorização.

Ribeirão Preto, de de 2015.

Assinatura do Responsável pela Instituição:

Pesquisadoras:

Mariana Ducatti Almeida

RG: 46.026.274 - 9

End: Rua Henrique Dumont, 1375, apt $^{\mathbf{0}} 38$

Ribeirão Preto/SP

Telefone: (16) 3967 - 2659
Prof. Dr ${ }^{\mathrm{a}}$ Andréia Schmidt

RG: 2.243 .897

End. Av. Bandeirantes, 3900

Ribeirão Preto/SP

Telefone: $3602-3742$

Comitê de Ética em Pesquisa da Faculdade de Filosofia, Ciências e Letras de Ribeirão Preto - USP Avenida Bandeirantes, 3900 - bloco 3 - sala 16 - 14040-901 - Ribeirão Preto - SP - Brasil Fone: (16) 3602-4811 / Fax: (16) 3633-2660

E-mail: coetp@ffclrp.usp.br 


\section{Apêndice 2 - Termo de Compromisso Livre e Esclarecido}

\section{TERMO DE CONSENTIMENTO LIVRE E ESCLARECIDO - Cuidador}

Meu nome é Mariana Ducatti Almeida e estou realizando uma pesquisa de doutorado que tem como título "ESTUDOS SOBRE A PRODUÇÃO DE DISCURSO EM IDOSOS COM DEMÊNCIA DE ALZHEIMER NA FASE INICIAL”, sob orientação da profa. Dra. Andréia Schmidt, professora da Pós-Graduação em Psicobiologia da Universidade de São Paulo. Nessa pesquisa, estamos estudando maneiras de ajudar idosos que tenham problemas de comunicação/fala a melhorem seu discurso. Para selecionar os idosos que participarão da pesquisa, precisaremos fazer uma avaliação de memória e da cognição (avaliando a capacidade dele se localizar no tempo e no espaço e de responder algumas questões de raciocínio lógico), por meio de dois testes, chamados de Mini Exame do Estado Mental, e Montreal CognitiveAssessment (MOCA). Além disso, precisamos avaliar se os possíveis participantes apresentam depressão, por meio do Teste "Inventário Beck de Depressão", e também avaliar se eles se lembram do nome de uma série de figuras, por meio do teste para Afasia M1-Alpha. Os resultados de todos esses testes serão disponibilizados para o participante (faremos uma entrevista com cada um, contando os resultados dos testes) e para a instituição com finalidade de serem anexados ao prontuário de cada residente.

A pesquisa não envolverá nenhum custo, assim como não haverá nenhuma remuneração, nem para o participante e nem para a instituição. Da mesma forma, não há riscos previsíveis para a participação dos idosos. O benefício esperado com a pesquisa é o desenvolvimento de novas formas de ajudar pessoas com perda de memória. Para o participante, especificamente, a pesquisa é uma espécie de exercício para a memória.

A identidade de todos os participantes e da instituição não serão divulgadas e os resultados da pesquisa serão usados exclusivamente para fins científicos, ou seja, para o desenvolvimento de estratégias que possam ajudar pessoas idosas que apresentem problemas de memória e linguagem, a manter ou recuperar o vocabulário. Esses resultados serão apresentados em congressos científicos, mas ainda assim, a identidade dos participantes e da instituição não serão divulgados.

Garantimos que o participante, seu familiar e a instituição na qual reside poderá ter acesso aos dados da pesquisa ou esclarecimentos sobre a mesma em qualquer 
momento que desejar, bastando, para isso, entrar em contato com as pesquisadoras por meio do telefone abaixo descrito, ou pessoalmente, uma vez que a coleta de dados ocorrerá nas dependências da própria instituição. Caso autorize a participação de seu familiar neste trabalho, por gentileza assine o termo de consentimento abaixo. Desde já, agradecemos a sua atenção e disponibilidade.

$\begin{array}{lll}\mathrm{Eu}, \ldots \text { (filho/filha/marido/esposa) } & \text { aceito } \\ & & \text { que } \\ & \text { através }\end{array}$

desse documento, participe da pesquisa acima descrita. Declaro que fui esclarecido(a) sobre esses procedimentos e que tenho sob minha guarda uma cópia desse termo de consenimento.

Ribeirão Preto, de de 2015 .

Assinatura do Participante: 


\section{Apêndice 3 - Entrevista Semi- Estruturada}

1. Dados Pessoais do Participante

Nome:

Data de nascimento:

Idade:

Endereço:

Telefone:

Escolaridade:

Estado Civil:

Profissão:

2. Estrutura Familiar:

Mora sozinho ( ) Mora com familiares ( ): Quem:

3. Informações sobre a rotina (atividades, funções na casa, etc...):

4. Informações sobre história de vida (trabalho, casamento, número de filhos):

5. Realiza algum tratamento? Se sim, qual? Qual a medicação utilizada?

6. Percurso da Demência (no caso dos idosos com DA): evolução da DA; queixas de memória; problemas comportamentais; queixas psicológicas (isolamento, depressão, falta de interesse):

7. Outras informações: 
Apêndice 4 - Transcrição dos Resultados do Estudo 2

\begin{tabular}{|c|c|c|}
\hline \multicolumn{3}{|r|}{ Grupo Controle } \\
\hline \multicolumn{3}{|r|}{ P1 } \\
\hline \multicolumn{2}{|c|}{ Fase 1} & $\begin{array}{l}\text { O menino gostava muito de andar de cavalo e ele está subindo no cavalo. Aqui } \\
\text { ele já está galopeando. Aqui o cavalo... O cachorro tentou morder o cavalo e o } \\
\text { cavalo empinou e ele caiu no chão. }\end{array}$ \\
\hline \multirow{3}{*}{ Fase 2} & Etapa 1 & $\begin{array}{l}\text { Pré: Ele estava assistindo TV e a imagem apagou e ele foi brincar na caixa. } \\
\text { Pós: O homem vinha trazendo uma caixa de TV. O Cascão ficou todo contente. } \\
\text { Contente e ao mesmo tempo assustado. Aí ele tirou a TV da caixa e o Cascão } \\
\text { ficou bastante contente. Depois o Cascão entrou dentro da caixa de TV para } \\
\text { brincar de se esconder. }\end{array}$ \\
\hline & Etapa 2 & $\begin{array}{l}\text { Pré: Ele estava indo para uma igrejinha e aqui tinha um cemitério e por respeito } \\
\text { ele tirou o chapéu. Pra surpresa dele, lá dentro da igreja tinha.... (silêncio). (P: } \\
\text { e o que acontece no final?) (Silêncio). } \\
\text { Pós: Eu não sei o nome dele... Mas, ele ia bem triste para o confessionário. Lá } \\
\text { ele confessou para o padre todos os pecados e saiu todo contente porque estava } \\
\text { livre dos pecados. }\end{array}$ \\
\hline & Etapa 3 & $\begin{array}{l}\text { Pré: É o Cascão? (P: Isso. O que aconteceu com eles?). O Cascão era tão sujo } \\
\text { quanto o porco. Não gostava de tomar banho e no fim ele foi morar junto com } \\
\text { o porco na casinha. } \\
\text { Pós: O Cascão fez uma casa pro porco. Como estava chovendo eles se } \\
\text { esconderam lá. }\end{array}$ \\
\hline \multicolumn{2}{|c|}{ Fase 3} & $\begin{array}{l}\text { Era uma vez um menino que gostava muito de andar a cavalo. Certa hora ele ia } \\
\text { galopeando a cavalo e tinha um cachorro tentou morder a pata do cavalo; o } \\
\text { cavalo se assustou, empinou jogando o menino no chão. }\end{array}$ \\
\hline \multicolumn{3}{|r|}{$\mathbf{P 2}$} \\
\hline \multicolumn{2}{|c|}{ Fase 1} & $\begin{array}{l}\text { O cachorro está mordendo o cavalo... Ele espanta o cavalo, que assusta; o } \\
\text { menino cai do cavalo, que vai embora. }\end{array}$ \\
\hline Fase 2 & Etapa 1 & $\begin{array}{l}\text { Pré: O menino está com a televisão na mão, tira a televisão da caixa e o outro } \\
\text { menino compra a televisão. É isto? } \\
\text { Pós: } O \text { menino vem com a televisão. O meninão não. Deve ser o pai dele. Ele } \\
\text { chega com a televisão, abre na casa dele na frente do menino. O menino fica } \\
\text { contente, mas depois pega a caixa televisão e leva para o meio do serrado pra } \\
\text { brincar. }\end{array}$ \\
\hline
\end{tabular}




\begin{tabular}{|c|c|c|}
\hline & Etapa 2 & $\begin{array}{l}\text { Pré: "Eu não entendi nada" (Idoso afirma que não irá narrar a história por não } \\
\text { ter entendido as imagens). } \\
\text { Pós: O homem triste, foi pra igreja, confessou com o padre e alivou-se. }\end{array}$ \\
\hline & Etapa 3 & $\begin{array}{l}\text { Pré: Chovinista eu nem sei o que é isso. É a casinha do cachorro. O menino foi } \\
\text { pegar e depois ele entrou dentro da casa dele. } \\
\text { Pós: O menino foi passear com o cãozinho dele e o tempo começou a trovejar; } \\
\text { e começou a chover. Então eles entraram na casinha dele. }\end{array}$ \\
\hline \multicolumn{2}{|c|}{ Fase 3} & $\begin{array}{l}\text { O menino pegou o cavalo e montou. E o cachorro mordeu o cavalo. Por isto o } \\
\text { cavalo derrubou o menino e correu. }\end{array}$ \\
\hline \multicolumn{3}{|r|}{ P3 } \\
\hline \multicolumn{2}{|c|}{ Fase 1} & $\begin{array}{l}\text { Um garoto estava subindo a cavalo... Ele montou num cavalo e galopou. Depois } \\
\text { o cavalo assustou e ele ficou amedrontado e quase caiu do cavalo e caiu. O } \\
\text { cavalo sumiu. }\end{array}$ \\
\hline \multirow{3}{*}{ Fase 2} & Etapa 1 & $\begin{array}{l}\text { Pré: Um rapaz entregava uma TV. Ao chegar na casa, a criança ficou alegre } \\
\text { ao receber. Mas o que fez mesmo foi sentar na caixa pra brincar e homem ficou } \\
\text { espiando. } \\
\text { Pós: O rapaz foi entregar uma TV e a criança sentiu-se muito contente, muito } \\
\text { feliz ao receber a caixa. O homem está entregando uma televisão que é azul e } \\
\text { menino está muito feliz com os bracinhos abertos recebendo a TV. Mas eles } \\
\text { quis mesmo é sentar na caixa de TV, até abanou a mão de alegria. O outro } \\
\text { homem está atrás dele, só olhando. }\end{array}$ \\
\hline & Etapa 2 & $\begin{array}{l}\text { Pré: Um senhor chega a capelinha e tira o chapéu. Ele está pedindo... Está } \\
\text { orando, pedindo para o santo da capelinha. Ele ajoelhou na capelinha assustado. } \\
\text { Apareceu um homem na janela da capelinha. Ele está assustado! Depois ele } \\
\text { saiu da igreja, tirou o chapéu. Estava feliz. O outro menino, que estava ali, } \\
\text { olhou espantado pra ele, sem entender. } \\
\text { Pós: Um senhor foi a uma capelinha. Ele está com o chapéu na mão fazendo } \\
\text { um pedido com a expressão um pouco assustado. Ele está ajoelhando, fazendo } \\
\text { o pedido, meio assustado, traumatizado. O padre apareceu na janelinha e está } \\
\text { olhando espantado. Depois ele saiu da igreja feliz com o chapéu na mão e foi } \\
\text { ao encontro da criança. }\end{array}$ \\
\hline & Etapa 3 & $\begin{array}{l}\text { Pré: Um menino tinha um cachorrinho. Ele se distraia muito com o } \\
\text { cachorrinho. Gostava muito. Um dia ele viu um vulto atrás dele. Ele e o } \\
\text { cachorrinho assustaram. O que era aquele vulto? Não descobriram. Então os } \\
\text { dois entraram na casinha vendo o que se passava pra fora. Eles estavam } \\
\text { tremendamente assustados. } \\
\text { Pós: Um menino que tinha um cachorrinho e ele se distraia muito com o } \\
\text { cachorrinho. Gostava muito da criação. Ao lado tinha um casinha, que era do } \\
\text { cachorro. O menino e o cachorrinho estavam distraídos. De repente ouviram }\end{array}$ \\
\hline
\end{tabular}




\begin{tabular}{|c|c|c|}
\hline & & $\begin{array}{l}\text { um vulto atrás deles e ficaram assustados. Era um raio. } \mathrm{O} \text { menino e o } \\
\text { cachorrinho entraram na casinha e ficaram com a cabeça de fora olhando o } \\
\text { movimento da chuva assustados... }\end{array}$ \\
\hline \multicolumn{2}{|c|}{ Fase 3} & $\begin{array}{l}\text { O menino estava tentando subir no cavalo. Ele se esforçou muito. Ele } \\
\text { conseguiu subir no cavalo e está andando normalmente... E foi... Depois um } \\
\text { cachorro assustou o cavalo e o cavalo assustou o cachorro... O cachorro está } \\
\text { avançando no cavalo e o menino está assustado e quase cai do animal. Depois } \\
\text { ele cai. }\end{array}$ \\
\hline \multicolumn{3}{|r|}{$\mathrm{P} 4$} \\
\hline \multicolumn{2}{|c|}{ Fase 1} & $\begin{array}{l}\text { O menino quer subir no cavalo e o cachorrinho está perto... Ele está em cima. } \\
\text { Ele está em cima do cavalo. O cachorro assustou o cavalo. Ele caiu do cavalo. }\end{array}$ \\
\hline \multirow{3}{*}{ Fase 2} & Etapa 1 & $\begin{array}{l}\text { Pré: Aqui ele trouxe uma televisão na caixa. O menino está sentado esperando. } \\
\text { Aqui ele tirou a televisão pra fora da caixa e o garoto está contente e aqui ele } \\
\text { está dentro da caixa, o garoto, pra brincar. } \\
\text { Pós: Ele veio com a caixa para a criança e a criança se expressou contente. Está } \\
\text { sentado em cima do carpete; do tapete. Aí ele já tirou a televisão da caixa e a } \\
\text { criança já ficou feliz. Mas aqui (aponta para a tirinha 3) a criança foi brincar } \\
\text { dentro da caixa... Ele entrou dentro da caixa pra brincar. }\end{array}$ \\
\hline & Etapa 2 & $\begin{array}{l}\text { Pré: Aqui ele vai indo pra igreja. Aqui ele já está no confessionário. Aqui ele } \\
\text { tá conversando com o menino, né? } \\
\text { Pós: Ele está apavorado e o menino está atrás dele. Ele está se aproximando da } \\
\text { igreja. Ele entra na igreja e está ajoelhado. O padre não está dando atenção... O } \\
\text { padre está virado... Depois o homem saiu da igreja... Parece que está contente! } \\
\text { Por isto foi de encontro do garoto. }\end{array}$ \\
\hline & Etapa 3 & $\begin{array}{l}\text { Pré: É a casinha do Chovinista. Ele está apresentando a casa para o } \\
\text { cachorrinho. Ele está virando pra cá e ele puxando aqui, arrumando... Algo } \\
\text { chamando a atenção dele. CABRUM. Começa a chover e os dois entram na } \\
\text { casinha. } \\
\text { Pós: Ele está mostrando a casa para o cachorro. Está com as ferramentas aqui, } \\
\text { não sei se é pra trabalhar. Deve ser pra trabalhar... Ele estava trabalhando na } \\
\text { casa do cachorro. A casa está com a portinha meio fechada, não sei por qual } \\
\text { motivo. Mas começa a chover e então os dois entram dentro da casa e ficam } \\
\text { olhando pra fora. }\end{array}$ \\
\hline \multicolumn{2}{|c|}{ Fase 3} & $\begin{array}{l}\text { O menino está querendo montar no cavalo e o cachorrinho está esperando aqui } \\
\text { perto dele. Aqui ele já está montado e ele já começa a correr. Ele está em cima } \\
\text { do cavalo e o cachorrinho está à frente dele, latindo. Por isto, o menino caiu do } \\
\text { cavalo e o cavalo correu e ele ficou aqui com o cachorrinho que está socorrendo } \\
\text { ele. }\end{array}$ \\
\hline
\end{tabular}




\begin{tabular}{|c|c|c|}
\hline \multicolumn{3}{|r|}{ P5 } \\
\hline \multicolumn{2}{|c|}{ Fase 1} & $\begin{array}{l}\text { O menino montou um cavalo bravo e tinha um cachorro latindo pro cavalou, } \\
\text { que ficou bravo e derrubou o menino. }\end{array}$ \\
\hline \multirow{3}{*}{ Fase 2} & Etapa 1 & $\begin{array}{l}\text { Pré: O pai do Cascão deu uma televisão para ele, mas falou que só se ele } \\
\text { tomasse banho poderia usar. Como ele não tomou, ele ficou só com a caixa pra } \\
\text { brincar. } \\
\text { Pós: O pai do Cascão trouxe uma TV pra ele. Ele comprou e mostrou. Mas ele } \\
\text { falou que se ele quisesse ver, ele teria que tomar banho. Como ele não gosta de } \\
\text { tomar banho, ele foi brincar com a caixinha lá fora. }\end{array}$ \\
\hline & Etapa 2 & $\begin{array}{l}\text { Pré: O Chico Bento perguntou para o amigo o que ele tinha. "Ah, eu tô muito } \\
\text { triste". Aí o Chico Bento falou pra ele: "Vai lá e confessa para o padre. } \\
\text { Conversa com ele, troca uma ideia que ele te perdoa.". Ele falou: "É". O } \\
\text { homem foi, conversou com o padre e saiu leve. } \\
\text { Pós: O Chico viu o amigo dele muito triste. Coração disparado... Aí ele falou: } \\
\text { "Vai até o padre e conversa com ele e pede ajuda, conversa com ele que ele } \\
\text { pode resolver os seus problemas, pelo menos de consciência.". Aí ele foi e } \\
\text { resolveu. Saiu todo leve da igreja. }\end{array}$ \\
\hline & Etapa 3 & $\begin{array}{l}\text { Pré: O Cascão estava com o porquinho dele, o Chovinista. Aí ameaçou o } \\
\text { tempo, um temporal e eles correram pra dentro da casinha. } \\
\text { Pós: O Cascão estava conversando com o porquinho dele, o Chovinista e o } \\
\text { tempo armou e eles se abrigaram na casinha do cachorro. }\end{array}$ \\
\hline \multicolumn{2}{|c|}{ Fase 3} & $\begin{array}{l}\text { O menino saiu pra cavalgar e chamou o cachorro. O cachorro assustou o cavalo, } \\
\text { que saiu correndo e fez o menino cair. }\end{array}$ \\
\hline \multicolumn{3}{|r|}{ P6 } \\
\hline \multicolumn{2}{|c|}{ Fase 1} & $\begin{array}{l}\text { Uma criança monta num cavalo e tem um cachorro na frente dele. A criança } \\
\text { montada no cavalo e o cavalo empinando pra pegar o cachorro. A criança } \\
\text { galopava com o cavalo e o cachorro ia na frente. Aí, o cachorro latiu para o } \\
\text { cavalo, que assustou e o menino caiu no chão. O cavalo saiu correndo. O } \\
\text { cachorro foi perto da criança, pra ajudar. }\end{array}$ \\
\hline Fase 2 & Etapa 1 & $\begin{array}{l}\text { Pré: Esse aqui é a pessoa carregando a tv. O do lado a pessoa tá com a tv já } \\
\text { posta pra pôr no lugar e a outra pessoa apontando para alguma coisa, não sei. } \\
\text { E agora, esse aqui, tem um com a mão fechada dizendo alguma coisa e o outro } \\
\text { do lado reparando. } \\
\text { Pós: Esse aqui está carregando a caixa de tv e o menino está preocupado porque } \\
\text { vai cair. O menino tá... Esse aqui, o pai, entrega a tv e o filho está contente e } \\
\text { pedindo pra colocar a tv no lugar, no lugar próprio dela. E depois o menino vai } \\
\text { brincar dentro da caixa: ou fazendo de carrinho ou fazendo de berço e o pai tá } \\
\text { com cara de "cuidado". }\end{array}$ \\
\hline
\end{tabular}




\begin{tabular}{|c|l|l|}
\hline Etapa 2 & $\begin{array}{l}\text { Pré: Ele estava triste, então foi pra igreja se confessar. O padre é forte e deu } \\
\text { um conselho e então ele saiu alegre de lá. } \\
\text { Pós: O homem estava triste e por isto foi se confessar. Depois da confissão saiu } \\
\text { aliviado e foi falar um amigo. }\end{array}$ \\
\hline Etapa 3 & $\begin{array}{l}\text { Pré: (Silêncio). Ela vai levando o cachorro, apontando a casa. Aqui ela está } \\
\text { apontando que já está chegando na casa... pra entrar. E aqui já entraram na casa } \\
\text { e estão na varanda ou na calçada. } \\
\text { Pós: O garoto está levando o cachorrinho pra casa. Na porta da casa tinha um } \\
\text { martelo, uma serra e ele foi arrumar a casa do cachorro... Mas eles ficam } \\
\text { olhando pra trás como se estivesse faltando alguma coisa. Nisto, começa a } \\
\text { chover muito. Dá a impressão que eles estão correndo da chuva porque vão se } \\
\text { esconder na casa do cachorro. Fim. }\end{array}$ \\
\hline Fase 3 & $\begin{array}{l}\text { O garoto está montando num cavalo perto de um cachorro. Ele (aponta para o } \\
\text { cachorro) assusta o cavalo, o menino cai e o cavalo foge. }\end{array}$ \\
\hline
\end{tabular}

\begin{tabular}{|c|c|c|}
\hline & & Grupo Experimental \\
\hline \multicolumn{3}{|r|}{ P11 } \\
\hline \multicolumn{2}{|c|}{ Fase 1} & $\begin{array}{l}\text { Pré: O cachorro está assustando o animal, o cavalo. (silêncio). Aqui também } \\
\text { (silêncio)... E depois, piorou. }\end{array}$ \\
\hline \multirow{3}{*}{ Fase 2} & Etapa 1 & $\begin{array}{l}\text { Pré: Ele vai trocar de lugar a televisão (silêncio). Tirou a televisão de dentro } \\
\text { da caixa e entrou. } \\
\text { Pós: Ele como a TV... A criança sorri por isso, mas quer brincar com a caixa } \\
\text { daTV. }\end{array}$ \\
\hline & Etapa 2 & $\begin{array}{l}\text { Pré: Ele está querendo colocar o chapéu na cabeça e não está conseguindo. } \\
\text { Um menino fica vendo ele fazer isso. } \\
\text { Pós: Ele está meio assustado... E por isso ele vai pra dentro da igreja. Ele foi } \\
\text { falar com o padre. Depois, também, continuo lá. Agora ele saiu pra fora mais } \\
\text { feliz. O menino viu tudo isso. }\end{array}$ \\
\hline & Etapa 3 & $\begin{array}{l}\text { Pré: Tinha um cachorrinho e uma criança. (Silêncio). (O que acontece } \\
\text { depois?). Eles vão em paz. } \\
\text { Pós: Começou a chover e o menino e seu cachorrinho foram pra dentro da } \\
\text { casa do cachorrinho. }\end{array}$ \\
\hline \multicolumn{2}{|c|}{ Fase 3} & $\begin{array}{l}\text { O menino estava no cavalo. Um cachorro assustou o cavalo. Ele correu e } \\
\text { derrubou o menino. }\end{array}$ \\
\hline
\end{tabular}




\begin{tabular}{|c|c|c|}
\hline & & P12 \\
\hline \multicolumn{2}{|c|}{ Fase 1} & $\begin{array}{l}\text { Pré: } \mathrm{O} \text { menino tinha em cavalo e montava nele... (silêncio) ( } \mathrm{P} \text { : } \mathrm{O} \text { que } \\
\text { aconteceu depois?). Aconteceu que um dia o cachorro assusto o cavalo. O } \\
\text { cavalou pulou e o menino caiu dele. }\end{array}$ \\
\hline \multirow{3}{*}{ Fase 2} & Etapa 1 & $\begin{array}{l}\text { Pré: O menino está andando para encontrar este daqui. Aí está chamando o } \\
\text { menino pra ver televisão?! Ai ele vai ver a TV. } \\
\text { Pós: O homem está mostrando uma televisão pro menino... O menino ficou } \\
\text { contente. Ele ficou contente! Está vendo a televisão. }\end{array}$ \\
\hline & Etapa 2 & $\begin{array}{l}\text { Pré: } \text { O homem está indo embora... Andando.... O que ele tem a mão? Um } \\
\text { chapéu! Ele vai andando e encontra o outro menino. No final ele dá o chapéu } \\
\text { para o menino. } \\
\text { Pós: O homem vai pra... Ele vai pra igreja. Está triste. Fala com o padre e sai } \\
\text { muito contente. }\end{array}$ \\
\hline & Etapa 3 & $\begin{array}{l}\text { Pré: Tem um cachorrinho e ele está em frente da casa do cachorro e depois } \\
\text { ele vai embora, pra dentro da casa. } \\
\text { Pós: Começa com o cachorro e o menino. Ele está conversando com o } \\
\text { cachorrinho. Aí muda o tempo. Começa a chover e eles vão pra casinha se } \\
\text { esconder. }\end{array}$ \\
\hline \multicolumn{2}{|c|}{ Fase 3} & $\begin{array}{l}\text { Este aqui é um... Cavalo. O cachorrinho tá mexendo com ele. Enquanto isso, } \\
\text { o menino monta no cavalo e vai andar. No final ele leva um tombo porque o } \\
\text { cachorro latiu para o cavalo. }\end{array}$ \\
\hline \multicolumn{3}{|r|}{ P13 } \\
\hline \multicolumn{2}{|c|}{ Fase 1} & $\begin{array}{l}\text { O menino está pelejando pra subir no cavalo. Mas ele subiu. Agora aqui ele } \\
\text { subiu e o cavalo está correndo e aqui ele caiu do cavalo. }\end{array}$ \\
\hline \multirow{3}{*}{ Fase 2} & Etapa 1 & $\begin{array}{l}\text { Pré: Ele pegou a TV e levou pra casa dele pra olhar. Aqui ele já está com... } \\
\text { Eu não sei o que é dele, mas estão olhando a TV. Não é isto? No fim ele olhou } \\
\text { e olhou para onde trouxe pra cá e ficou espantado. } \\
\text { Pós: Ele foi olhar na televisão. Chegou lá já tava com... Aqui ele ficou bravo } \\
\text { e queria dar um soco. }\end{array}$ \\
\hline & Etapa 2 & $\begin{array}{l}\text { Pré: Tum. Tum. Tum. Ele tem um negócio na mão. Ele olhou pra esse } \\
\text { negócio... E no final ele levou um susto. Não sei mais nada. } \\
\text { Pós: Ele foi levar... Foi levar o chapéu. Ele foi pra casa dele, chegou lá e } \\
\text { mostrou o chapéu. }\end{array}$ \\
\hline & Etapa 3 & $\begin{array}{l}\text { Pré: Ele olhou pra trás... O que ele queria ver que está atrás? Aqui está } \\
\text { olhando pra frente. Aqui está pra trás. Chovinista. }\end{array}$ \\
\hline
\end{tabular}




\begin{tabular}{|c|c|c|}
\hline & & $\begin{array}{l}\text { Pós: Ele saiu da casa, foi pra casinha dele e chegou aqui e entrou na } \\
\text { Chovinista. }\end{array}$ \\
\hline \multicolumn{2}{|c|}{ Fase 3} & $\begin{array}{l}\text { Ele pegou um cavalo pra montar. Montou nele. Ele foi andar no cavalo e o } \\
\text { cavalo derrubou ele. }\end{array}$ \\
\hline \multicolumn{3}{|r|}{ P14 } \\
\hline \multicolumn{2}{|c|}{ Fase 1} & Ele está andando com o cavalo... Depois ele caiu, né?! \\
\hline \multirow{3}{*}{ Fase 2} & Etapa 1 & $\begin{array}{l}\text { Pré: Isto daqui eu já vi na televisão. Eu não sei. Ele está olhando pra alguma } \\
\text { coisa. Não sei mais. } \\
\text { Pós: Ele mostra a caixa de TV para o menino. Aí o menino está rindo. Ele } \\
\text { não quer a TV. Ele quer a caixa pra brincar. }\end{array}$ \\
\hline & Etapa 2 & $\begin{array}{l}\text { Pré: O homem está olhando aqui... Aí eu não sei... Ele mostrou o chapéu para } \\
\text { o menino. } \\
\text { Pós: Ele tá olhando a igreja. É uma igreja. Aí ele foi lá e conversou com o } \\
\text { padre. Ficou feliz. Depois foi falar para o menino. }\end{array}$ \\
\hline & Etapa 3 & $\begin{array}{l}\text { Pré: Ele falou para o cachorro entrar dentro da casinha. Ele ficou brabo com } \\
\text { ele. (Silêncio). Mas no final ele ficou pertinho do cachorro. } \\
\text { Pós: O menino fala "entra na casinha". Ele está brabo com o cachorro. Aí } \\
\text { como choveu, eles tiveram medo e entraram na casinha. }\end{array}$ \\
\hline \multicolumn{2}{|c|}{ Etapa 3} & $\begin{array}{l}\text { Ele está montado no cavalo e o cachorro esta brabo. (Silêncio). O cavalo estâ } \\
\text { dando coice e agitado nele e por isto o menino caiu do cavalo. }\end{array}$ \\
\hline \multicolumn{3}{|r|}{ P15 } \\
\hline \multicolumn{2}{|c|}{ Fase 1} & $\begin{array}{l}\text { Ele está montando a cavalo e começou a andar. O cachorro não gostou muito } \\
\text { O cavalo também não gostou e deu um ponta pé nele, então ele caiu e } \\
\text { machucou. }\end{array}$ \\
\hline \multirow{3}{*}{ Fase 2} & Etapa 1 & $\begin{array}{l}\text { Pré: O pai deu uma televisão pra ele. Quando tirou da caixa ele ficou todo } \\
\text { feliz. Mas depois ele pegou a caixa pra fazer de cavalo. } \\
\text { Pós: O pai do Cascão chegou com a caixa de televisão e ele ficou todo feliz. } \\
\text { Tirou da caixa e ele ficou mais feliz ainda. Aí ele pegou a caixa e fez a caixa } \\
\text { de cavalo. }\end{array}$ \\
\hline & Etapa 2 & $\begin{array}{l}\text { Pré: Ele está com a cabeça quente. Mas não dá pra saber porque. Ele não fala } \\
\text { nada. Depois ele vai confessar para o padre e ele sai todo alegre. Feliz da vida } \\
\text { Pós: Ele estava com a cabeça quente, aí entrou na igreja e foi confessar para } \\
\text { o padre e saiu todo feliz da vida de dentro da igreja porque o padre deve ter } \\
\text { falado muita coisa boa pra ele. }\end{array}$ \\
\hline & Etapa3 & $\begin{array}{l}\text { Pré: Um porco. O Cascão. Um martelo. A casa. Tempestade. O Cascão tem } \\
\text { medo disto e por isto entrou dentro da casinha. }\end{array}$ \\
\hline
\end{tabular}




\begin{tabular}{|c|c|c|}
\hline & & $\begin{array}{l}\text { Pós: Ele estava brincando com o cão. O tempo estava bom, mas começou a } \\
\text { fechar. Aí começou a relampear e chover. Eles correram pra dentro da } \\
\text { casinha. }\end{array}$ \\
\hline \multicolumn{2}{|c|}{ Fase 3} & $\begin{array}{l}\text { O menino está subindo no cavalo pra cavalgar. O cachorro está abanando o } \\
\text { rabinho pra ele. Ele montou no cavalo e o cachorro rosnou. Aí o cavalo } \\
\text { empinou pra dar uma patada nele (aponta para o cachorro) e o cachorro ficou } \\
\text { pi pi pi... Ai o homem caiu do cavalo e o cavalo foi embora. }\end{array}$ \\
\hline \multicolumn{3}{|r|}{ P16 } \\
\hline \multicolumn{2}{|c|}{ Fase 1} & $\begin{array}{l}\text { Montado no cavalo. Esse é.... Montado no cavalo e pegando, não sei o que } \\
\text { que é isso. Ah, não. Esse é rabo. Ele está montado no cavalo e ele caiu do } \\
\text { cavalo. }\end{array}$ \\
\hline \multirow{3}{*}{ Fase 2} & Etapa 1 & $\begin{array}{l}\text { Pré: Esse é televisão. Esse é caixa de televisão. Esse é caixa de televisão e } \\
\text { esse é saindo da caixa. } \\
\text { Pós: O menino viu a caixa. O moço tira uma tv da caixa. Mas ele quis é entrar } \\
\text { dentro da caixa pra brincar. }\end{array}$ \\
\hline & Etapa 2 & $\begin{array}{l}\text { Pré: Eu não sei. } \\
\text { Pós: O homem está meio assustado. Ele está com um chapéu e meio } \\
\text { assustado. Ele vai na igreja. O homem está se confessando com o padre. Aí } \\
\text { ele fica feliz e muito mais tranquilo. Ah, eu não sei mais. }\end{array}$ \\
\hline & Etapa 3 & $\begin{array}{l}\text { Pré: Que história eu vou contar? Eu não sei. (P: repetição da instrução). Eles } \\
\text { estão brincando com o cachorrinho. Aqui é a casa. Ele entrou dentro de casa. } \\
\text { Pós: Era o cão e o menino, e essa é a casa deles. Eles vão entrar dentro de } \\
\text { casa porque está chovendo. }\end{array}$ \\
\hline \multicolumn{2}{|c|}{ Fase 3} & $\begin{array}{l}\text { Esse menino vai montar no cavalo e o cachorrinho está olhando. Está correndo } \\
\text { com o cavalo e o cão latindo. Depois o cavalo foi embora, derrubando o } \\
\text { menino por causa do cão. }\end{array}$ \\
\hline
\end{tabular}

